NUREG/CR-6543

SAND97-2544

\title{
Effects of Smoke on \\ Functional Circuits
}

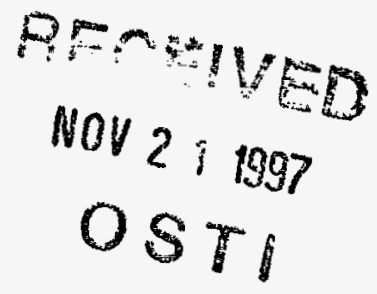

Prepared by

T. J. Tanaka

Sandia National Laboratories

Prepared for

U.S. Nuclear Regulatory Commission

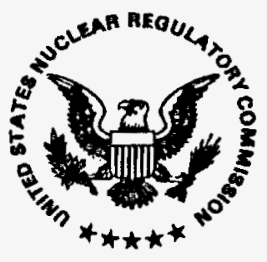




\section{AVAILABILITY NOTICE}

Availability of Reference Materials Cited in NRC Publications

Most documents cited in NRC publications will be available from one of the following sources:

1. The NRC Public Document Room, 2120 L Street, NW., Lower Level, Washington, DC 20555-0001

2. The Superintendent of Documents, U.S. Government Printing Office, P. O. Box 37082, Washington, DC 20402-9328

3. The National Technical Information Service, Springfield, VA 22161-0002

Although the listing that follows represents the majority of documents cited in NRC publications, it is not intended to be exhaustive.

Referenced documents avaliable for inspection and copying for a fee from the NRC Public Document Room include NRC correspondence and internal NRC memoranda; NRC bulletins, circulars, information notices, inspection and investigation notices; licensee event reports; vendor reports and correspondence; Commission papers; and applicant and licensee documents and correspondence.

The following documents in the NUREG series are available for purchase from the Government Printing Office: formal NRC staff and contractor reports. NRC-sponsored conference proceedings, international agreement reports, grantee reports, and NRC booklets and brochures. Also available are regulatory guides, NRC regulations in the Code of Federal Regulations, and Nuclear Regulatory Commission Issuances.

Documents avallable from the National Technical Information Service include NUREG-series reports and technical reports prepared by other Federal agencies and reports prepared by the Atomic Energy Cormmission, forerunner agency to the Nuclear Regulatory Commission.

Documents available from public and special technical libraries include all open literature items, such as books, journal articles, and transactions. Federal Register notices. Federal and State legislation, and congressional reports can usually be obtained from these libraries.

Documents such as theses, dissertations, foreign reports and transiations, and non-NRC conference proceedings are available for purchase from the organization sponsoring the publication cited.

SIngle copies of NRC draft reports are available free, to the extent of supply, upon written request to the Office of Administration. Distribution and Mail Services Section, U.S. Nuclear Regulatory Commission, Washington, DC 20555-0001.

Copies of industry codes and standards used in a substantive manner in the NRC regulatory process are maintalned at the NRC Library. Two White Flint North, 11545 Rockville Pike, Rockville. MD 20852-2738, for use by the public. Codes and standards are usually copyrighted and may be purchased from the originating organizatlon or, if they are American National Standards. from the American National Standards Institute. 1430 Broadway, New York, NY 10018-3308.

\section{DISCLAIMER NOTICE}

This report was prepared as an account of work sponsored by an agency of the United States Government. Neither the United States Govemment nor any agency thereof, nor any of their employees, makes any warranty, expressed or implied, or assumes any legal liability or responsibility for any third party's use, or the results of such use, of any information, apparatus, product, or process disclosed in this report, or represents that its use by such third party would not infringe privately owned rights. 


\section{Effects of Smoke on Functional Circuits}

Manuscript Completed: April 1997

Date Published: October 1997

Prepared by

T. J. Tanaka

Sandia National Laboratories

Albuquerque, NM 87185-0747

C. Antonescu, NRC Project Manager

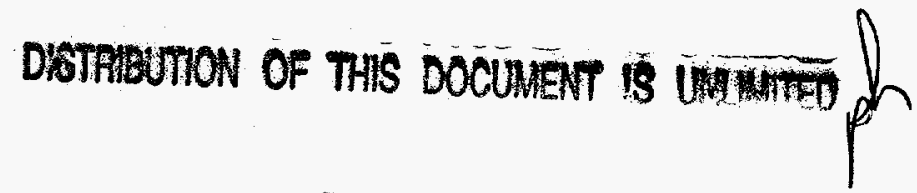

Prepared for

Division of Systems Technology

Office of Nuclear Regulatory Research

U.S. Nuclear Regulatory Commission

Washington, DC 20555-0001

NRC Job Code W6051

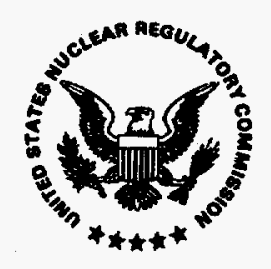


Previous reports in series:

NUREG/CR-6479, SAND96-2633, T. J. Tanaka, S. P. Nowlen, and D. J. Anderson, "Circuit Bridging of Components by Smoke," Sandia National Laboratories, Albuquerque, NM, October 1996. 


\section{DISCLAMIER}

Portions of this document may be illegible in electronic image produets. Images are produced from the best available original document. 


\section{DISCLAIMER}

This report was prepared as an account of work sponsored by an agency of the United States Government. Neither the United States Government nor any agency thereof, nor any of their employees, makes any warranty, express or implied, or assumes any legal liability or responsibility for the accuracy, completeness, or usefulness of any information, apparatus, product, or process disclosed, or represents that its use would not infringe privately owned rights. Reference herein to any specific commercial product, process, or service by trade name, trademark, manufacturer, or otherwise does not necessarily constitute or imply its endorsement, recommendation, or favoring by the United States Government or any agency thereof. The views and opinions of authors expressed herein do not necessarily state or reflect those of the United States Government or any agency thereof. 


\begin{abstract}
Nuclear power plants are converting to digital instrumentation and control systems; however, the effects of abnormal environments such as fire and smoke on such systems are not known. There are no standard tests for smoke, but previous smoke exposure tests at Sandia National Laboratories have shown that digital communications can be temporarily interrupted during a smoke exposure. Another concern is the long-term corrosion of metals exposed to the acidic gases produced by a cable fire. This report documents measurements of basic functional circuits during and up to 1 day after exposure to smoke created by burning cable insulation. Printed wiring boards were exposed to the smoke in an enclosed chamber for 1 hour. For high-resistance circuits, the smoke lowered the resistance of the surface of the board and caused the circuits to short during the exposure. These circuits recovered after the smoke was vented. For low-resistance circuits, the smoke caused their resistance to increase slightly. A polyurethane conformal coating substantially reduced the effects of smoke. A high-speed digital circuit was unaffected. A second experiment on different logic chip technologies showed that the critical shunt resistance that would cause failure was dependent on the chip technology and that the components used in the smoke exposures were some of the most smoke tolerant. The smoke densities in these tests were high enough to cause changes in high impedance (resistance) circuits during exposure, but did not affect most of the other circuits. Conformal coatings and the characteristics of chip technologies should be considered when designing digital circuitry for nuclear power plant safety systems, which must be highly reliable under a variety of operating and accident conditions.
\end{abstract}





\section{CONTENTS}

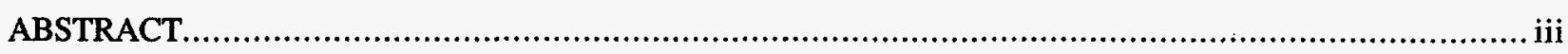

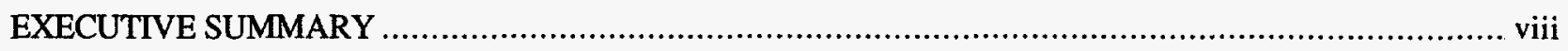

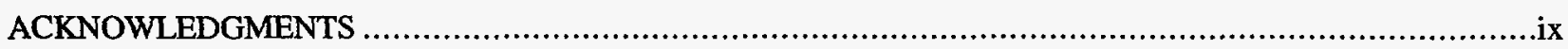

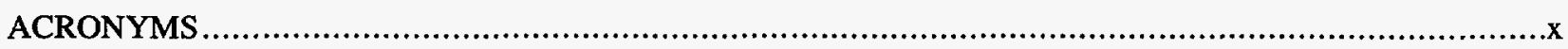

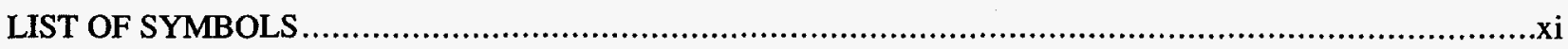

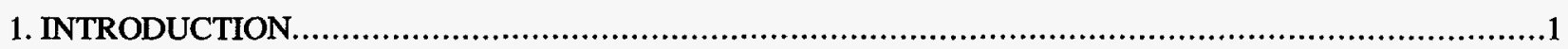

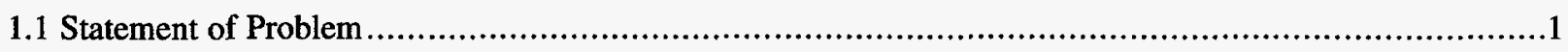

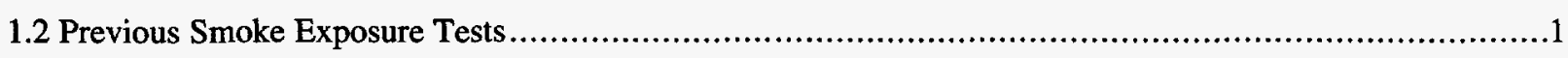

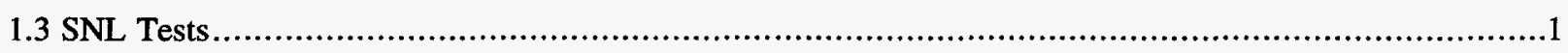

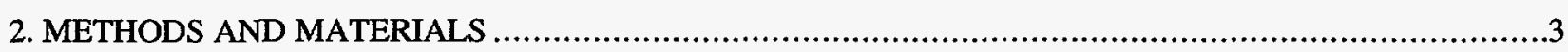

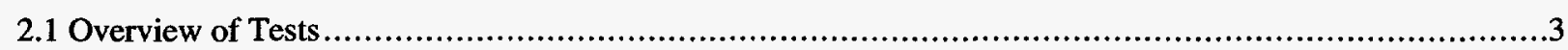

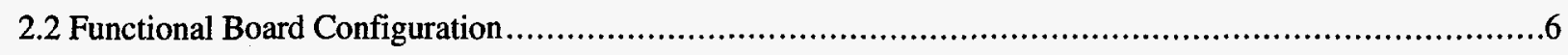

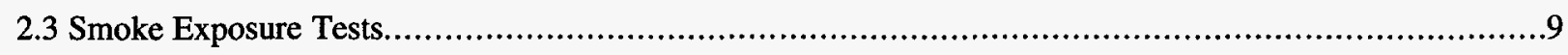

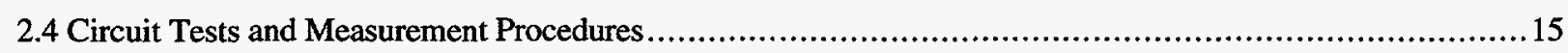

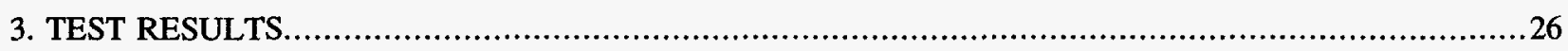

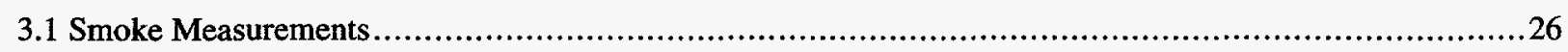

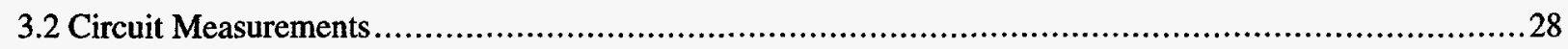

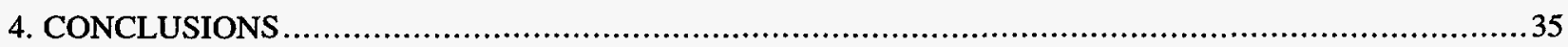

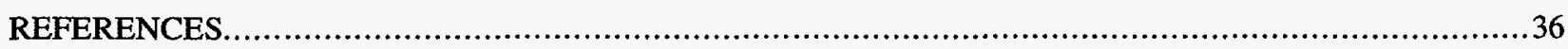

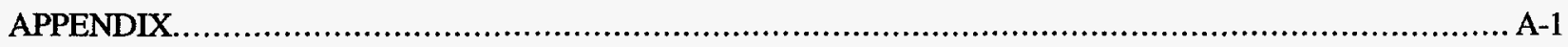




\section{LIST OF FIGURES}

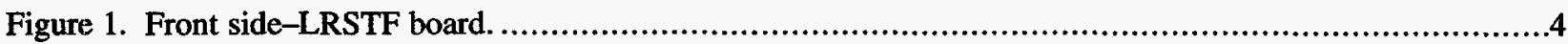

Figure 2. Two transmission lines for transmission line coupling measurement..........................................4

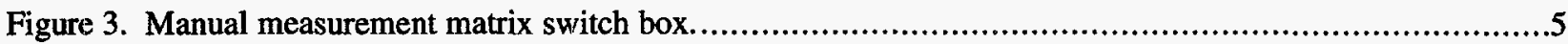

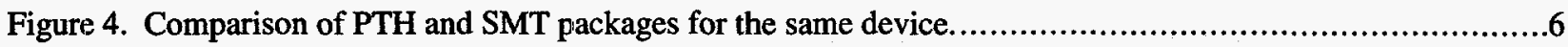

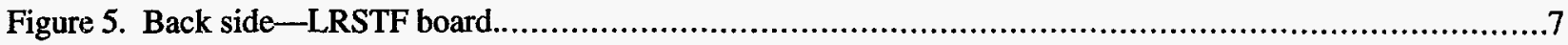

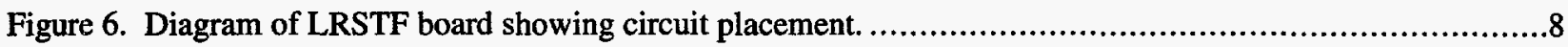

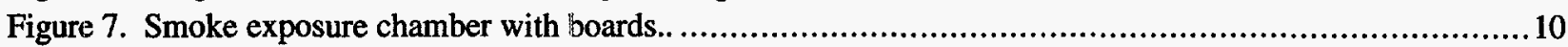

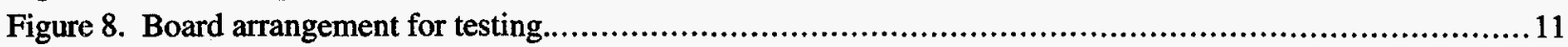

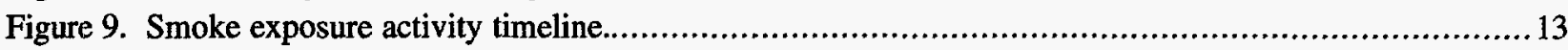

Figure 10. Quartz crystal microbalances for the measurement of soot deposition.......................................13

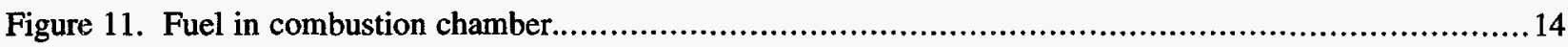

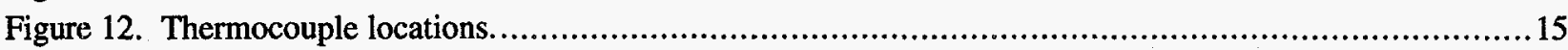

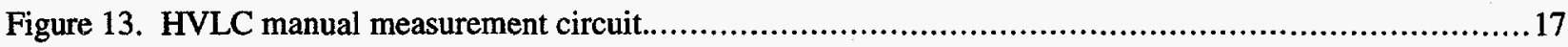

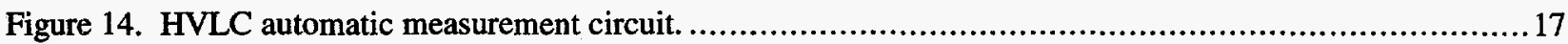

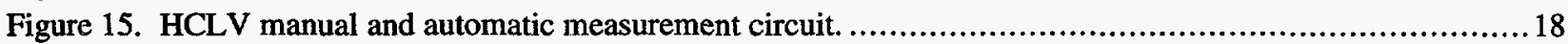

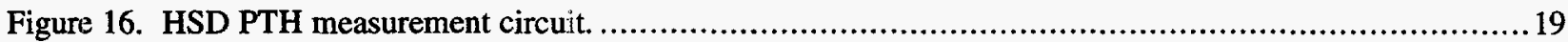

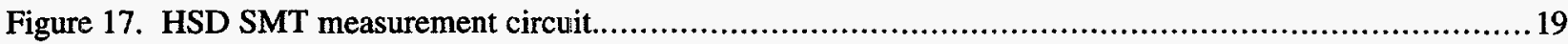

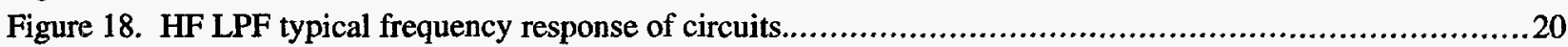

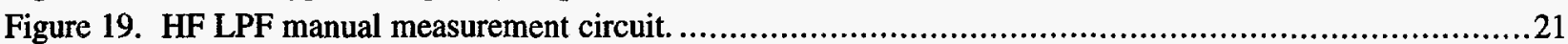

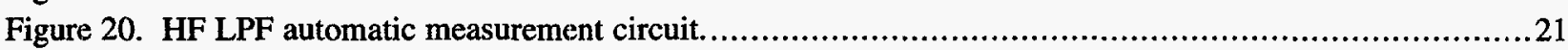

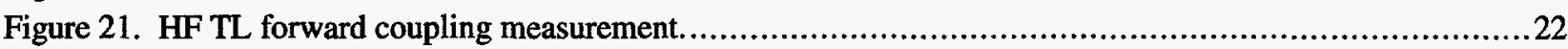

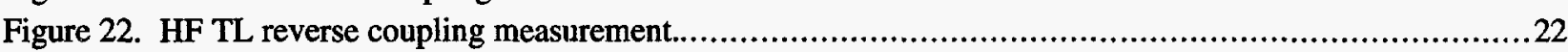

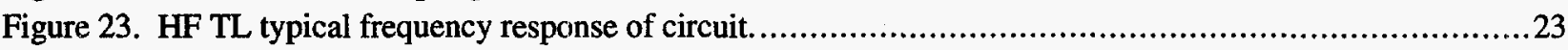

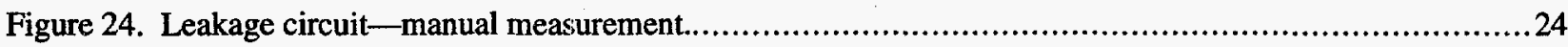

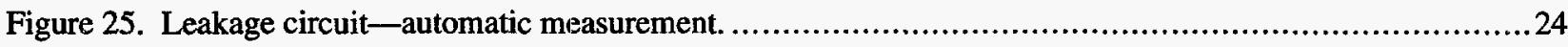

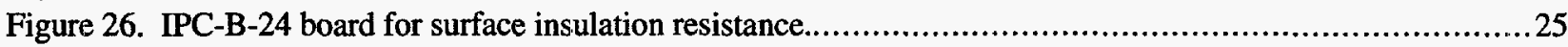

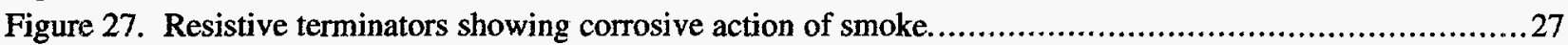

Figure 28. HVLC PTH vs. time for a high-fuel, high-flux burn. ..................................................28

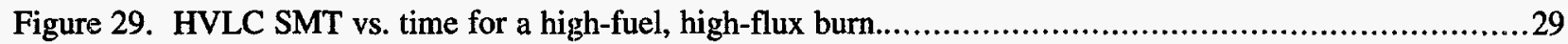

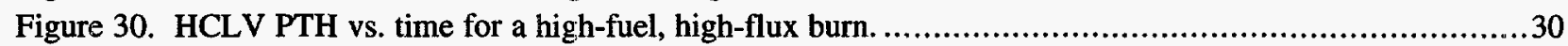

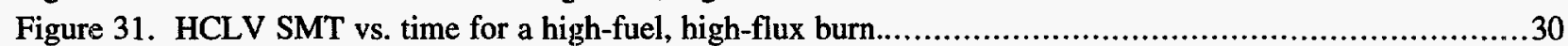

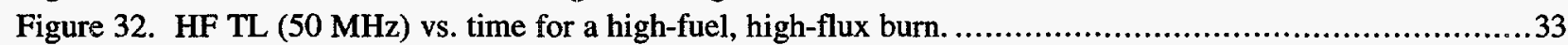

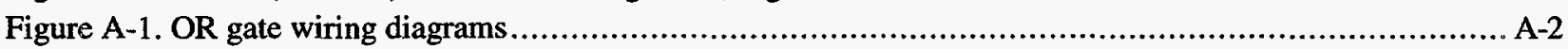

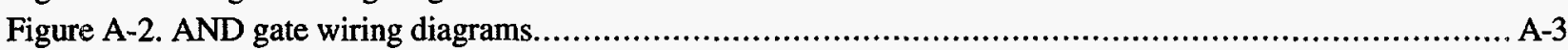




\section{LIST OF TABLES}

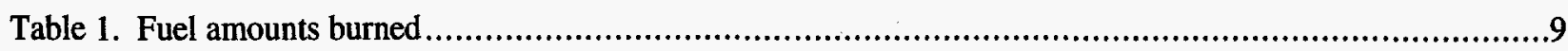

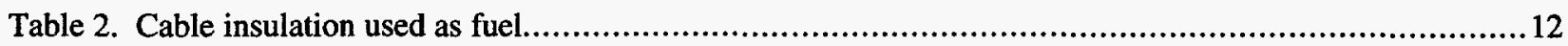

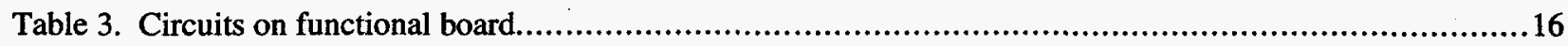

Table 4. Leakage measurement parameters for automatic measurement system........................................25

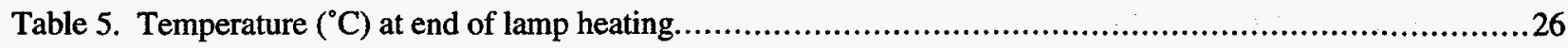

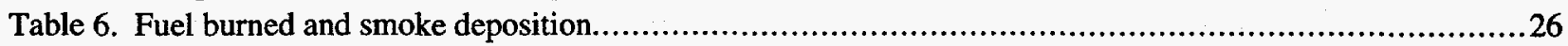

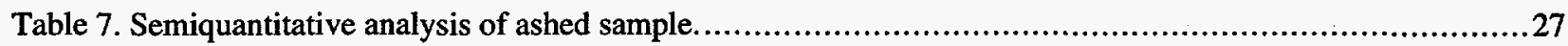

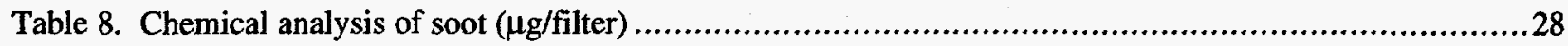

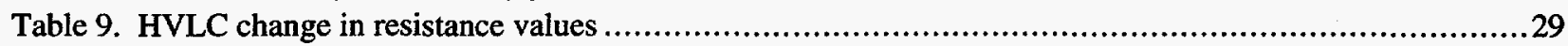

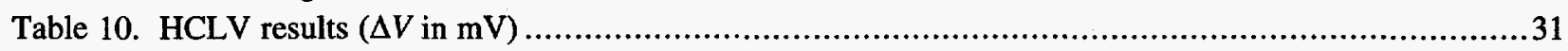

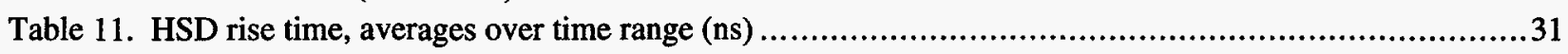

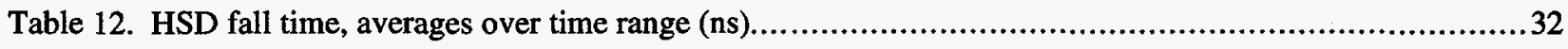

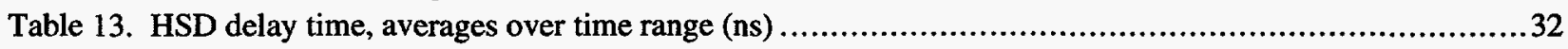

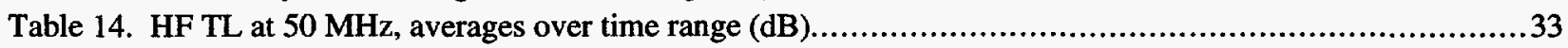

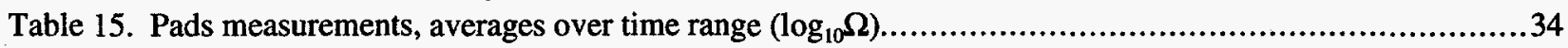

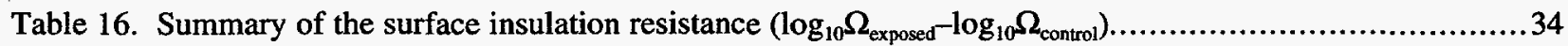

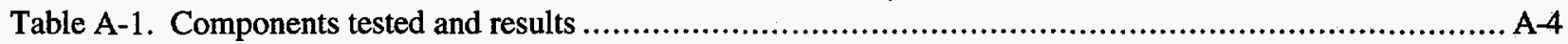

Table A-2. Minimum high level and maximum low levels for logic families.......................................... A-5 


\section{EXECUTIVE SUMMARY}

Nuclear power plants are replacing their analog I\&C equipment with digital I\&C equipment; however, there is concern about the effects of abnormal or severe environments on these new control systems. A potentially severe environment is smoke from an electrical fire. Smoke may impair the operation of electrical circuits by shorting leads, corroding contacts, and inducing stray capacitance. To investigate some of these effects, functional boards containing circuits sensitive to these failure modes were exposed to smoke from burning cable insulation. The components on the boards were those commonly used in modern electrical circuits. Three fuel levels were used in these experiments and corresponded to burning 3,25 , and $50 \mathrm{~g}$ per cubic meter of air. All tests were conducted at $75 \%$ relative humidity because earlier tests showed that high humidity increases failures. Circuit performance was measured during the smoke exposure.

The tests showed that the high-resistance circuit (high voltage, low current, HVLC) was the most susceptible to smoke. Its high impedance $(50 \mathrm{M} \Omega$ ) was shorted by smoke during the exposure, but recovered after the smoke was vented. This shorting occurred for small concentrations of smoke produced by burning $3 \mathrm{~g}$ of fuel per cubic meter of air. At medium and high fuel levels, the resistance of the HVLC circuit typically decreased by $90 \%$ during the smoke exposure. Resistance was lost in these circuits because the current found an alternative path between conductors. Printed wiring boards generally have very high resistance, $>10^{12}$ ohms. When smoke occurs in the vicinity of this circuit, however, the resistance outside of the circuit is lower than that through the circuit and the current leaks around the circuit. Other circuits that were sensitive to a decrease in surface insulation resistance were also affected temporarily during the smoke exposure.

The resistance of the low-resistance circuit (high current, low voltage, HCLV at $1.4 \Omega$ ) was permanently increased by the smoke, implying that the contacts were corroded. This is a different failure mode than the failure of the HVLC circuit described above as current leakage. However, the change was very small $(<2 \%)$.

A polyurethane conformal coating brushed on half of the test boards substantially reduced the damaging effects of smoke.

The high-speed digital circuit was not affected by smoke, even at the highest fuel level. The main component tested in this circuit was an advanced TTL (FAST) chip. An experiment that compared the failure of chip technologies in the presence of a shunt resistance showed that a FAST chip is one of the most tolerant to smoke. The results of this experiment show that technologies with a high output current are more smoke tolerant. Previous tests of complementary metal-oxide semiconductor (CMOS) chips at fuel levels of $100 \mathrm{~g}$ per cubic meter caused failures and the experiment using shunt resistances showed that CMOS chips are more sensitive to smoke than FAST chips. The smoke density in the current experiment was not high enough to cause FAST chips to fail.

The test results suggest that conformal coatings and the characteristics of chip technologies should be considered when designing digital circuitry to be used in nuclear power plant safety systems. 


\section{ACKNOWLEDGMENTS}

I would like to thank all of the people who have contributed to this project and the writing of this report. This work has been sponsored by the USNRC Office of Research under the project management of Christina Antonescu. John Garcia helped create the smoke environments and cleaned up the equipment for each test. Andrea Hirst assembled most of the automated measurement system and wrote programs to control it. Karla Waters analyzed and plotted the data for this report. Dennis Huffman and Dennis Anderson, of the Low-Residue Soldering Task Force (LRSTF),

patiently answered questions on testing boards, helped design the experiment, and provided the manual matrix switch. Steve Nowlen provided consultation on fire testing and fixed the environmental chamber when necessary. Kathy King and Mary Ellen Puckett assisted in the assembly of the LRSTF boards, working with manufacturers when necessary. This report could not have been written without the electrical engineering advice and support of my husband, Dr. Stephen J. Martin, who volunteered so many good ideas, such as testing gates with a shunt resistor. 


\section{ACRONYMS}

CMOS

DIP

FAST

HCLV

HF LPF

HF TL

HSD

HVLC

I\&C

LRSTF

NAND

PGA

PTH

QCM

SMB

SMT

SNL

SOIC

TTL

USNRC complementary metal-oxide semiconductor

dual-in-line package

advanced Schottky (TTL family)

high current, low volttage

high-frequency low-pass filter

high-frequency transrnission line

high-speed digital

high voltage, low current

instrumentation and control

low-residue soldering task force

not-AND gate

pin grid array

plated-through hole

quartz crystal microbalance

subminiature coaxial connector, type B (mil-C-39012)

surface mounted technology

Sandia National Laboratories

small-outline integrated chip

transistor-to-transistor logic

U. S. Nuclear Regulatory Commission 


\section{LIST OF SYMBOLS}

Ammeter
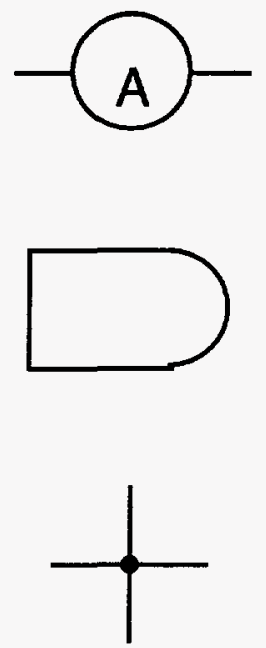

Connector

Connection

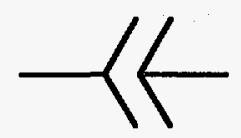

Current source
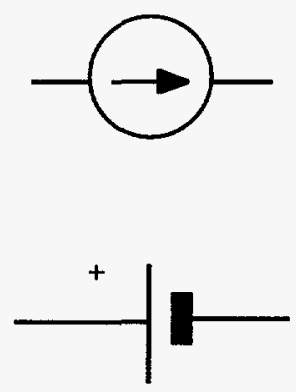

DC power supply

Ground

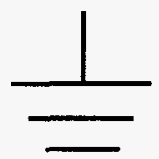

Inductor

NAND gate
No connection

Operational amplifier

OR gate

Oscilloscope

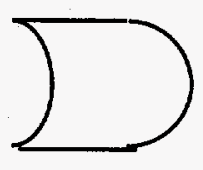

Resistor

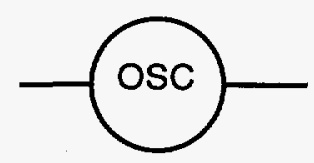

Sine-wave generator

Square-wave generator

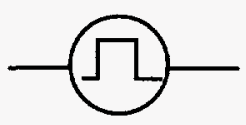

Variable resistor

Voltmeter 


\section{INTRODUCTION}

\subsection{Statement of Problem}

Existing instrumentation and control (I\&C) technology at nuclear power plants is aging, and analog replacements tend to be obsolete. The added functions available in digital $I \& C$ are motivating utilities to adopt this technology in their plants. These technologies have several advantages and in fact have been in widespread use in the non-nuclear industry for several years. However, there is concern about their use in safety-related systems in nuclear power plants owing to the lack of experience with such equipment in severe environments.

Since smoke is a severe environment, the United States Nuclear Regulatory Commission (USNRC) started a program to determine the impact of smoke on digital I\&C equipment. This report presents the results of recent USNRC-sponsored smoke exposure tests on functional circuits at Sandia National Laboratories (SNL). An earlier report in this program focused on circuit bridging of components through reduced insulation resistance between leads that was caused by smoke (Tanaka, Nowlen, and Anderson, 1996).

Oak Ridge National Laboratory is reviewing existing environmental qualification standards for digital I\&C equipment and applicable regulatory guides." Under USNRC sponsorship, it is also conducting research on the environmental qualification of digital equipment that includes tests relating to electromagnetic interference, high temperature, and high humidity (Korsah and coauthors, 1996; Korsah, Clark and Wood, 1994).

\footnotetext{
- Kofi Korsah, Tina Tanaka, and Mahbubul Hassan, Technical Basis for Environmental Qualification of Microprocessor-Based Safety-Related Equipment in Nuclear Power Plants. Draft report NUREG/CR-6479, Oak Ridge National Laboratory, Oak Ridge, TN.
}

\subsection{Previous Smoke Exposure Tests}

There are no standardized tests for electronic equipment in a smoke environment. However, there are standard tests for measuring the corrosivity of smoke from different types of materials. Typically they consist of measuring the metal loss as a result of corrosion or the acidity of the smoke (Caudill and coauthors, 1995).

Highly acidic smoke contributes to increased corrosion. While such measurements indicate the destructive quality of smoke as it corrodes contacts, they do not account for smoke-caused failures, such as shorted circuits, increased leakage currents, and arcing.

Most analyses of smoke damage are performed after a fire and do not take into account the effects of smoke during the fire (Reagor, 1992). Post-fire analysis is important for insurance companies in evaluating the salvageability of equipment, but it does not address the need of nuclear power plants, which is to be able to monitor reactor performance continuously throughout all unusual events. By actively monitoring equipment during a smoke exposure, tests performed at SNL have indicated that smoke can cause circuit bridging during as well as after a fire.

The SNL program has concentrated on determining the impact of smoke on a variety of equipment, ranging from simple components to networked computer systems, during and 24 hours after a fire. These tests show that smoke may interrupt communications between computers on networks or between computers and other microprocessor boards. Tests of empty component packages show that smoke lowers the resistance between leads and may therefore cause electrical shorting, arcs, and increased leakage currents (Tanaka, Nowlen, and Anderson, 1996).

\subsection{SNL Tests}

This report summarizes the results of smoke exposure tests on circuit boards with simple functional circuits designed by a government-industry cooperative effort, 
the Low-Residue Soldering Task Force (LRSTF) (Iman and coauthors, 1995a). The LRSTF designed two printed circuit boards to test soldering methods. Their tests were carried out in two phases and the SNL tests used the boards designed for phase 2 (Iman and coauthors, 1995b). The functionality of the boards was tested in the presence of smoke for a range of densities and burning conditions. 


\section{METHODS AND MATERIALS}

\subsection{Overview of Tests}

Fifty-five Low-Residue Soldering Task Force boards were manufactured for the smoke exposure tests. The LRSTF boards contain nine simple circuits, which are described in Section 2.4. These circuits made it easier to determine the effects of smoke than if a complex microprocessor-based board had been used. Figures 1 and 2 show the printed wiring boards used for this series of tests. The board in Figure 1 contains most of the active circuits except for the transmission lines, which are shown in Figure 2. The phase 2 design of the boards included the circuits shown in Figures 1 and 2 on the same board, but because the transmission lines were left off of the board shown in Figure 1, the printed circuit board shown in Figure 2 had to be manufactured for these tests.

Of the 55 sets of LRSTF boards (each set consisted of a main board as shown in Figure 1 and a board containing the transmission lines as shown in Figure 2), 26 sets were brushed with a conformal polyurethane coating $^{\dagger}$ and the rest were left bare. Four sets of boards were exposed per smoke test for a total of 12 smoke exposure tests and one nonsmoke, high-humidity test (13 tests in all). During each test, an uncoated board and a polyurethane-coated board were exposed to smoke, and an uncoated board and a polyurethane-coated board served as controls and were not exposed to smoke. These unexposed boards were monitored simultaneously with the other boards being tested.

The test boards were placed in a smoke exposure chamber inside an environmental chamber in which temperature and humidity were controlled before and after the exposure. The smoke was produced in a manner similar to the tests documented in Tanaka, Nowlen, and Anderson (1996).

The boards were subjected to one of six different smoke conditions, which were varied by the amount of fuel used to produce the smoke and the heat flux used to

\footnotetext{
† P18M by Hysol, a solvent-based, one-component urethane coating cured at room temperature.
}

burn the fuel. The order of conditions and the selection of boards were determined by a random draw. Three amounts of fuel and two heat flux levels were used for the six smoke exposure conditions. Each condition was repeated once.

To determine the condition of the boards before and after the exposures, the procedures for testing the circuits with a test matrix switch (Figure 3) developed by the LRSTF were followed. This allowed comparisons to be made between the boards manufactured for the low-residue solder tests and those used for these tests.

A preliminary test of possible nonsmoke effects was run prior to the smoke exposures to determine if the electromagnetic fields generated from currents to the quartz heating lamps would affect the circuits and if humidity alone would affect the circuits. The lamps were turned on when the functional boards were in the test configuration. The test lasted for 15 minutes, the length of time of the burn for the smoke tests. A second preliminary test was performed with the same test specimens. In this test, the humidity was raised to $75 \pm 5 \%$ RH. This determined the effect of high humidity on the functional circuits.

All of the low-resistance circuits (coated and uncoated) increased in resistance when the lamps were on, but 30 minutes later returned to their previous resistances. The lamps probably increased the temperature of the resistors which increased the resistance of the circuits. Since these circuits are very low in resistance, they were the most sensitive to the change in temperature. None of the other circuits reacted to the lamps. The uncoated high-resistance circuits reacted to the change in humidity by first decreasing in resistance, and then increasing back to their original values within 1 hour. The coated high-resistance circuits did not react as much to the change in humidity. The high humidity probably lowered the resistance of the surface of the board slightly, but the currents on the surfaces can heat the surface and cause the resistance to rise again. 


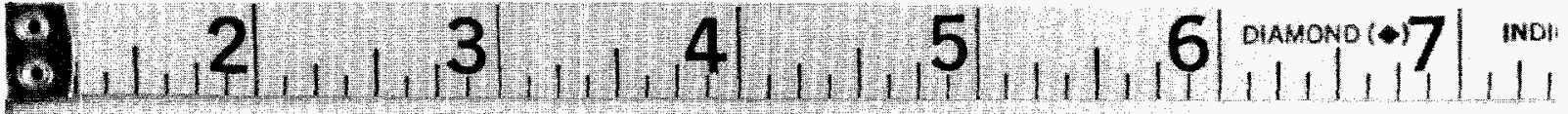

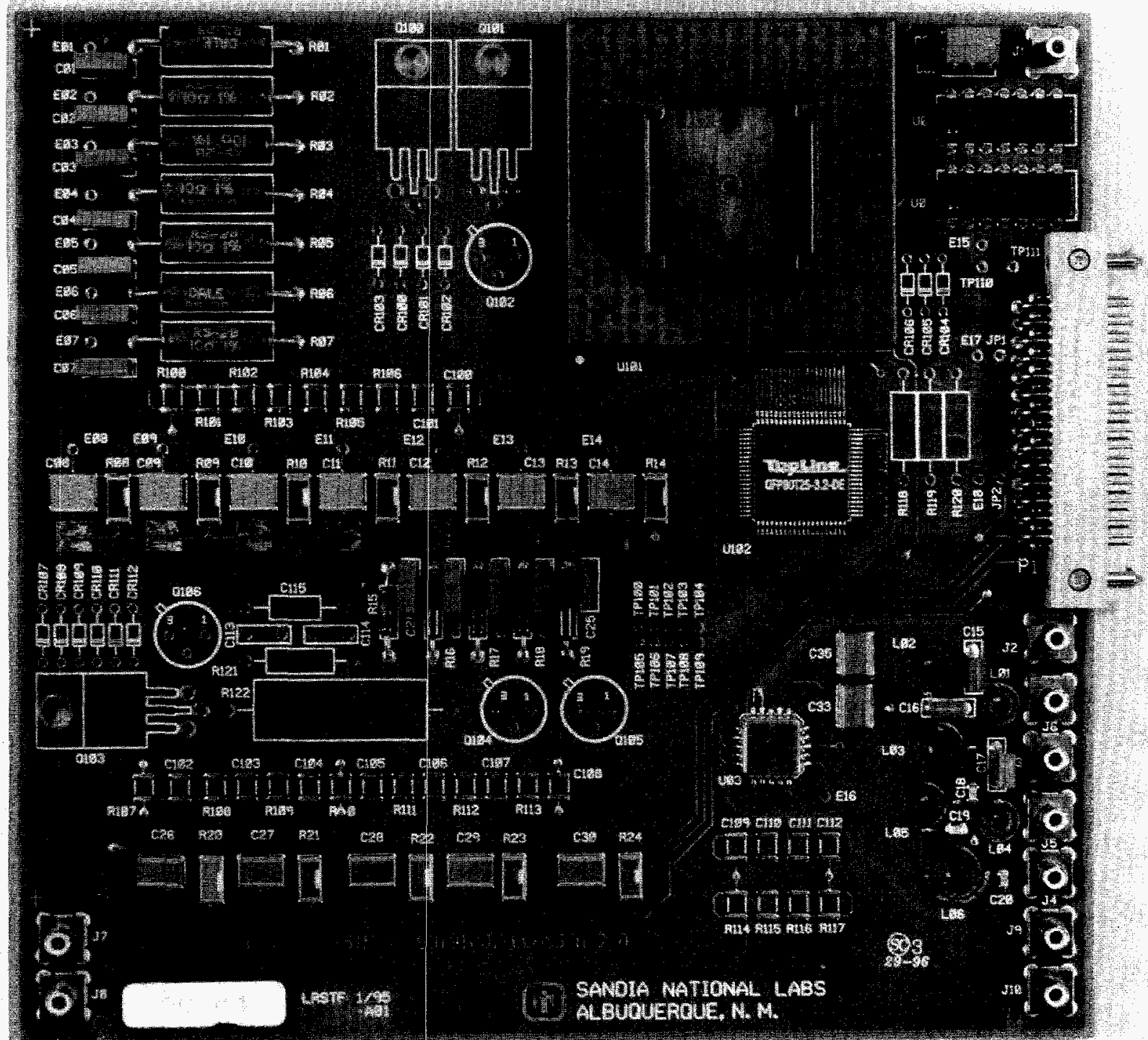

Figure 1. Front side-LRSTF board.

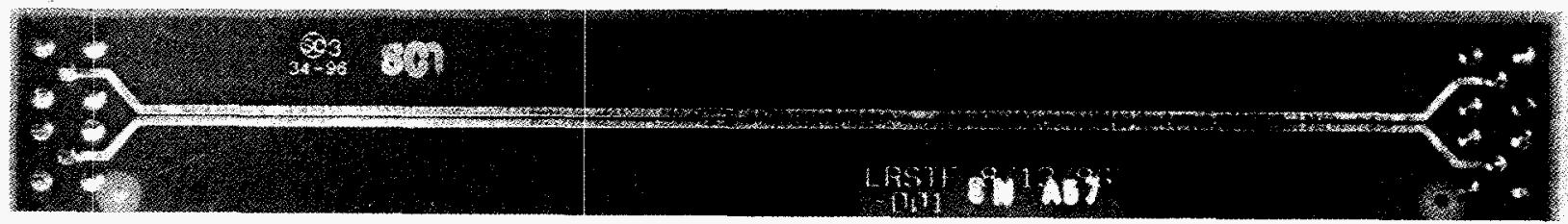

Figure 2. Two transmission lines for transmission line coupling measurement. 


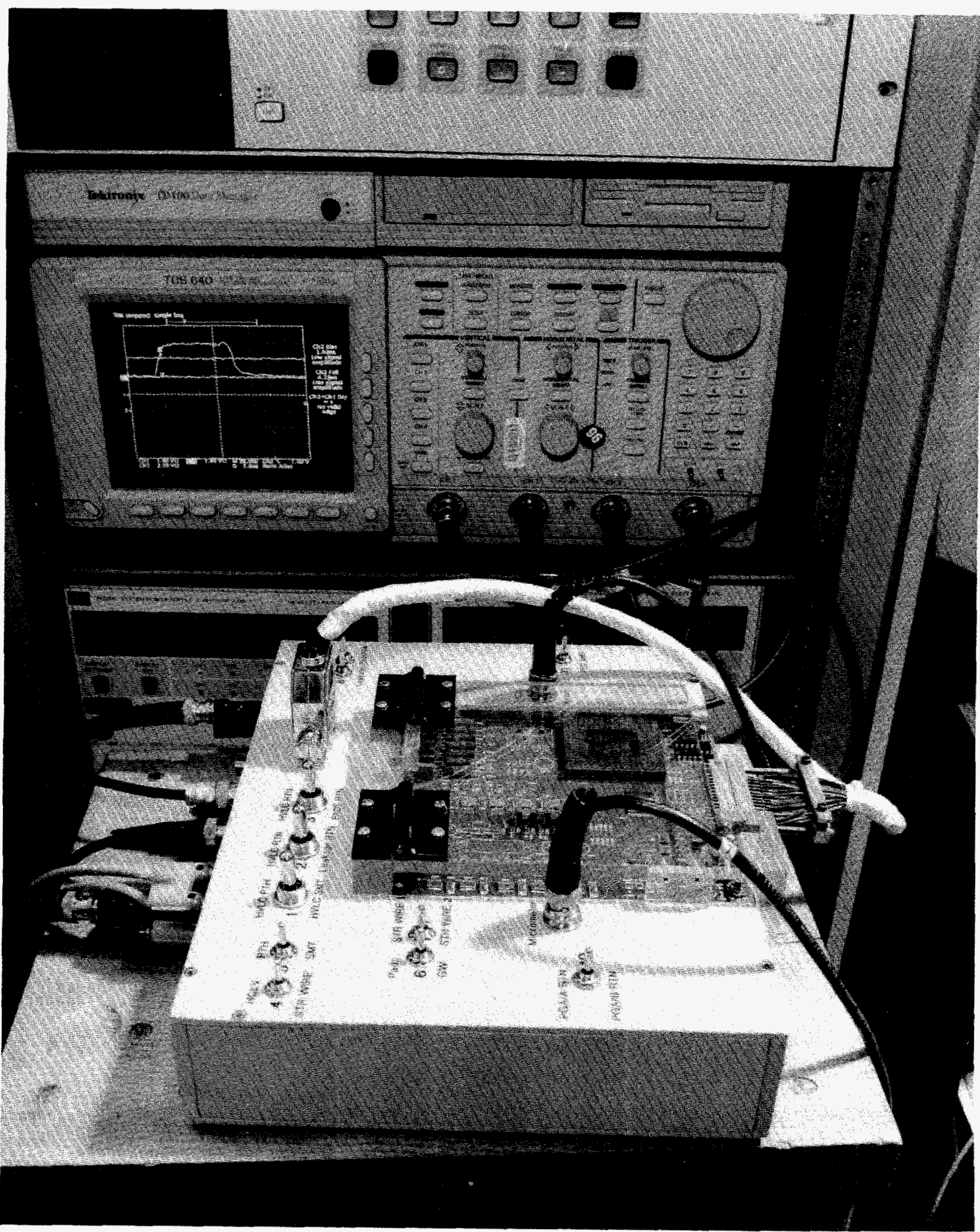

Figure 3. Manual measurement matrix switch box. 


\subsection{Functional Board Configuration}

The LRSTF board was designed to evaluate the use of low-residue solder flux (a procedure in which the flux remains on the printed wiring board after soldering). Both plated-through hole (PTH) and surface-mounted components (SMT) were used on this board to represent the two major types of components that may be used in a modern circuit board. Modern digital components use smaller packages whose contacts are also smaller and spaced closer together. An example of the differences can be seen in Figure 4, which shows the same logic chip enclosed in two different standard packages. The dual-in-line package (DIP) on the right uses plated-through holes to connect to a printed wiring board, while the small-outline integrated chip (SOIC) package on the left, an SMT component, is soldered to the surface of the board.

A variety of circuits were selected to represent the circuits that could be used in general applications; they include high-voltage, high-current, high-frequency, and high-speed digital circuits. For these four types of circuits, a separate circuit in the form of PTH and SMT components was included on the printed circuit board. The functional boards consisted of four layers; that is, there were two pieces of FR-4 ${ }^{\ddagger}$ insulated circuit board material that were laminated together, each with traces on both sides (three layers of dielectric in all). The layers were electrically connected by drilling holes into the circuit board and allowing solder to flow through the holes and form "vias." For many of the circuits, one of the middle layers served as a ground plane, while the other middle layer served as an electrical connection to various circuits.

The original LRSTF board design included several "dummy" parts that served no function other than providing crevices in which residue could deposit. Since the objective of these tests was to determine the functionality of circuits, only the functional circuits were completed; the dummy circuits were left bare of components.

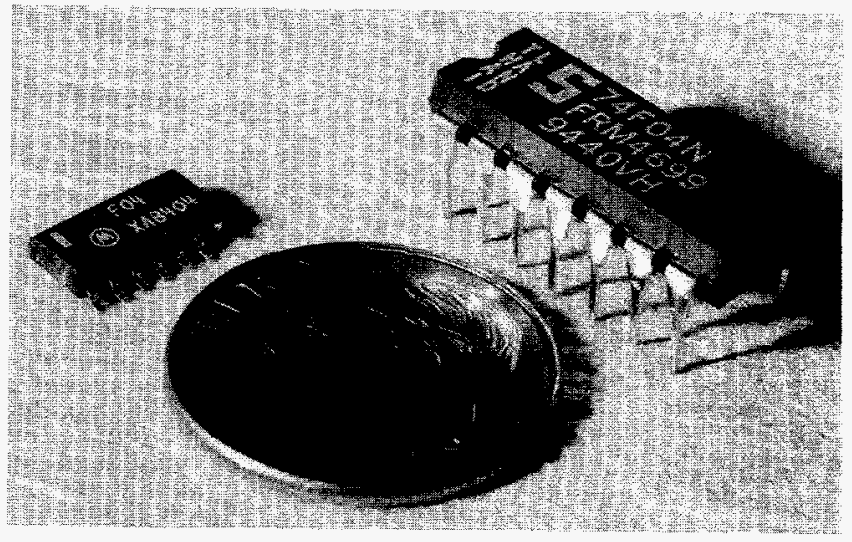

Figure 4. Comparison of PTH and SMT packages for the same device.

Figure 5 shows the back of the board in Figure 1. Leads for PTH components can be seen penetrating though the back of the functional board in Figure 5, whereas these leads are absent for SMT components. The printed circuit board can be schematically divided into isolated circuits as shown in Figure 6.

Comparisons with Figure 1 allow identification of the components in each of the circuits. More detail on each circuit is provided in the following sections. Details on the development of each circuit can be found in Iman and coauthors (1995a).

\footnotetext{
${ }^{\ddagger}$ FR-4 is a National Electrical Manufacturer's Assosiation (NEMA) grade for an epoxy-glass laminated printed wiring board with a self-extinguishing resin system.
} 


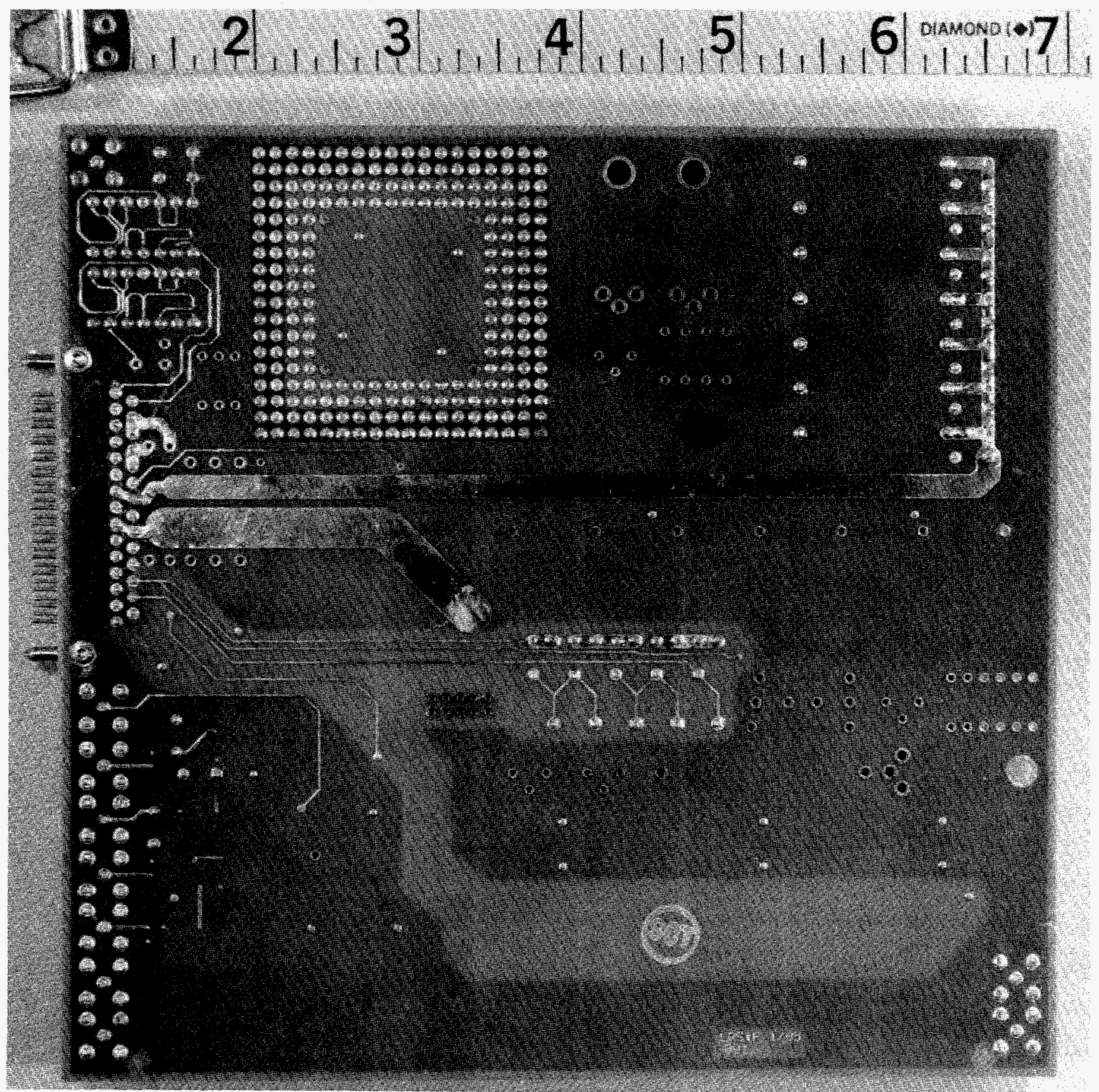

Figure 5. Back side-LRSTF board. 


\section{SMB,}

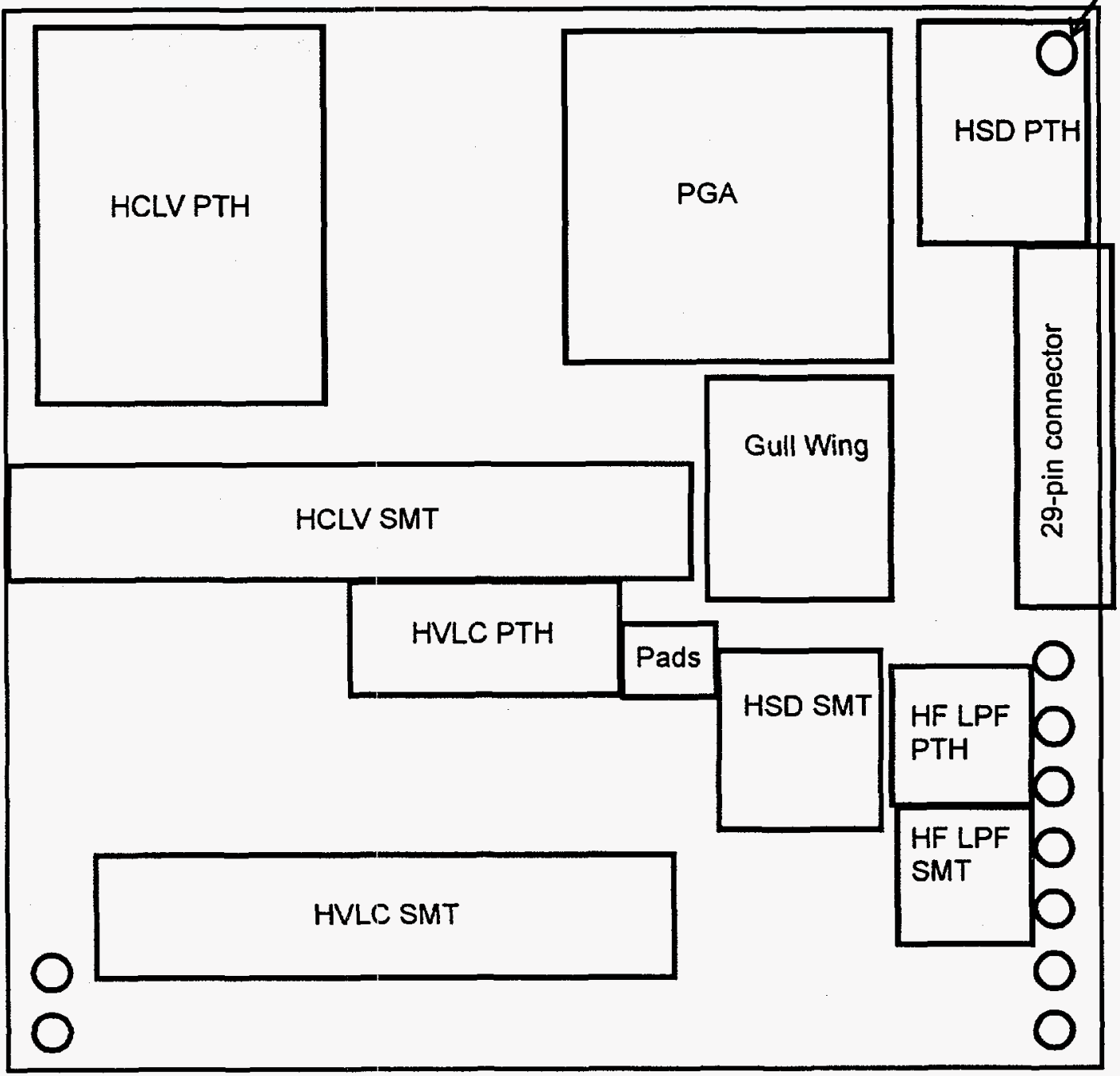

Figure 6. Diagram of LRSTF board showing circuit placement. (SMB, subminiature type B connector; HCLV, high current low voltage; PGA, pin grid array; HSD, highspeed digital; HVLC, high voltage low current; HF LPF, high-frequency low-pass filter) 


\subsection{Smoke Exposure Tests}

\subsubsection{Procedure}

In order to produce smoke in a standard and reproducible way, a draft corrosivity test standard produced by the E5.21.70 subtask group of the American Society for Testing and Materials was followed. The fuel was burned using radiant heat from a tungsten-quartz lamp inside a cylindrical quartz combustion chamber. The smoke production and exposure equipment is shown in Figure 7. The radiant heat lamps were adjusted so that a fixed heat flux was produced at the fuel surface. The heat flux was measured with a Schmidt-Boelter (thermopile) heat flux meter before each test to determine the amount of heat incident on the fuel at the beginning of the test. Small variations in the positions of the lamps can affect the heat flux that is incident on the sample. As smoke is produced, the quartz chamber becomes coated with soot, which reduces the heat flux. No attempts were made to compensate for this effect. Smoke rises up a stainless steel chimney into the smoke exposure chamber. Although the combustion cell has a small opening, no substantial amount of fresh air is allowed into the chamber during the exposure.

The smoke exposure chamber is contained within an environmental chamber that allows control of temperature and humidity before and after the exposure. The temperature and humidity levels of the environmental chamber were $24^{\circ} \mathrm{C}\left(75^{\circ} \mathrm{F}\right)$ and $75 \%$ $\mathrm{RH}$ for all of these tests. These levels were selected because they were judged to be realistic for a nuclear power plant after a fire. Because the smoke exposure chamber is sealed off from the environmental chamber during the smoke exposure, there is no effective control over temperature and humidity during the exposure.

The smoke exposure tests consisted of monitoring four functional board sets at a time, two sets in the smoke chamber (Figure 8) and two sets outside the smoke chamber (Figure 7) while smoke was added to the exposure chamber and for 24 hours thereafter. In addition, two IPC-B-24 boards were included in the tests, one inside the smoke chamber and one outside the smoke chamber with the control functional boards. Half of the functional boards were coated with polyurethane and half were uncoated.
Three levels of fuel were tested-high $\left(50 \mathrm{~g} / \mathrm{m}^{3}\right)$, medium $\left(25 \mathrm{~g} / \mathrm{m}^{3}\right)$, and low $\left(3 \mathrm{~g} / \mathrm{m}^{3}\right)$-defined in terms of fuel available to burn per volume of air available (Table 1). Each density level simulated the amount of smoke per volume of air that is likely to occur for different fire scenarios (Tanaka, Nowlen, and Anderson, 1996). As reported in Tanaka, Nowlen, and Anderson (1996), typical electrical cabinets in nuclear power plants range in size from 0.85 to $85 \mathrm{~m}^{3}$. The amount of fuel in these cabinets averages $25 \mathrm{~kg} / \mathrm{m}^{3}$. The high fuel level in Table 1 corresponds to burning $2 \%$ of the fuel in an average cabinet and then determining the effect on equipment located within the cabinet. This scenario of equipment located in the same cabinet as the fire produces the highest likely smoke density in which the exposed electrical equipment is not burned but can be damaged by smoke. The medium fuel level corresponds to a significant fire in a general room (smaller than the control room). Other scenarios could also yield this same smoke density, for example, electrical equipment located in the same cabinet as a fire, but with only $1 \%$ of the fuel burning. The low level of smoke density corresponds to a cabinet fire in the control room. Since the control room is very large compared with most other rooms in a nuclear power plant and it contains much of the control equipment, a special effort was made to include the low smoke densities that may affect equipment located within a control room while another electrical equipment cabinet is burning. For most scenarios, no dilution of the smoke by ventilation was assumed because fire dampers should close the vents to general areas. However, for the large cabinet fire in the control room, the smoke was assumed to be diluted by an equivalent of 10 air changes per hour based on activation of the control room emergency vent mode (Jacobus, 1984).

Table 1. Fuel amounts burned

\begin{tabular}{lccc}
\hline Fire scenario & $\begin{array}{c}\text { Smoke } \\
\text { level }\end{array}$ & $\begin{array}{c}\text { Fuel/air } \\
\text { ratio } \\
\left(\mathbf{g} / \mathbf{m}^{\mathbf{3}}\right)\end{array}$ & $\begin{array}{c}\text { Amount } \\
\text { of fuel } \\
(\mathbf{g})\end{array}$ \\
\hline $\begin{array}{l}\text { Large cabinet fire } \\
\text { in control room }\end{array}$ & Low & 3 & 0.6 \\
$\begin{array}{l}\text { General area fire } \\
\text { Small cabinet }\end{array}$ & Medium & 25 & 5 \\
$\begin{array}{l}\text { fire (equipment } \\
\text { in cabinet) }\end{array}$ & & 50 & 10 \\
\hline
\end{tabular}




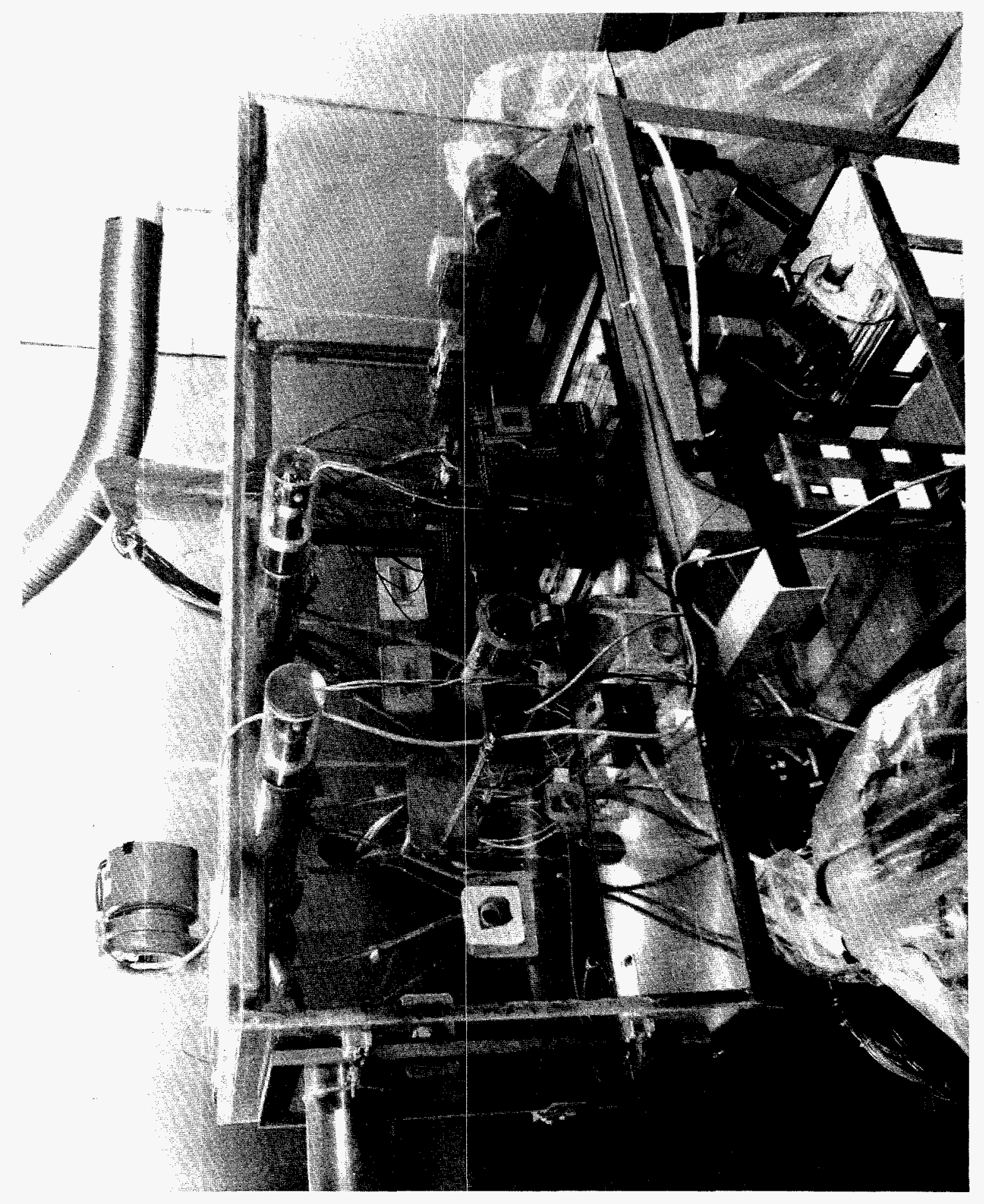

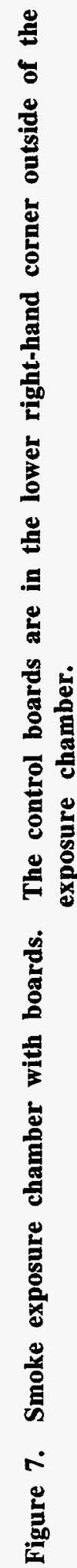




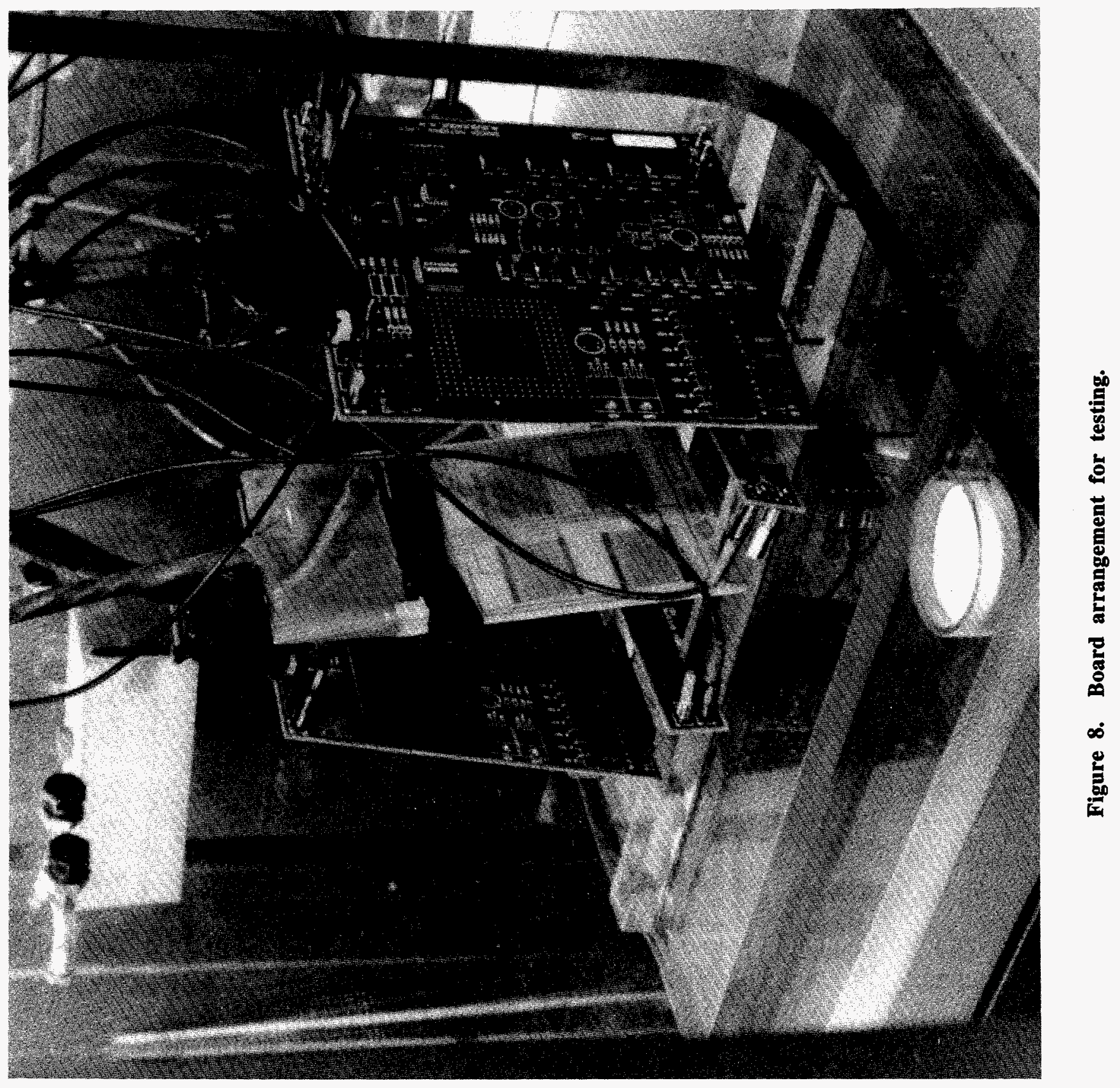


The volume of the smoke exposure chamber used for this test was $0.2 \mathrm{~m}^{3}$, one-third the size of the smallest cabinets used in plants. It is easier to perform repeated tests on a small scale and in a small volume than in full-scale tests. However, some assumptions must then be made on the amount of fuel that should be burned to replicate a full-scale fire on the small scale of these tests. Since we did not know whether the amount of fuel burned should be scaled by volume or by surface area of the test chamber, volume was arbitrarily selected. Earlier, during the circuit bridging tests, shorting occurred midway through burning the fuel (Tanaka, Nowlen, and Anderson, 1996). Thus, for the high level in the current tests we used only $\mathbf{5 0}$ $\mathrm{g} / \mathrm{m}^{3}$. Since a threshold value for smoke density was desired, a middle value of $25 \mathrm{~g} / \mathrm{m}^{3}$ was also included. The low level was the same as the low level for the circuit bridging tests on components. All tests were run at $>70 \% \mathrm{RH}$, which corresponds to a controller setting of $75 \% \mathrm{RH}$. The tests were run at high and low heat flux levels: $50 \mathrm{~kW} / \mathrm{m}^{2}$ for high (flaming) and $25 \mathrm{~kW} / \mathrm{m}^{2}$ for low (smoldering).

Since the smoke exposure chamber volume of $0.2 \mathrm{~m}^{3}$ was smaller than that used for the circuit bridging tests reported in Tanaka, Nowlen, and Anderson (1996), the amount of fuel needed was very small. To make the test valid for a general cable fire rather than a specific cable material, a mixture of cables was burned. Rather than cutting small lengths of cable, the cable jacket and insulation materials were stripped from the conductors and ground into small particles.

The fuel mixture is summarized in Table 2. The fuel includes insulation and jacket material from different environmentally qualified cables currently in use at plants (Bustard and Holzman, 1994). The mixture was based on a rough estimate of the relative popularity of each material using the ratio for the number of plants using that material to the total number in the Bustard and Holzman report. It is intended to be representative of cables found in all plants rather than a single material or plant.

As indicated previously, the fuel was burned at two heat flux levels $-25 \mathrm{~kW} / \mathrm{m}^{2}$ and $50 \mathrm{~kW} / \mathrm{m}^{2}$. These levels were provided by the quartz lamps used to heat the fuel. The flux level was measured without any fuel in the combustion chamber. A control program that compared the heat flux level with the output of the thermopile determined the voltage level at which the lamps were to be powered for the smoke exposure. The $25-\mathrm{kW} / \mathrm{m}^{2}$ level corresponds to a smoldering fire; tests at this level were performed without igniting the fuel. The $50-\mathrm{kW} / \mathrm{m}^{2}$ level corresponds to a flaming fire; after 2 minutes of heating, the fuel was ignited with a butane pilot light and the fire was allowed to burn until the fuel was exhausted.

The smoke exposure procedure is shown schematically in Figure 9. At the beginning of each test cycle, the circuit board functions were measured using the manual procedure developed by the LRSTF. This was done in the laboratory area with no humidity or temperature controls. The boards were then placed in the smoke exposure chamber and automatic measurements began as the humidity was increased to $75 \% \mathrm{RH}$.

When the humidity reached $75 \% \mathrm{RH}$, the smoke exposure chamber was closed and the lamps turned on for 15 minutes. While the lamps were on, the fuel was either ignited (high flux) or allowed to smolder (low flux). After the lamps were turned off, a small fan was turned on to mix the smoky atmosphere. The smoke exposure chamber remained closed for 1 hour. After

Table 2. Cable insulation used as fuel

\begin{tabular}{l|llcc}
\hline & & & & Fraction \\
Cable name & Insulation & Jacket & Plants & of plants \\
\hline Rockbestos Firewall III & FRXLPE & CSPE & 61 & 0.222 \\
Anaconda Flameguard 1kv & EPR & CSPE & 35 & 0.127 \\
Brand Rex XLPE & XLPE & CSPE & 30 & 0.109 \\
Okonite Okolon & EPR & CSPE & 26 & 0.095 \\
Kerite HTK & & & 25 & 0.091 \\
Rockbestos Coax (le) & & & 24 & 0.087 \\
Raychem XLPE & XLPE & & 23 & 0.084 \\
Dekoran Dekorad & EPDM & CSPE & 19 & 0.069 \\
BIW & EPR & CSPE & 19 & 0.069 \\
Kerite FR & & & 13 & 0.047 \\
\hline
\end{tabular}




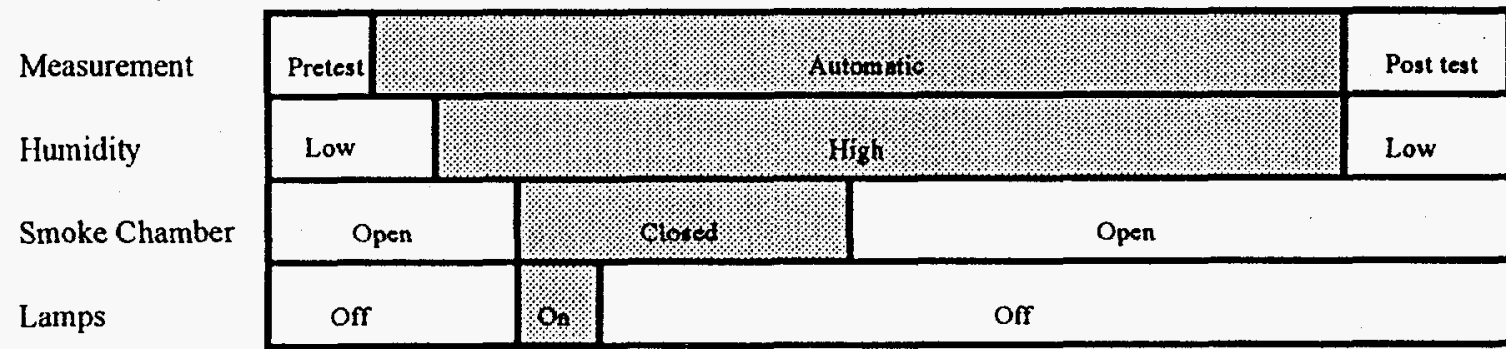

Time (hrs)

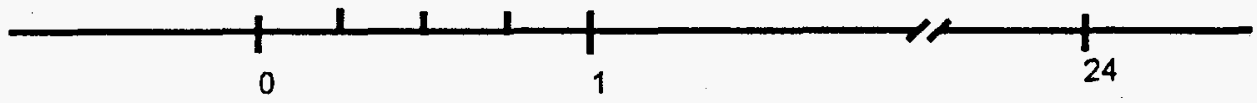

Figure 9. Smoke exposure activity timeline.

the smoke exposure chamber was vented through a hood, the chamber doors were opened to allow the humidity-controlled air into the combustion chamber. The circuits were continually monitored for 24 hours starting at the time the lamps were turned on.

The control boards were treated in a manner similar to the exposed boards; their functions were checked before the test using a manual measurement system. The control boards were then placed outside the smoke exposure chamber but inside the environmental chamber while the humidity was increased. When the smoke exposure chamber was closed to start the smoke exposure, the control boards were enclosed in a plastic bag to ensure that any smoke leaking from the chamber did not drift over to the control boards. The control boards remained in the bag throughout the exposure. The bag was then opened while the smoke exposure chamber was vented and remained opened throughout the remainder of the automatic measuring period.

After the automatic measurement period, both the exposed and control boards were measured again using the manual procedure. These measurements were made within 1 hour of the end of the automatic procedure, but were in the general laboratory, which had no humidity controls and a temperature of approximately $20^{\circ} \mathrm{C}$.

\subsubsection{Measurement Techniques and Equipment}

\subsubsection{Soot Deposition}

Two quartz crystal microbalances (QCM) oriented in horizontal and vertical directions were used to determine how much smoke was deposited on surfaces (Figure 10). The QCM oscillates at its natural frequency (approximately $5 \mathrm{MHz}$ ), which is determined by the oscillation mode and the mass of the crystal. As smoke is deposited, the crystal oscillates at a slower frequency, much as a loaded spring with a changing mass. The change in frequency is related to the change in mass by the following equation:

$$
\Delta M=-\frac{4.419 E+11}{f_{0}^{2}} \Delta f
$$

where $f_{0}$ is the starting frequency of the $\mathrm{QCM}, \Delta f$ is the change in frequency $(\mathrm{Hz})$ from $f_{0}$, and the resulting change in mass $(\Delta M)$ is in $\mu \mathrm{g} / \mathrm{cm}^{2}$. The constant multiplier $(4.419 \mathrm{E}+11)$ is dependent on the dimensions of the original QCM crystal.

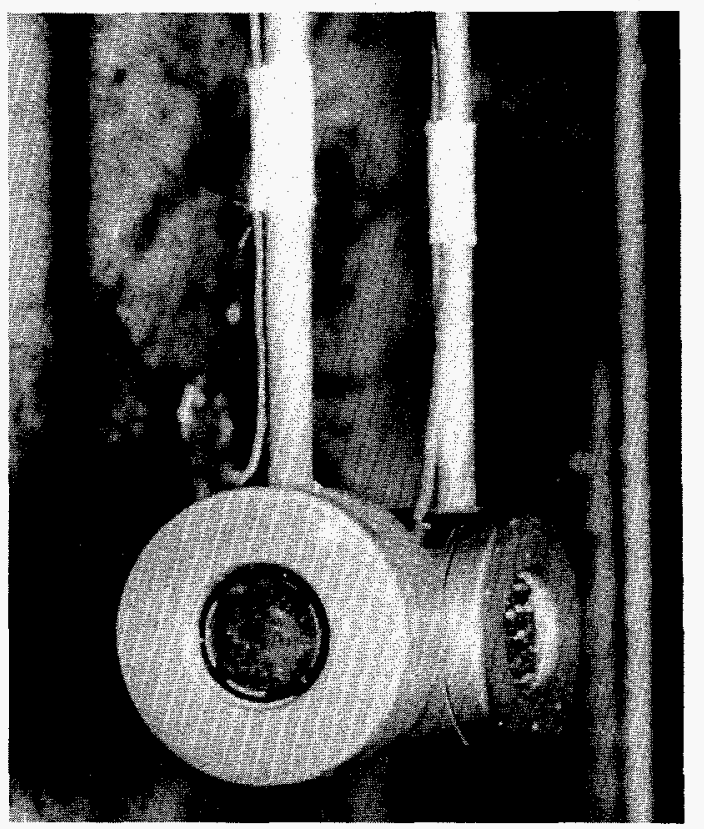

Figure 10. Quartz crystal microbalances for the measurement of soot deposition. 


\subsubsection{Fuel Weight Loss}

Before the test, the fuel was placed in aluminum trays on top of a load cell within the quartz combustion chamber (Figure 11). The trays were weighed before and after each test to determine how much fuel was burned. The load cell also provided active monitoring of the weight loss as the fuel was burned.

\subsubsection{Temperature and Humidity}

Temperature was measured using five thermocouples in the smoke exposure chamber (Figure 12) and two thermocouples with the control boards.

Thermocouples 1 to 3 were located in the ceiling of the smoke exposure chamber. Thermocouple 4 was located along the floor of the smoke exposure chamber.

Thermocouple 5 was located in the same area as the functional boards and could be used to determine the temperature near the bottom of the boards.

Thermocouples 6 and 7 were located in the bag with the control boards during the smoke exposure. They were exposed to the environmental chamber when the bag was opened, after the exposure period.
Humidity inside the environmental chamber (but outside the smoke exposure chamber) was monitored and controlled for a 24-hour period. Since the smoke exposure chamber was sealed during the exposure period (1 hour), the humidity that was measured during this time did not indicate the humidity at the board locations. The plastic bag around the control boards was sealed just before the start of the smoke exposure and opened after the exposure; thus the humidity surrounding the control boards was treated in the same manner as the smoke-exposed boards, i.e., humidity was controlled before and after but not during exposure.

\subsubsection{Chemical Analysis}

The soot was analyzed using ion chromatography, which detects specific acidic compounds containing $\mathrm{Cl}$, $\mathrm{Br}, \mathrm{F}$, and $\mathrm{SO}_{4}$. The soot was collected on $4.25-\mathrm{cm}$ diameter ashless filter papers placed on the bottom of the smoke exposure chamber, away from other interfering materials.

The fuel was also analyzed for percent bromine, chlorine, fluorine, and ash after burning. The gross heat of combustion was measured in this process.

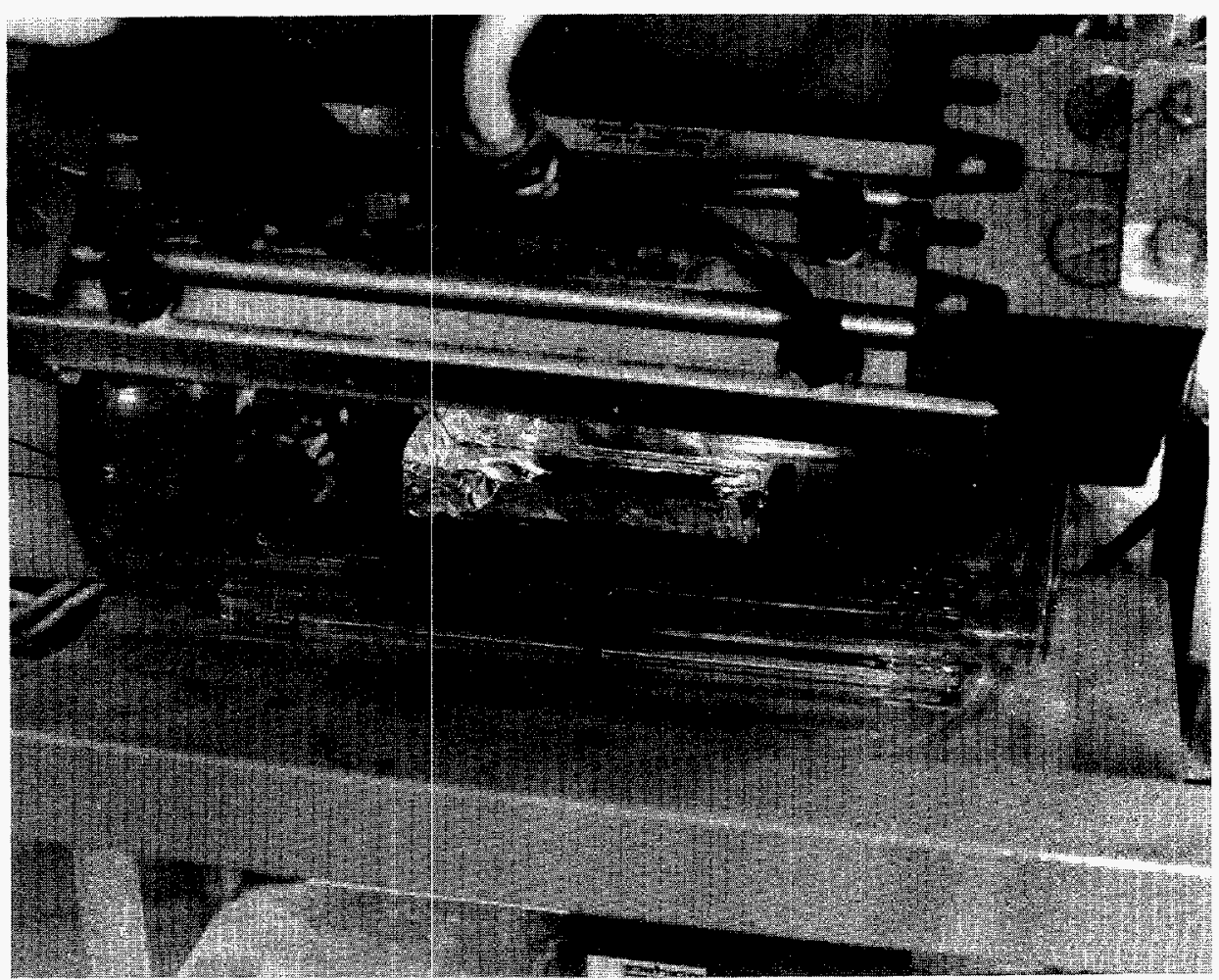

Figure 11. Fuel in combustion chamber. 


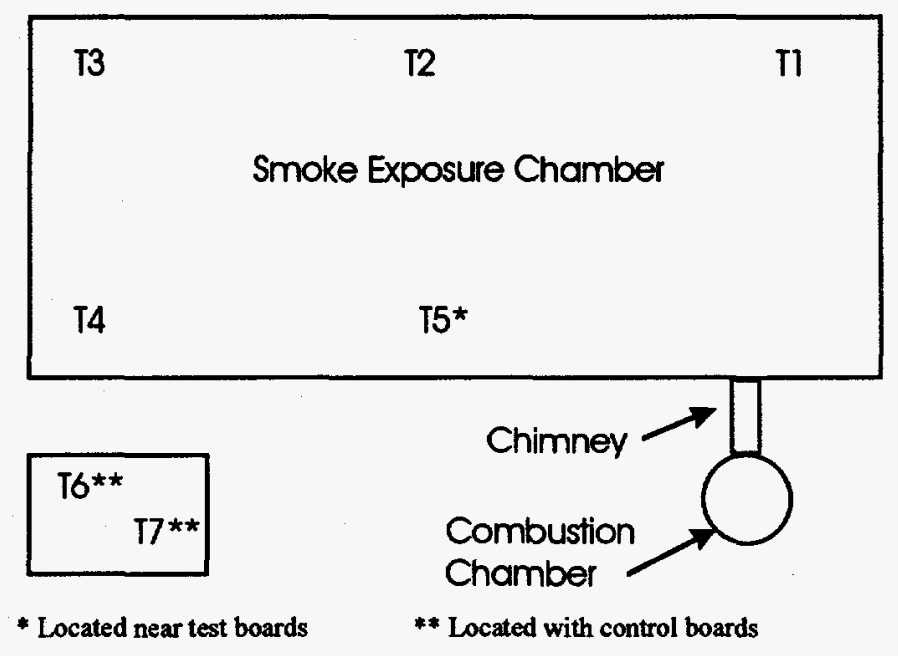

Figure 12. Thermocouple locations.

A semiquantitative spectrographic analysis of the ash sample was also performed to determine the presence of metals.

\subsection{Circuit Tests and Measurement Procedures}

\subsubsection{Overview}

As indicated earlier, the manual testing procedures developed by the LRSTF were followed. All of the functional boards were tested before and after each exposure using a method developed by the LRSTF that employs a manually operated switch box. These tests were performed outside of the environmental chamber; thus, the humidity and temperature were not controlled. The conditions were those of the standard laboratory environment, which was generally $68^{\circ} \mathrm{F}$ and 10 to $20 \%$ RH. The post-test measurements were performed within 1 hour of the end of the monitoring period in the smoke exposure chamber.

Automatic measurement of in situ equipment is important in order to capture malfunctions that may occur during a fire. Therefore, an automatic monitoring system was assembled to test the functional boards in a manner similar to the manual measurements, but that could complete the task in 3 minutes for all four sets of boards. This assembly required more switches and longer cables than the manual measurement system because the measurement instruments were located in the general laboratory outside the testing area. Since additional cable length and switches tend to decrease high-frequency signals, direct comparisons between manual and automatic measurements may not be consistent.

Automatic measurements of the functionality and leakage currents were taken at approximately 3-minute intervals. This is the amount of time that it takes to cycle through all of the measurements. Automatic measurements of the environment within the smoke chamber were made at intervals of 5 seconds while the lamps were on and at intervals of 1 minute thereafter.

A set of specific measurements was made on each of 9 active circuits to characterize the operation of the circuits during smoke exposures. Since both highfrequency and direct current measurements were made on these boards, two types of connectors were used: coaxial subminiature connectors of type B (SMB) and a 29-pin connector. The 29-pin connector was also used to connect to ground, $+5 \mathrm{Vdc}$, and to the input pulse for the high-speed digital circuit. Table 3 presents a list of circuits and connectors through which these circuits were accessed. These circuits were designed to test the limits of the soldering process and are very sensitive to poor manufacturing practice. Because the functional board was designed by the LRSTF to study low-residue solder processes rather than digital I\&C circuits, the board included analog as well as digital circuits. For example, the high-voltage, high-current, and high-frequency circuits test for extremes in analog circuits. Although these analog circuits are not commonly used in digital I\&C circuits, they may be a part of a sensor package, and their evaluation to 
Table 3. Circuits on functional board

\begin{tabular}{l|lll}
\hline Circuit & SMT & PTH & Connector \\
\hline High voltage low current (HVLC) & $x$ & x & 29 pin \\
High current low voltage (HCLV) & $x$ & $x$ & 29 pin \\
High-speed digital (HSD) & $x$ & x & 29 pin and SMB \\
High-frequency low-pass filter (HF LPF) & x & x & SMB \\
High-frequency transmission line (HF TL) & N/A & N/A & SMB \\
Leakage measurement: & & & \\
$\quad$ & & $x$ & 29 pin \\
$\quad$ Pads & $x$ & & 29 pin \\
$\quad$ Gull wing & & $x$ & 29 pin \\
\hline
\end{tabular}

a The transmission lines are traces on the prinled circuit boards and have no components to be classified as either SMT or PTH.

determine what is most easily affected by smoke is important. The high-speed digital circuit is a simple logic gate that is similar to digital I\&C design. Many digital designs also include transmission lines in the forms of traces on printed circuit boards, but they are usually covered with a solder mask and do not normally run parallel to other traces for as long as they do on this board (which is avoided because it encourages cross-talk). Leakage measurements serve as a diagnostic and do not resemble any actual circuits.

In addition to the automatic measurements conducted on the functional boards, surface insulation resistance was also measured on the uncoated IPC-B-24 boards.

\subsubsection{Individual Circuits}

\subsubsection{High Voltage Low Current}

The high-voltage low-current circuit (HVLC) is a series of $10-\mathrm{M} \Omega$ resistors and $0.1-\mathrm{mF}$ capacitors designed to determine if flux residue would lower the resistance between contacts enough to change the circuit's performance. A high voltage $(300 \mathrm{Vdc})$ was applied to this circuit during both the manual and automated tests, although originally the LRSTF planned to apply 500 Vdc. However, $500 \mathrm{Vdc}$ was found to cause arcing, so a lower voltage was suggested by the LRSTF. As discussed in Iman and coauthors (1995a), the voltage between traces is expected to be approximately $60 \mathrm{~V}$. Smoke is expected to lower the resistance between contacts and thus the HVLC circuit should be highly affected by the smoke.

The HVLC circuit was measured manually with the matrix switch box shown in Figure 3 using the circuit in Figure 13. A total of $300 \mathrm{Vdc}$ was applied across the circuit and the current was measured using an ammeter. The $10-\mathrm{k} \Omega$ resistor in the measurement circuit would limit the current if the HVLC circuit completely shorted. Since this was a direct current (dc) measurement, only the steady-state operation of the circuit needed to be considered; the capacitors do not affect the steady-state current. The capacitors, however, provided additional sites for possible leakage currents. The expected current can be calculated as follows:

$$
\begin{aligned}
R_{\text {toall }} & =10 \mathrm{M} \Omega+10 \mathrm{M} \Omega+10 \mathrm{M} \Omega+10 \mathrm{M} \Omega \\
& +10 \mathrm{M} \Omega+10 \mathrm{k} \Omega \\
& =50.01 \mathrm{M} \Omega
\end{aligned}
$$$$
I=\frac{V}{R_{\text {total }}}=\frac{300 \mathrm{~V}}{50.01 \mathrm{M} \Omega}=6.0 \mu \mathrm{A}
$$

The automated HVLC circuit measurement was performed by measuring voltage instead of current. These voltages were measured across an additional pair of in-series resistors that were located outside of the environmental chamber. The circuit is shown in Figure 14. The current through the circuit can be calculated using Ohm's law:

$$
\begin{aligned}
R_{\text {total }} & =5 \times 10 \mathrm{M} \Omega+10 \mathrm{M} \Omega+1 \mathrm{M} \Omega \\
& =61 \mathrm{M} \Omega \\
V_{s}= & I R_{\text {total }}=300 \mathrm{~V} \\
V_{o}= & I \times 1 \mathrm{M} \Omega \\
= & V_{s} \times \frac{1 \mathrm{M} \Omega}{61 \mathrm{M} \Omega} \\
= & 4.9 \mathrm{~V}
\end{aligned}
$$




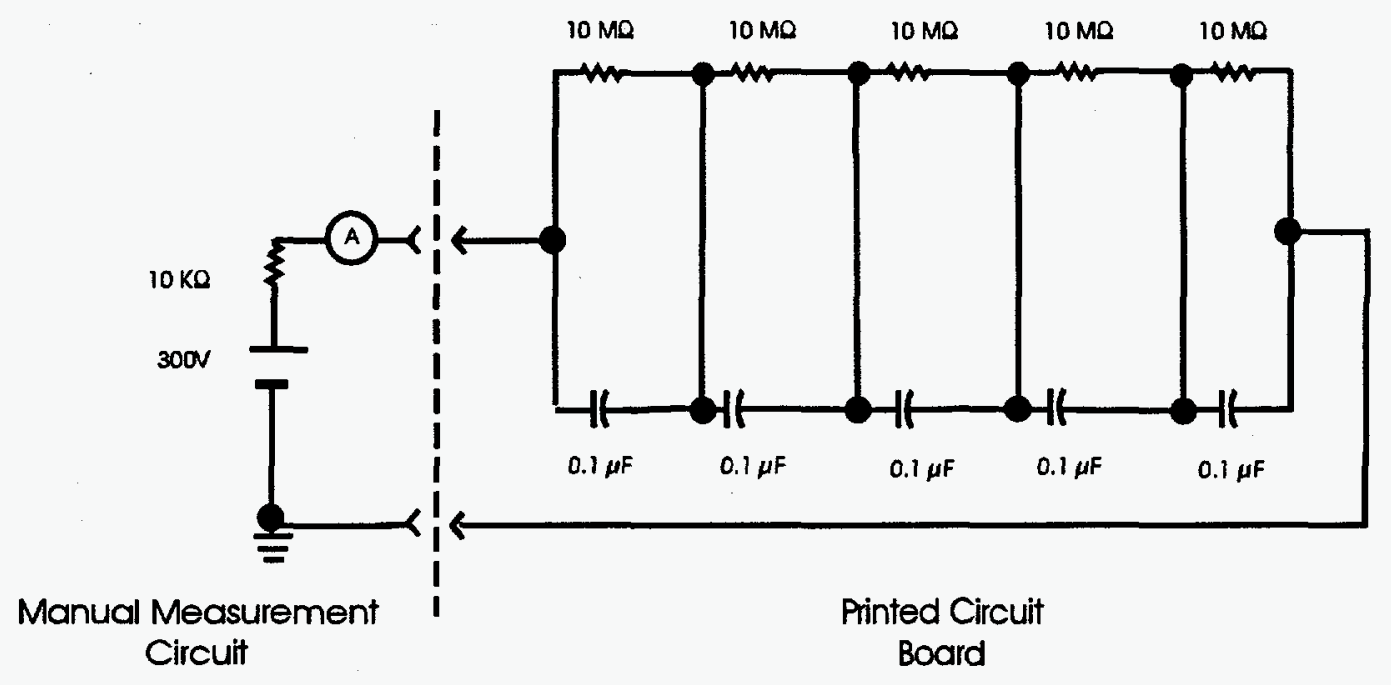

Figure 13. HVLC manual measurement circuit.

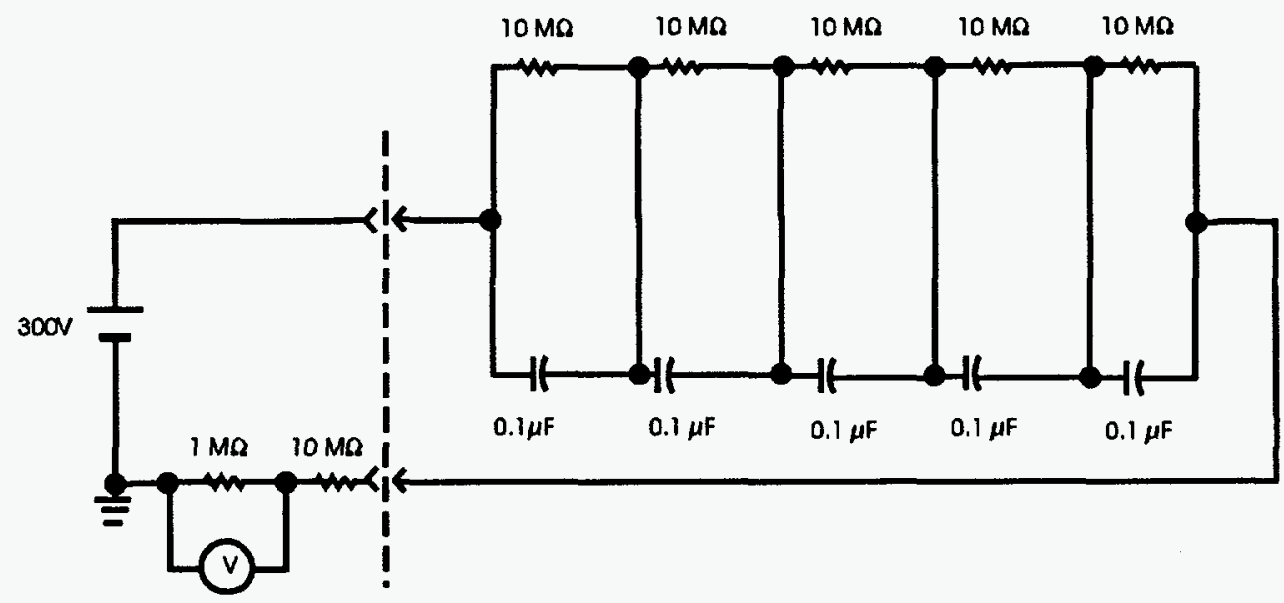
Automatic Measurement
Circuit
Printed Circuit
Board

Figure 14. HVLC automatic measurement circuit.

These in-series resistors limit the current from the power supply to $27 \mu \mathrm{A}$ and divide the supply voltage so that $V_{O}<27 \mathrm{Vdc}$ if the HVLC circuit shorts.

Since the measurements from the two systems are different (one is in terms of current and the other voltage), comparisons between them must be made by converting the results to similar units. The current through the automated measurement system is not the same as the current through the manual system because of the additional in-series resistors. The resistance of the HVLC circuit, however, is independent of the measurement system and can be calculated for both cases as follows:

$$
R_{\mathrm{HVLC}}=\frac{300 \mathrm{~V}}{I_{\text {manual }}}-10 \mathrm{k} \Omega
$$

and

$$
R_{\mathrm{HVLC}}=\frac{300 \mathrm{~V} \times 1 \mathrm{M} \Omega}{V_{\text {automated }}}-11 \mathrm{M} \Omega
$$




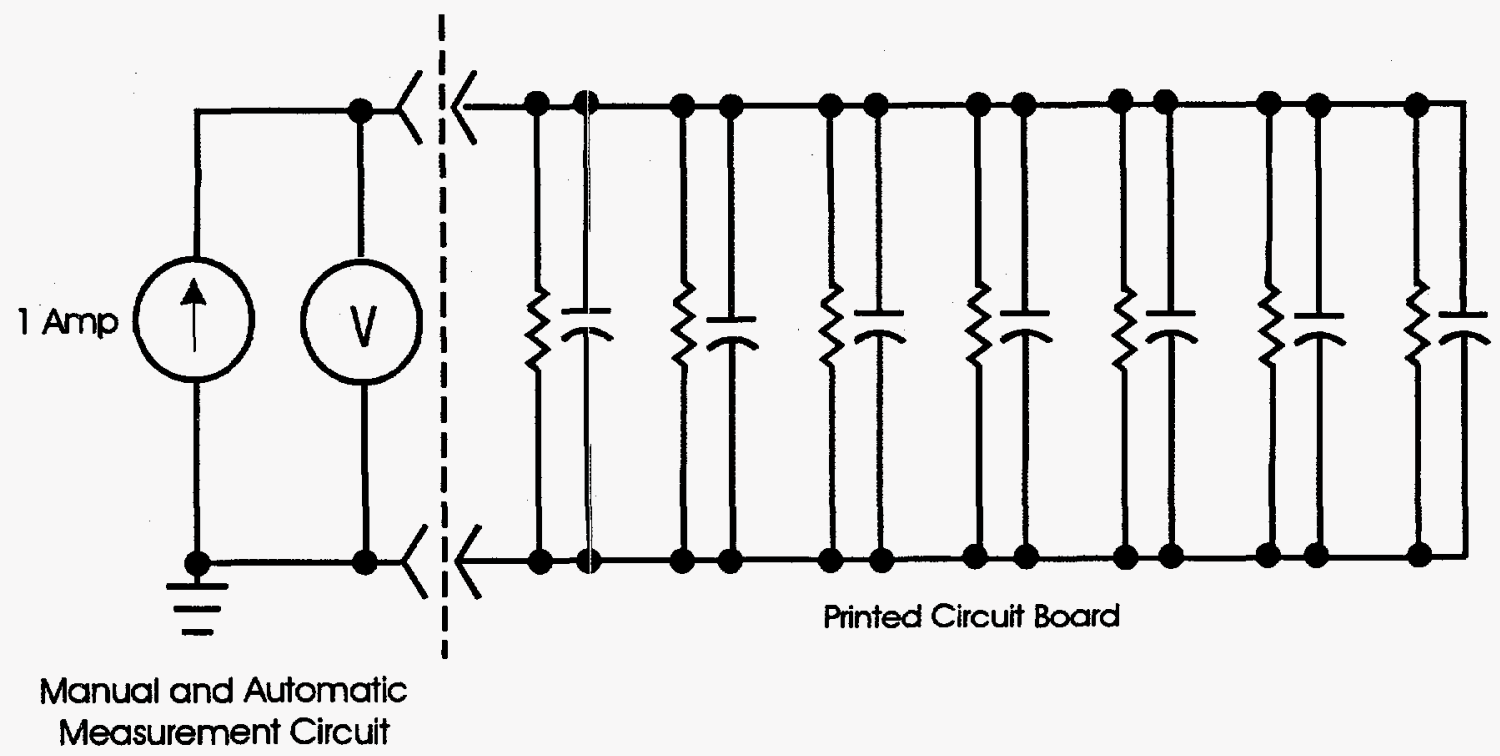

Figure 15. HCLV manual and automatic measurement circuit.

\subsubsection{High Current Low Voltage}

The high-current low-voltage circuit (HCLV) consists of parallel resistors and capacitors driven by a current source as shown in Figure 15. The HCLV circuit was included on the functional board to test solder joints, because cracks in these joints increase the resistance of a circuit. Changes in resistance are measured by the changes in voltage needed to maintain the high current level of $1 \mathrm{~A}$.

Both the manual and automatic measurements of the boards were conducted in the same manner. A current source was applied across the HCLV circuit and the voltage necessary to maintain $1 \mathrm{~A}$ across the circuit was determined. Because the manual and automatic measurements used different cables to supply this current (the current supply cable for the manual system was about $1 \mathrm{~m}$ long; the automatic system supply included relays and an additional $3 \mathrm{~m}$ ), the voltages from the two measurement systems differed by a constant amount, as shown in the following equations:

$$
\begin{aligned}
& V_{\text {manual }}=1 \mathrm{~A}\left(R_{\mathrm{HCLV}}+R_{\text {manual }}\right) \\
& V_{\text {automatic }}=1 \mathrm{~A}\left(R_{\mathrm{HCLV}}+R_{\text {automatic }}\right)
\end{aligned}
$$

where

$$
\begin{aligned}
\frac{1}{R_{\mathrm{HCLV}}} & =\frac{1}{10 \Omega}+\frac{1}{10 \Omega}+\frac{1}{10 \Omega}+\frac{1}{10 \Omega}+\frac{1}{10 \Omega} \\
& +\frac{1}{10 \Omega}+\frac{1}{10 \Omega} \\
& =\frac{7}{10 \Omega}
\end{aligned}
$$

and $R_{\text {manual }}$ and $R_{\text {automatic }}$ are the resistances in the cables of the respective measurement systems. Because the test conditions maintain a constant current of $1 \mathrm{~A}$, the differences between the manual and automatic measurements should be a constant [1 $\mathrm{A}\left(R_{\text {automatic }}-\right.$ $\left.R_{\text {manual }}\right)$ ]. Since this is a steady-state measurement, the capacitors are not included in the equation for voltage.

Smoke may attack solder joints because of its corrosive nature; however, this may take longer than the exposure and measurement period of the tests. Very little change in these circuits is expected because the resistance of the circuit is already very low $(1.4 \Omega)$ and it was found in previous experiments that the immediate effect of smoke is to lower resistance rather than raise it (Tanaka, Nowlen, and Anderson, 1996).

\subsubsection{High-speed Digital}

The high-speed digital (HSD) circuit consisted of logical NAND gates (not-AND) that were connected 


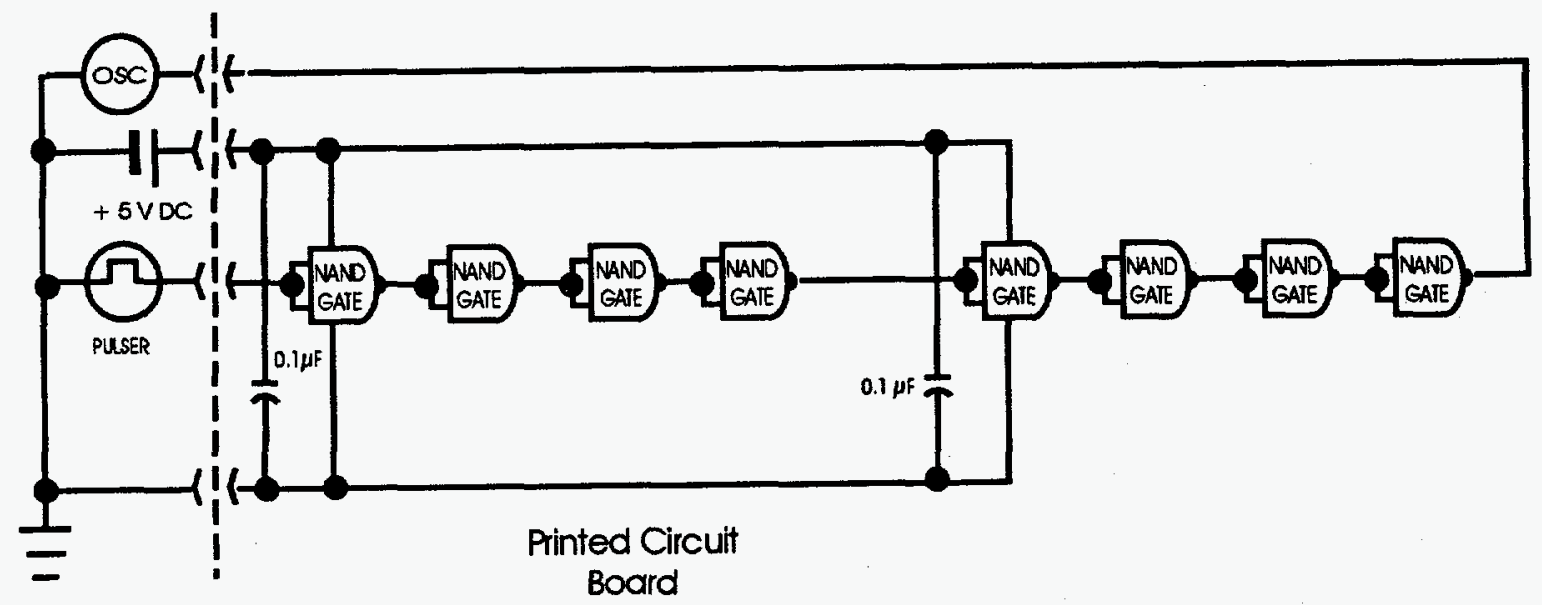

Manual and

Automatic

Measurement

Circuit

Figure 16. HSD PTH measurement circuit.

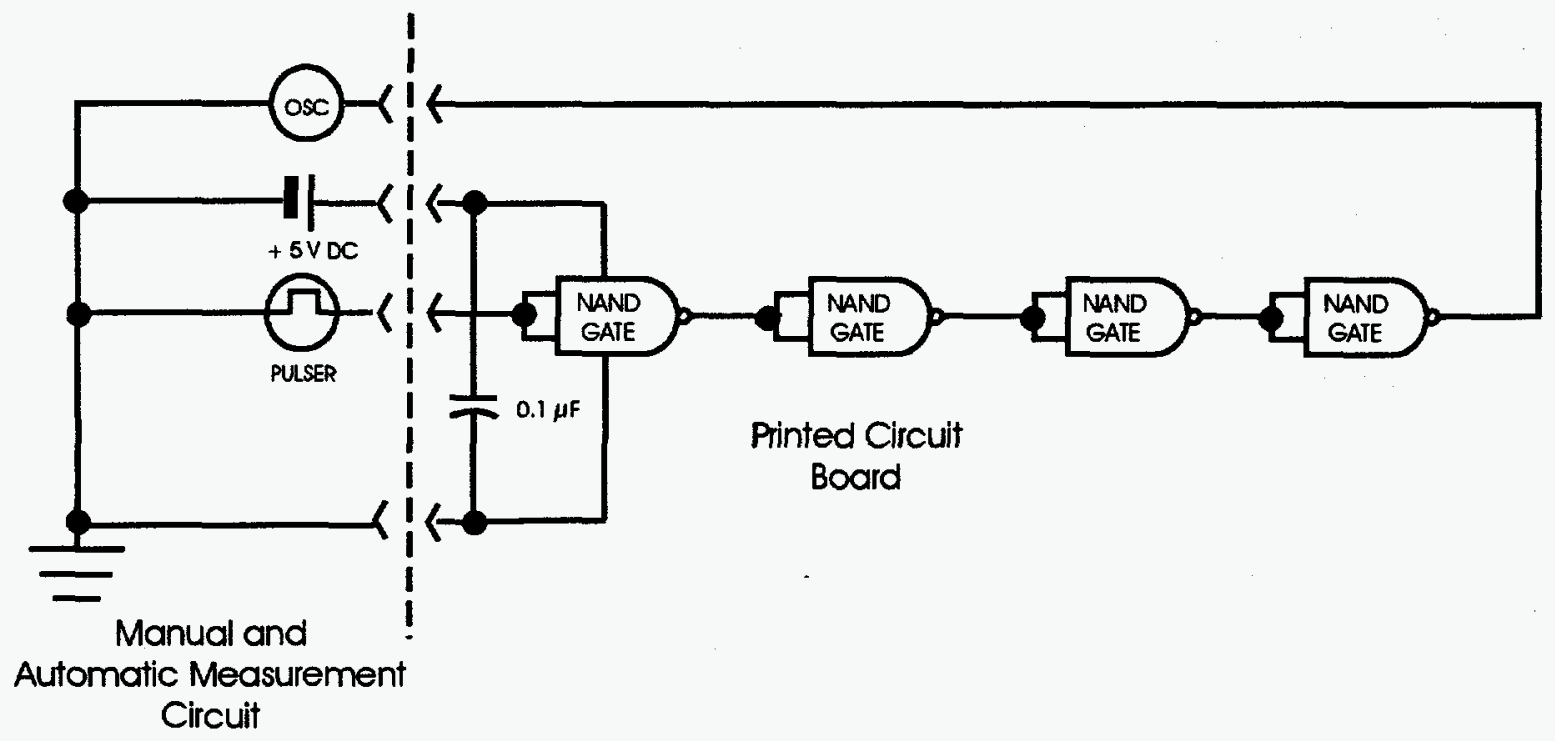

Figure 17. HSD SMT measurement circuit.

into a circuit so that an input pulse would generate a similar output pulse later in time. Two dual-in-line chips (SN54F00) were used for the PTH circuit (Figure 16) and one leadless chip carrier (54F00LMQB) was used for the SMT circuit (Figure 17). Each of these chips consisted of quad-dual-input NAND gates (quad refers to the four gates in each chip package and dual input refers to the number of input connections into each gate). These two circuit are identical except that the PTH circuit passes through eight NAND gates and the SMT circuit through only four NAND gates. The LRSTF decided to include four more gates on the PTH circuit so that they could investigate the quality of hand-soldered PTH components. The input signal, supply voltage $\left(\mathrm{V}_{\mathrm{CC}}\right)$, and ground were supplied through the 29-pin connector while the output was connected through a coaxial SMB connector. One capacitor was included for each chip (i.e., two for the PTH circuit and one for the SMT circuit) to prevent introducing spurious noise signals in the supply power.

There are several choices in the logic family and technology of the NAND gate chip, as shown in the appendix. The technology chosen by the LRSTF was the advanced Schottky (FAST) because it has one of 
the fastest switching times of all of the gates. Solder flux residues were expected to lengthen the switching time of the gates.

A 20-ns wide $+5 \mathrm{~V}$ pulse was used as an input signal and the output of the HSD was measured on a digitizing oscilloscope. The data collected on the HSD signal included rise time of the output pulse, fall time of the output pulse, and delay between the input and output pulses. The automated and manual measurements of the HSD circuit were performed in a similar manner, but the cable lengths used for the manual measurements were much shorter than for the automatic measurements. The manual measurement used cables less than $1 \mathrm{~m}$ while the automatic measurement used cables that were more than $4 \mathrm{~m}$. The cable length affected the measurements in two ways: the longer cable increased the delay time between pulses and degenerated the signal. Because the high-frequency components of a pulse are degraded in longer cables, rise times and fall times of signals become longer. Thus, for the automatic measuring systems, all three measurements-rise time, fall time, and delay time- - should be longer than for the manual measurement system.

\subsubsection{High-frequency Low-pass Filter}

The high-frequency low-pass filter (HF LPF) was designed to determine if the flux residues affect the circuits by adding capacitance or resistance to the printed circuit traces. The HF LPF consists of a series of inductors with capacitors between them connected to ground (see Figure 18). The inductor on the circuits consisted of spiral traces on the printed circuit board called spiral inductors. If sine waves of different frequencies are input into this circuit, the output is attenuated by different ratios; high frequencies are attenuated more than low frequencies. These circuits are designed to maintain a $50-\Omega$ impedance and connect easily to high-frequency measurement equipment.

The HF LPF circuits were measured manually using a network analyzer that measured the throughput of the circuit for frequencies between $50 \mathrm{MHz}$ and $1 \mathrm{GHz}$. The network analyzer operates by generating a sine wave electrical signal for a range of specified frequencies and measuring either the reflected or transmitted signals from the test circuit. The results are reported in (nondimensional) units called decibels (dB), defined as follows:

$$
\begin{aligned}
\mathrm{dB} & \equiv 10 \log _{10}\left(\frac{P_{\text {out }}}{P_{\text {in }}}\right) \\
& =20 \log _{10}\left(\frac{\left|V_{\text {out }}\right|}{\left|V_{\text {in }}\right|}\right)
\end{aligned}
$$

where $P_{\text {out }}$ and $P_{\text {in }}$ are output and input power, and $V_{\text {out }}$ and $V_{\text {in }}$ are output and input voltages, respectively. All of the measurements using the network analyzer were done in transmission mode (throughput).

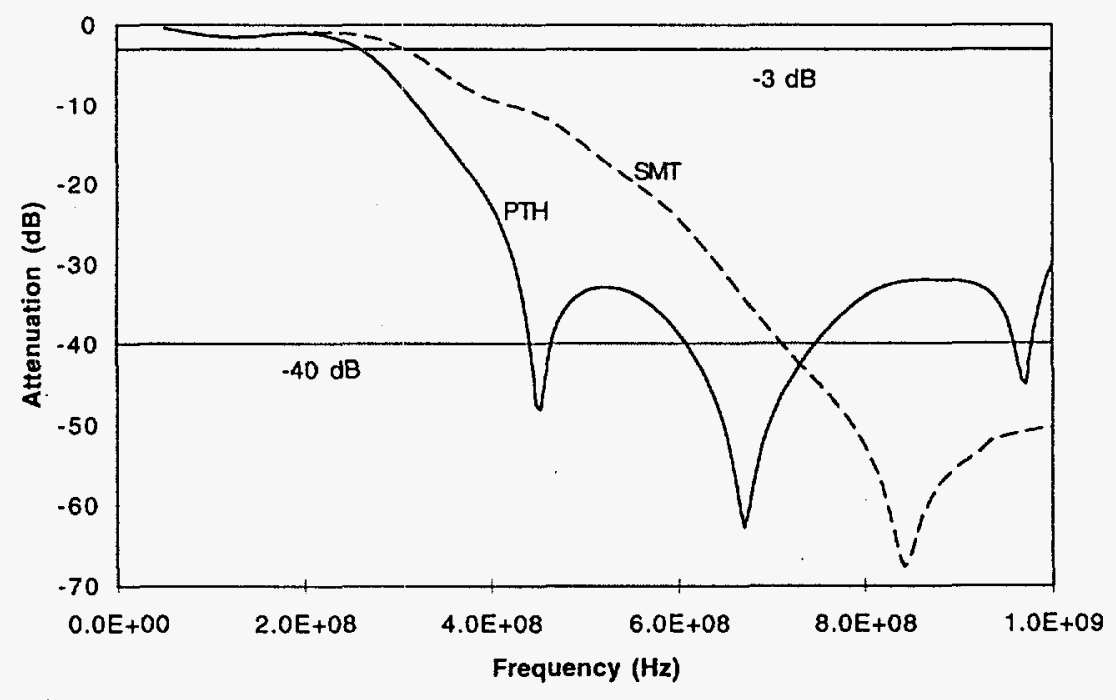

Figure 18. HF LPF typical frequency response of circuits. 
Measurement of the uncoated circuits yields results such as those shown in Figure 19. To limit the information to the minimum required, three data points were recorded for each HF LPF circuit: the amount of throughput at $50 \mathrm{MHz}$, the frequency at which the signal falls to $-3 \mathrm{~dB}$, and the frequency at which the signal falls to $-40 \mathrm{~dB}$. Lines on Figure 19 indicate these attenuation levels. Note that $-3 \mathrm{~dB}$ corresponds to a $V_{\text {in }} / V_{\text {out }}$ ratio of 0.7. Although the inductance and capacitance values in the two circuits were equivalent, characteristics of the HF LPF PTH and SMT circuits differ significantly over $300 \mathrm{MHz}$. As explained in Iman and coauthors (1995a), additional capacitance due to the leads on the PTH components changes the LPF circuit so that the PTH circuit cuts off at lower frequencies.

The automated test for the HF LPF circuit (Figure 20) consisted of inserting a $250-\mathrm{MHz}$ sine wave into the filter and measuring the output. This differs significantly from the manual measurement because the throughput is measured at only one frequency rather than a range of frequencies. This measurement was performed using a sine wave generator to produce the

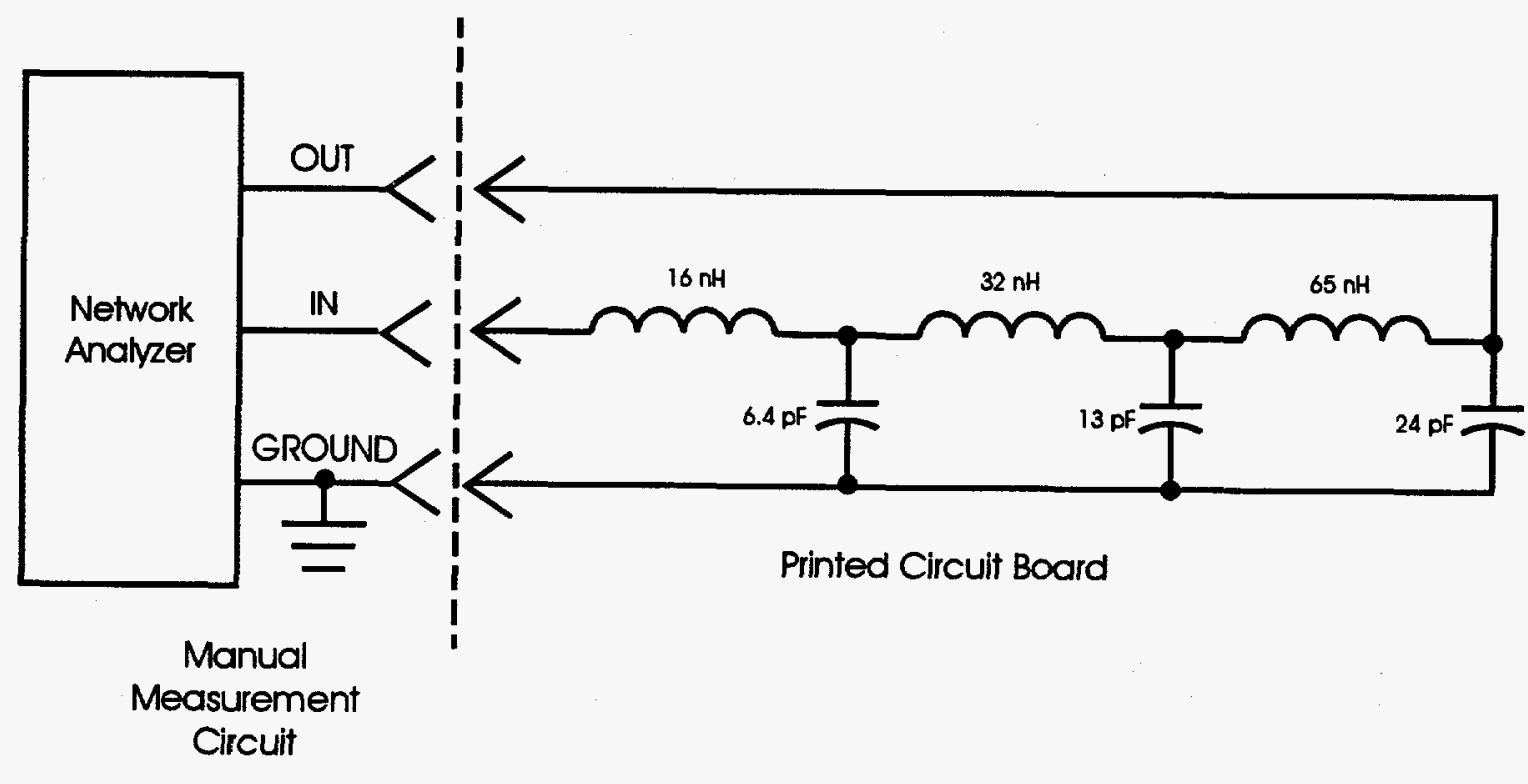

Figure 19. HF LPF manual measurement circuit.

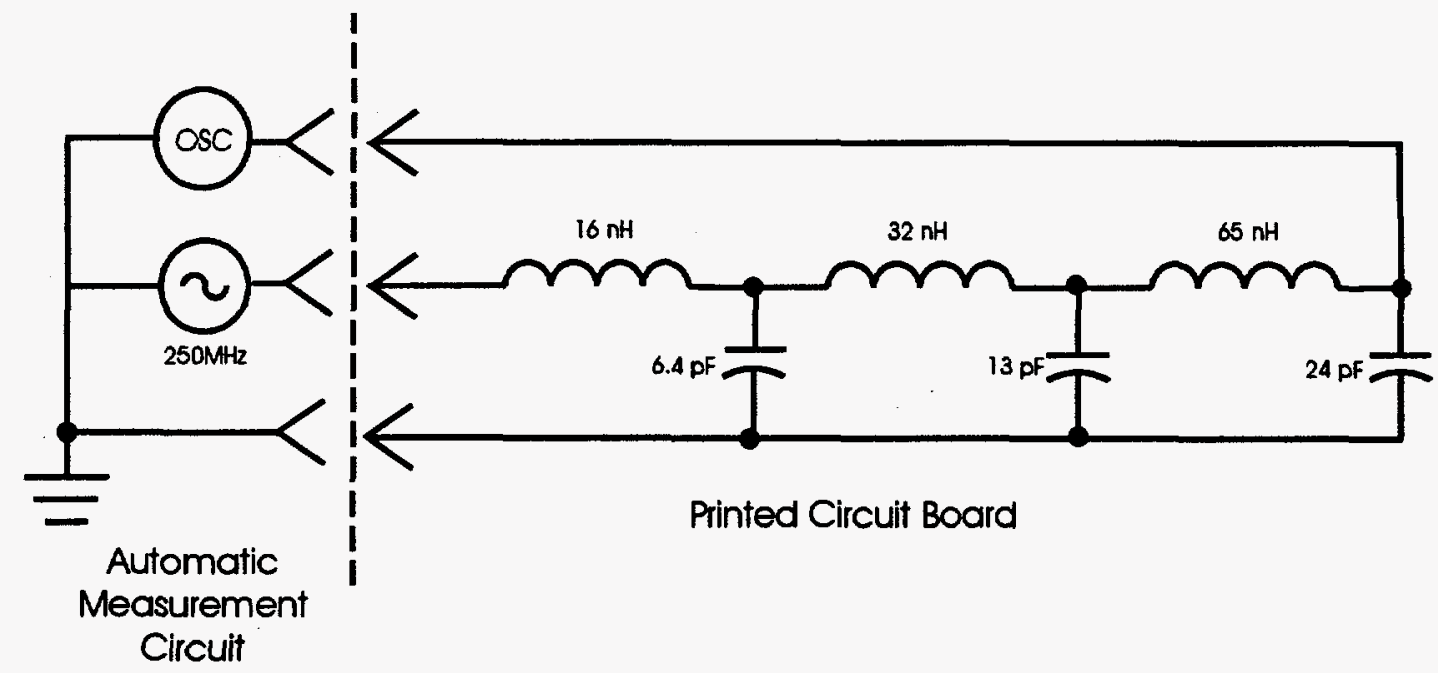

Figure 20. HF LPF automatic measurement circuit. 
input signal and a digitizing oscilloscope to analyze the output.

Automated and manual measurements were not compared because a comparison would require assumptions on the shape of the LPF curve. Future measurements on the manual system will include recording the throughput at $250 \mathrm{MHz}$.

\subsubsection{High-frequency Transmission Line}

Transmission lines are a means to transfer highfrequency signals from one part of a printed circuit board to another. They are designed to have constant characteristic impedances and to match the impedance of whatever they are connecting. The impedance of a transmission line is determined by the width of the line compared with the distance to the ground plane (thickness of the printed wiring board material) and dielectric constant of the circuit board material. The transmission lines in the LRSTF board were designed to have a $50-\Omega$ impedance.

The high-frequency transmission line (HF TL) was measured to determine coupling between two transmission lines located $0.25 \mathrm{~mm}(0.01 \mathrm{inch})$ apart and $12.7 \mathrm{~cm}$ long ( 5 inches), as shown in Figure 2. The coupling is expected to increase if conductive materials accumulate between the lines since the ideal condition is for the circuit board to act as a good insulator. The coupling is also expected to be frequency dependent. Two measurement configurations are possible in determining the transfer of signal from one transmission line to another, as shown in Figures 21 and 22. In the forward coupling configuration, connectors $\mathrm{J} 8$ and $\mathrm{J} 9$ are terminated with $50-\Omega$ resistors (a $50-\Omega$ resistor is placed between the signal line and ground), and in the reverse coupling configuration, connectors $\mathrm{J} 9$ and $\mathrm{J} 10$ are terminated. The throughput between unterminated connectors is then measured.

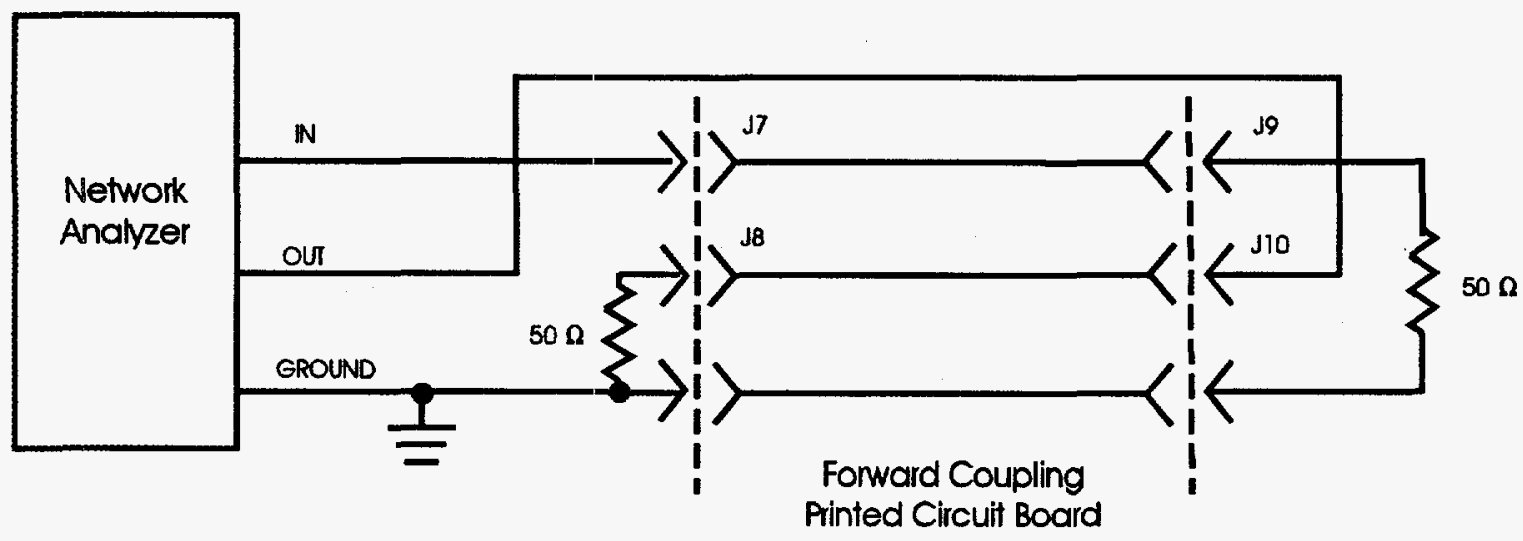

Figure 21. HF TL forward coupling measurement.

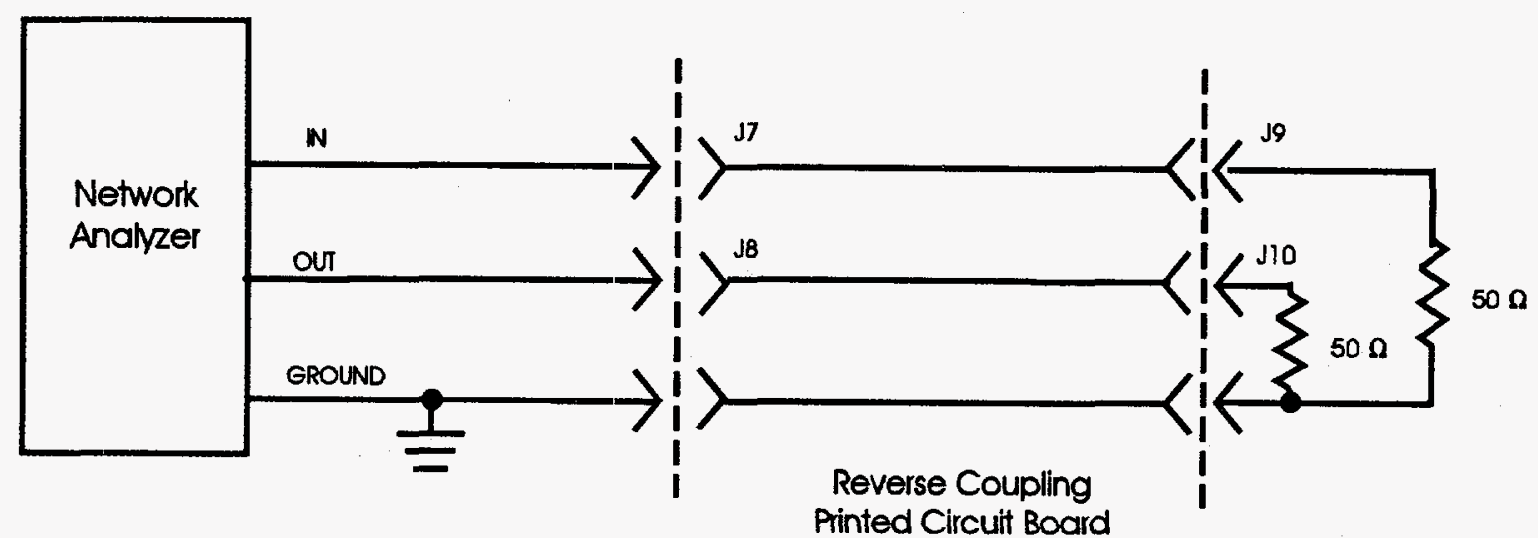

Figure 22. HF TL reverse coupling measurement. 


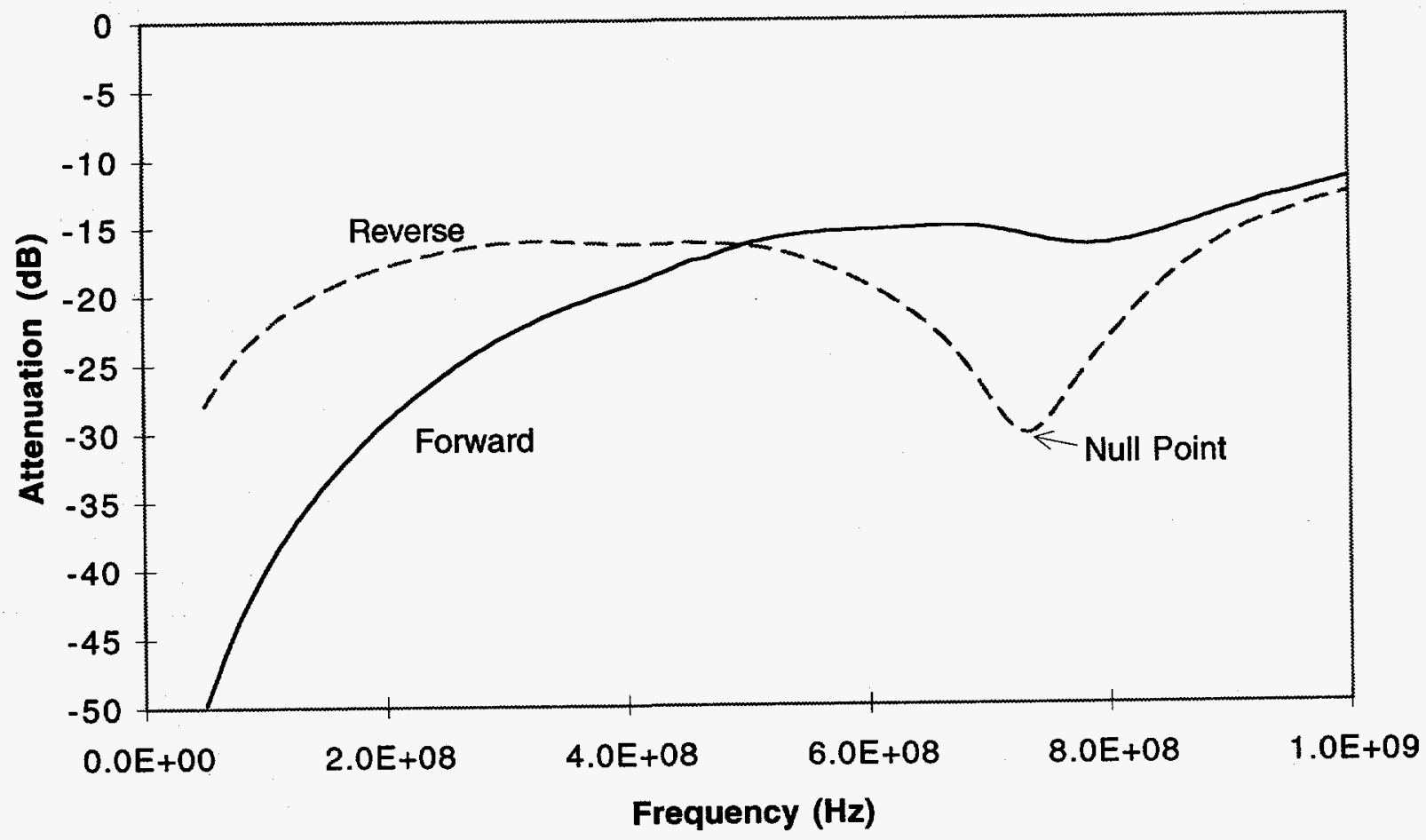

Figure 23. HF TL typical frequency response of circuit.

Figure 23 shows a typical output of the network analyzer for forward and reverse coupling.

The manual measurements of the boards consisted of testing both the forward coupling and reverse coupling configurations with a network analyzer. A range of frequencies between $50 \mathrm{MHz}$ and $1 \mathrm{GHz}$ was scanned in both cases. Data were recorded at specified values of frequency or attenuation:

Forward coupling: $50 \mathrm{MHz}, 500 \mathrm{MHz}$, and $1 \mathrm{GHz}$.

Reverse coupling: frequency of null point (Figure 23).

These measurements were made with short, $30-\mathrm{cm}$ coaxial cables that were compensated for frequency loss.

For the automated tests, only the forward coupling configuration was measured because changing the positions of the $50-\Omega$ terminating resistors requires physically handling the functional boards. The same forward coupling measurements were performed as previously described, but because four boards were exposed simultaneously, an additional $1.3-\mathrm{GHz}$ coaxial switch was included in the circuit as well as longer coaxial cables. As in the manual measurement case, the cables and switches were calibrated prior to the tests to allow compensation for frequency loss. Since the cables were longer and the circuit included the switches, more compensation was required for the automated than for the manual measurements. This frequency compensation is performed by the network analyzer.

\subsubsection{Leakage Measurements}

Current leakage is a primary method of failure that is expected for electronics that are manufactured with high levels of residue or are exposed to smoke. Although leakage measurements are not measurements of the actual function of a circuit, high levels of current leakage will lead to short circuits and faulty data transmission. Leakage measurements were performed in four areas on the circuit board:

(1) pads-plated-through holes that were spaced 0.25 mm (10-mil) apart,

(2) gull wing dummy component (GW),

(3) inner two rows of pin grid array (PGA/A), and

(4) outer two rows of pin grid array (PGA/B).

The gull wing dummy component was a plastic molded package that contained some circuitry. The outer two 
rows of the pin grid array included an additional solder mask that the inner two rows did not.

Manual measurements of the board consisted of biasing the circuit with $5 \mathrm{Vdc}$ and measuring the leakage current as shown in Figure 24. For the manual measurements, $5 \mathrm{Vdc}\left(V_{\mathrm{s}}\right)$ was applied only during the measurement and the ammeter was allowed to stabilize for 1 minute after the bias was switched on before the reading was recorded from the ammeter $\left(I_{\text {measureed }}\right)$.

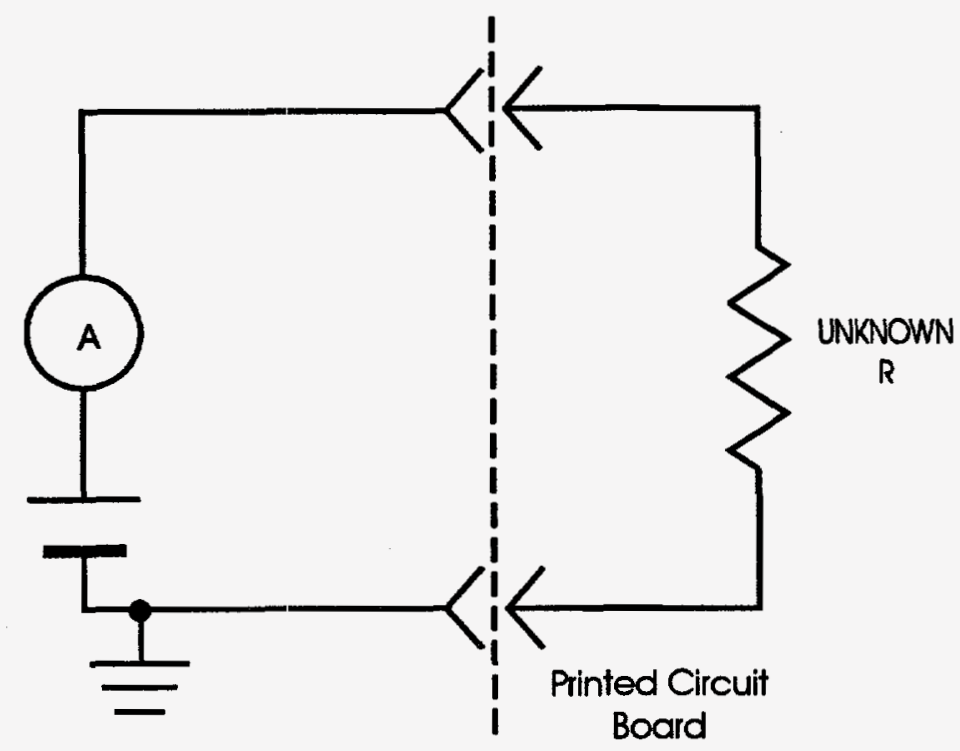

Manual Measurement

Circuit

Figure 24. Leakage circuit-manual measurement.

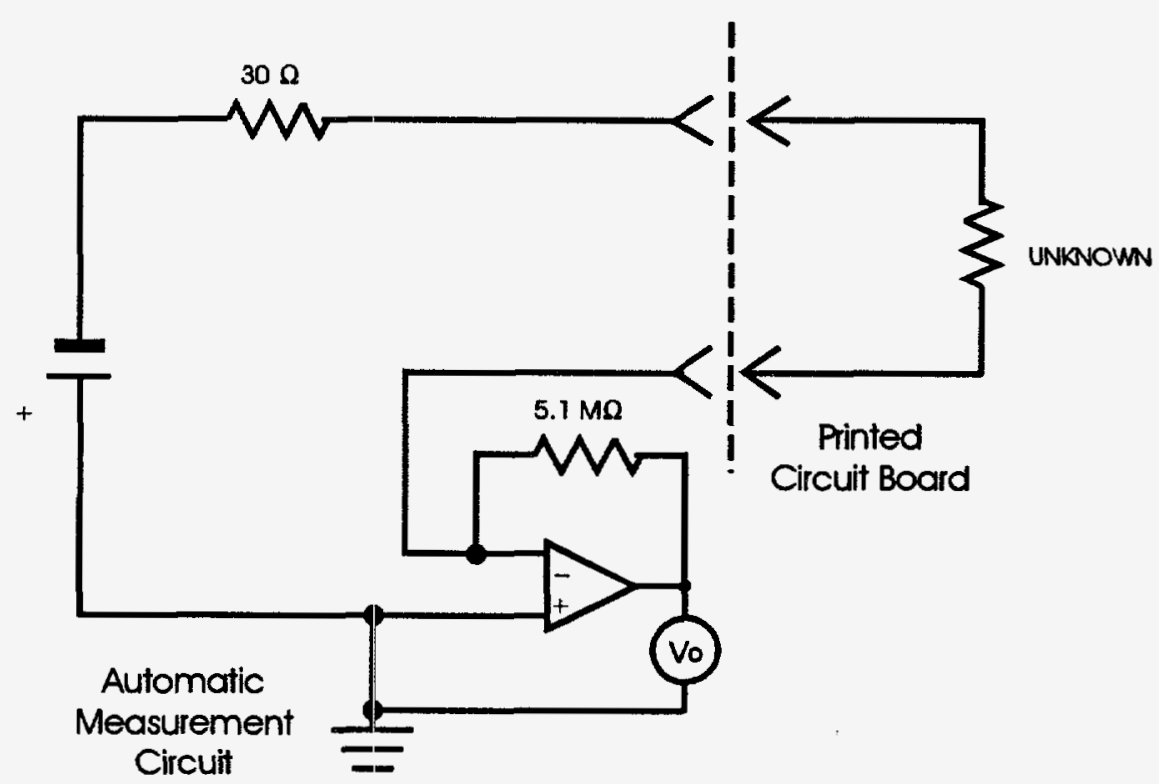

Figure 25. Leakage circuit-automatic measurement. 
The automated measurements were performed using the circuit shown in Figure 25. The 5-Vdc bias voltage $\left(V_{s}\right)$ was applied constantly during the exposure and monitoring period. The circuit converts the leakage current to voltage by the following equation:

$$
V_{\text {out }}=I_{\text {leakage }} \times R_{\text {feedback }}
$$

where the feedback resistance is $5.1 \mathrm{M} \Omega$ for all of the leakage measurements from the circuit board. The operational amplifier only allows output in the range of the supply voltage, $\pm 15 \mathrm{~V}$. This limits the range of observations to resistance values that are close in value to the feedback resistor. When the resistance is very high or very low compared with the feedback resistor, the voltage reading will be either zero or limited to +15 V. $V_{\text {out }}$ was measured with the voltmeter function of a data acquisition system.

The two measurements were converted to resistance through the component on the boards because of the differences between the measurements. The equations for conversion are, per Ohm's law:

$$
R_{\text {manual }}=\frac{V_{s}}{I_{\text {measured }}}
$$

and

$$
R_{\text {automatic }}=\frac{V_{s} \times R_{\text {feedback }}}{V_{\text {out }}}-R_{\text {limit }}
$$

where $R_{\text {limit }}$ was a $30-\Omega$ limiting resistor included in the automatic measurement circuit to prevent shorting the power supply when the leakage current was too high.

\subsubsection{IPC-B-24 Board}

The IPC-B-24 test board (Figure 26) was developed by the Institute for Interconnecting and Packaging Electronics Circuits (IPC) to measure surface insulation resistance on printed wiring boards (Pauls, 1992). High surface insulation resistance indicates a clean printed circuit board with little solder residue or ionic contamination. Smoke causes the resistance of the surface to decrease. Two IPC-B-24 boards were included in these tests and measured only with the automated system and the circuit shown in Figure 25.

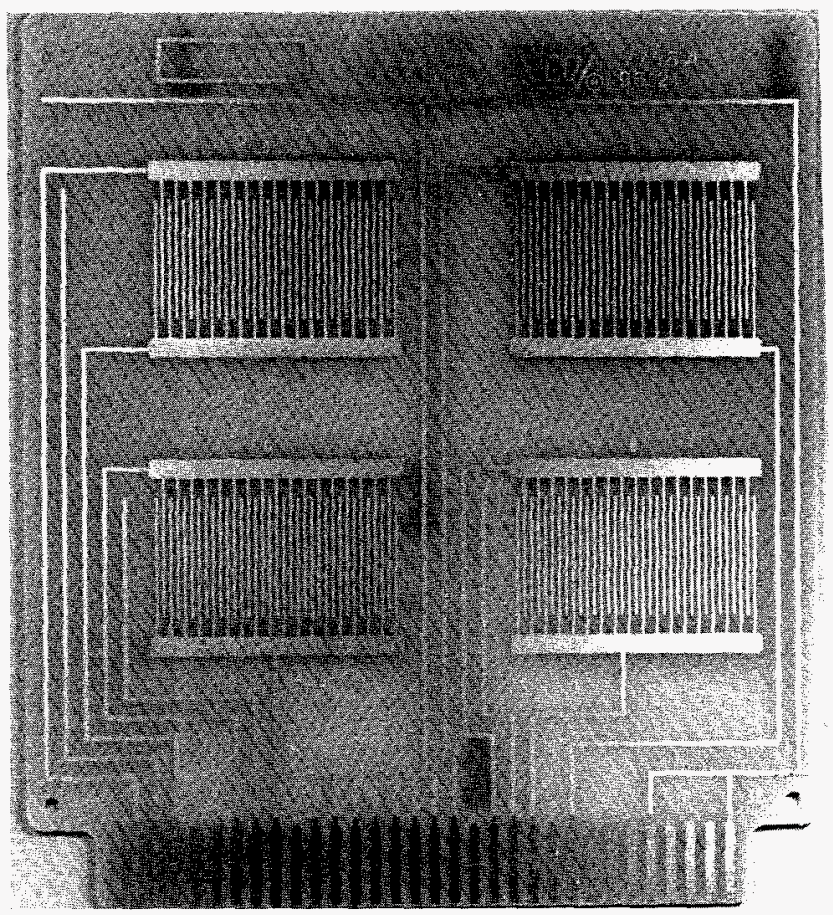

Figure 26. IPC-B-24 board for surface insulation resistance.

One board was placed outside the smoke in a bag with the control LRSTF boards, and one board was placed inside the smoke exposure chamber in a vertical orientation. Each IPC-B-24 board contained four identical interdigitated comb patterns with $0.5-\mathrm{mm}$ spaces between $0.4-\mathrm{mm}$ wide traces. These boards were also used in the circuit bridging tests performed at SNL.

For the four traces, two were biased with $5 \mathrm{Vdc}$ throughout the test and two were biased with $30 \mathrm{Vdc}$. The feedback resistors and current limiting resistors were also different, as shown in Table 4.

Table 4. Leakage measurement parameters for automatic measurement system

\begin{tabular}{c|cc}
\hline Circuit & $\begin{array}{c}\text { Bias voltage } \\
(\mathbf{V d c})\end{array}$ & $\begin{array}{c}\mathbf{R}_{\mathbf{F}} \\
(\Omega)\end{array}$ \\
\hline IPC-B-24 combs A and D & 30 & $5.1 \mathrm{k}$ \\
IPC-B-24 combs B and C & 5 & $5.1 \mathrm{M}$ \\
LRSTF leakage circuits & 5 & $5.1 \mathrm{M}$ \\
\hline
\end{tabular}




\section{TEST RESULTS}

\subsection{Smoke Measurements}

\subsubsection{Temperature and Humidity}

The chamber temperature was affected by both the flux level and the amount of fuel because the fuel also provided additional heat (Table 5). As expected, the temperatures at the top of the chamber (thermocouples 1,2 , and 3) were higher than those at the bottom of the chamber (thermocouples 4 and 5). Thermocouple 5 was probably somewhat shielded from high temperatures by the boards in addition to being near the bottom of the chamber. Thus, it had the lowest temperature of all of the thermocouples located in the smoke exposure chamber. The temperature for the control boards increased when the lamps were on because of radiant heating. The highest temperature in the chamber for the control boards (T6 or T7) was $32.1^{\circ} \mathrm{C}$.
The humidity also was affected by the radiant heat from the lamps, but since the sensor was not inside the smoke exposure chamber, the actual humidity that the boards were exposed to was not measured.

\subsubsection{Fuel Burned and Soot Deposition}

Soot deposition was higher on the horizontal than the vertical surfaces. More fuel was burned and more vertical deposition occurred in the flaming, high-flux burns than with the low-flux burns; however, the horizontal deposition was less for some of the highflux burns. Table 6 shows the results of measurements that were averaged for the tests with the same conditions.

Overall, as can be seen in Figure 27, the smoke was very corrosive to reactive metals. The figure shows an

Table 5. Temperature $\left({ }^{\circ} \mathrm{C}\right)$ at end of lamp heating

\begin{tabular}{|c|c|c|c|c|c|c|c|c|}
\hline $\begin{array}{c}\text { Flux } \\
\text { levell } \\
\left(\mathbf{k W} / \mathbf{m}^{2}\right) \\
\end{array}$ & $\begin{array}{r}\text { Fuel } \\
\text { level } \\
\left(\mathrm{g} / \mathrm{m}^{3}\right) \\
\end{array}$ & T 1 & $\mathbf{T} 2$ & T3 & T 4 & T5 & T6 & $\mathbf{T 7}$ \\
\hline 25 & 3 & 44.4 & 34.7 & 33.3 & 28.5 & 25.9 & 23.9 & 25.2 \\
\hline 25 & 25 & 46.3 & 35.6 & 35.0 & 28.8 & 25.2 & 24.7 & 24.7 \\
\hline 25 & 50 & 49.3 & 35.0 & 35.1 & 29.6 & 27.0 & 24.3 & 27.9 \\
\hline 50 & 0 & 47.8 & 41.0 & 36.0 & 31.5 & 29.9 & 22.6 & 22.1 \\
\hline 50 & 3 & 63.0 & 39.1 & 41.4 & 33.6 & 29.2 & 25.0 & 32.1 \\
\hline 50 & 25 & 73.5 & 55.4 & 48.2 & 38.2 & 32.8 & 24.7 & 30.7 \\
\hline 50 & 50 & 65.0 & 51.6 & 48.0 & 36.0 & 29.7 & 26.7 & 28.5 \\
\hline
\end{tabular}

Table 6. Fuel burned and smoke deposition

\begin{tabular}{cccccc}
\hline $\begin{array}{c}\text { Fuel } \\
\text { level } \\
\left(\mathbf{g} / \mathbf{m}^{\mathbf{3}}\right)\end{array}$ & $\begin{array}{c}\text { Fuel } \\
\text { available } \\
(\mathbf{g})\end{array}$ & $\begin{array}{c}\text { Flux } \\
\text { level } \\
\left(\mathbf{k} W / \mathbf{m}^{2}\right)\end{array}$ & $\begin{array}{c}\text { Fuel } \\
\text { burned } \\
(\mathbf{g})\end{array}$ & $\begin{array}{c}\text { Vertical } \\
\text { deposition } \\
\left(\mu \mathbf{g} / \mathbf{c m}^{2}\right)\end{array}$ & $\begin{array}{c}\text { Horizontal } \\
\mathbf{d e p o s i t i o n} \\
\left(\mu \mathbf{g} / \mathbf{c m}^{2}\right)\end{array}$ \\
\hline 3 & 0.6 & 25 & 0.27 & 0.4 & 2.8 \\
3 & 0.6 & 50 & 0.49 & 0.9 & 3.4 \\
25 & 5.0 & 25 & 3.12 & 2.1 & 45.3 \\
25 & 5.0 & 50 & 3.95 & 4.2 & 17.6 \\
50 & 10.0 & 25 & 6.49 & 3.2 & 94.8 \\
50 & 10.0 & 50 & 7.34 & 7.3 & 58.5 \\
\hline
\end{tabular}


Section 3

exposed and unexposed resistive terminator. The body of the terminator is brass with a gold-plated finish and the connector end is brass with a nickel finish. The gold finish was only slightly affected, but the nickel finish reacted strongly. The corroded nickel surface shown in Figure 27 was the bottom surface of the terminator as it was positioned horizontally during the exposure. The top surface was sooty, but not nearly as corroded.

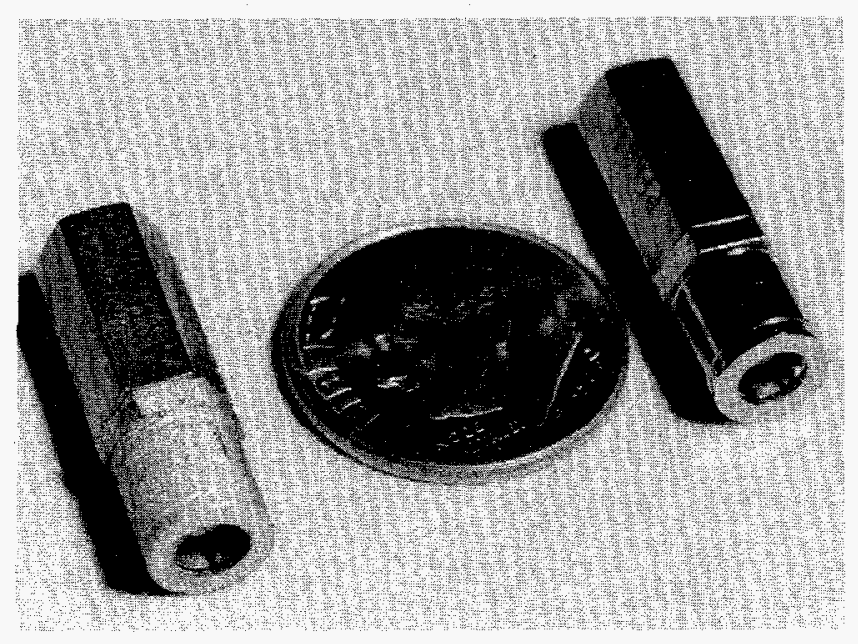

Figure 27. Resistive terminators showing corrosive action of smoke.
Test Results

\subsubsection{Chemical Analysis of Fuel}

Chemical analysis of the burned fuel showed these quantitative results:

$\begin{array}{lc}\text { \% Ash } & 23.04 \\ \text { \% Bromine } & 0.95 \\ \text { \% Chlorine } & 12.60 \\ \text { \% Fluorine } & 0.49 \\ \text { Gross heat of combustion, } \mathrm{J} / \mathrm{kg} & 2.4 \times 10^{7}\end{array}$

The semiquantitative analysis results for metals from the ashed sample are presented in Table 7.

Filter papers placed on the floor of the smoke exposure chamber were analyzed for $\mathrm{F}, \mathrm{Cl}$, and $\mathrm{Br}$. The results of the analyses of the soot on the $4.25-\mathrm{cm}$ diameter filters are shown in Table 8. The amount of chloride deposited on the filter is higher for the low flux level than for the high flux level exposures.

Table 7. Semiquantitative analysis of ashed sample.

\begin{tabular}{llll}
\hline Aluminum & $\mathrm{m}$ & Molybdenum & $\mathrm{ND}$ \\
Arsenic & $\mathrm{ND}$ & Niobium & $\mathrm{ND}$ \\
Antimony & $\mathrm{t} / \mathrm{m}$ & Nickel & $\mathrm{t}$ \\
Barium & $\mathrm{ND}$ & Phosphorus & $\mathrm{ND}$ \\
Beryllium & $\mathrm{ND}$ & Potassium & $\mathrm{ND}$ \\
Boron & $\mathrm{ft}$ & Sodium & $\mathrm{ND}$ \\
Bismuth & $\mathrm{ND}$ & Silicon & $\mathrm{P}$ \\
Cadmium & $\mathrm{ND}$ & Silver & $\mathrm{t}$ \\
Calcium & $\mathrm{m}$ & Strontium & $\mathrm{ND}$ \\
Chromium & $\mathrm{ND}$ & Tantalum & $\mathrm{ND}$ \\
Cobalt & $\mathrm{ND}$ & Tellurium & $\mathrm{ND}$ \\
Copper & $\mathrm{t}$ & Tin & $\mathrm{ND}$ \\
Iron & $\mathrm{ML}$ & Titanium & $\mathrm{PL}$ \\
Lead & $\mathrm{M}$ & Tungsten & $\mathrm{ND}$ \\
Lithium & $\mathrm{ND}$ & Vanadium & $\mathrm{ND}$ \\
Magnesium & $\mathrm{ML}$ & Zinc & $\mathrm{t} / \mathrm{m}$ \\
Manganese & $\mathrm{ND}$ & Zirconium & $\mathrm{ND}$ \\
Mercury & $\mathrm{ND}$ & & \\
\hline
\end{tabular}

Notes: $\mathrm{P}, 10$ to $100 \% ; \mathrm{M}, 1$ to $10 \% ; \mathrm{m}, 0.1$ to $1.0 \% ; t, 0.01$ to $0.1 \%$;

$\mathrm{ft}$, less than $0.01 \%$; L, lower half of range shown; ND, not detected. 
Table 8. Chemical analysis of soot ( $\mu$ g/filter)

\begin{tabular}{rr|ccl}
\hline $\begin{array}{c}\text { Fuel } \\
\text { level } \\
\left(\mathbf{g} / \mathbf{m}^{3}\right)\end{array}$ & $\begin{array}{c}\text { Flux } \\
\text { level } \\
\left(\mathbf{k W} / \mathbf{m}^{2}\right)\end{array}$ & Chloride & Bromide & Fluoride \\
\hline 3 & 25 & 95.5 & 2.1 & 0 \\
3 & 50 & 24 & 5.5 & 0.25 \\
25 & 25 & 92.6 & 96.6 & 0 \\
25 & 50 & 73.0 & 66.9 & 1.45 \\
50 & 25 & 147 & 181 & 1.25 \\
50 & 50 & 95.4 & 165 & 0 \\
\multicolumn{7}{l}{ Unexposed filter } & 3.9 & 0 & 0.7 \\
\hline
\end{tabular}

\subsection{Circuit Measurements}

\subsubsection{High Voltage Low Current}

The measurement for the HVLC circuit determined the resistance of the circuit. The high-voltage low-current circuit reacted to both smoke and humidity. The most common reaction to smoke was to lower the resistance of the circuit as shown in Figure 28 for the PTH circuit and Figure 29 for the SMT circuit for high-fuel, high-flux tests. For the PTH circuit, the coated boards showed a reduction in resistance due to the smoke, but soon recovered. The bare board circuit began to short and continued to short throughout the high-humidity exposure, but recovered as shown by the post-test measurements. The SMT circuit also shorted during the smoke exposure, but recovered in the latter stages of the automated measurement.

The loss of resistance of these circuits is a result of the current finding an alternative path between input and output conductors. Printed wiring boards generally have high resistance between trace lines, above $10^{12} \Omega$ (Pauls, 1992). The HVLC circuit has $50 \mathrm{M} \Omega$ across the circuit. When there is no smoke, the current flows through the path of least resistance, the 50-M $\Omega$ circuit. When smoke is introduced, the resistance of the air surrounding the circuit and the surface of the printed wiring board is lowered. The current then leaks through these alternative routes and the measured resistance of the circuit falls.

The phenomenon of shorting when first exposed to smoke and later recovery was observed in the circuit bridging tests at the lower smoke exposures (Tanaka, Nowlen and Anderson, 1996). Indeed, the "high"

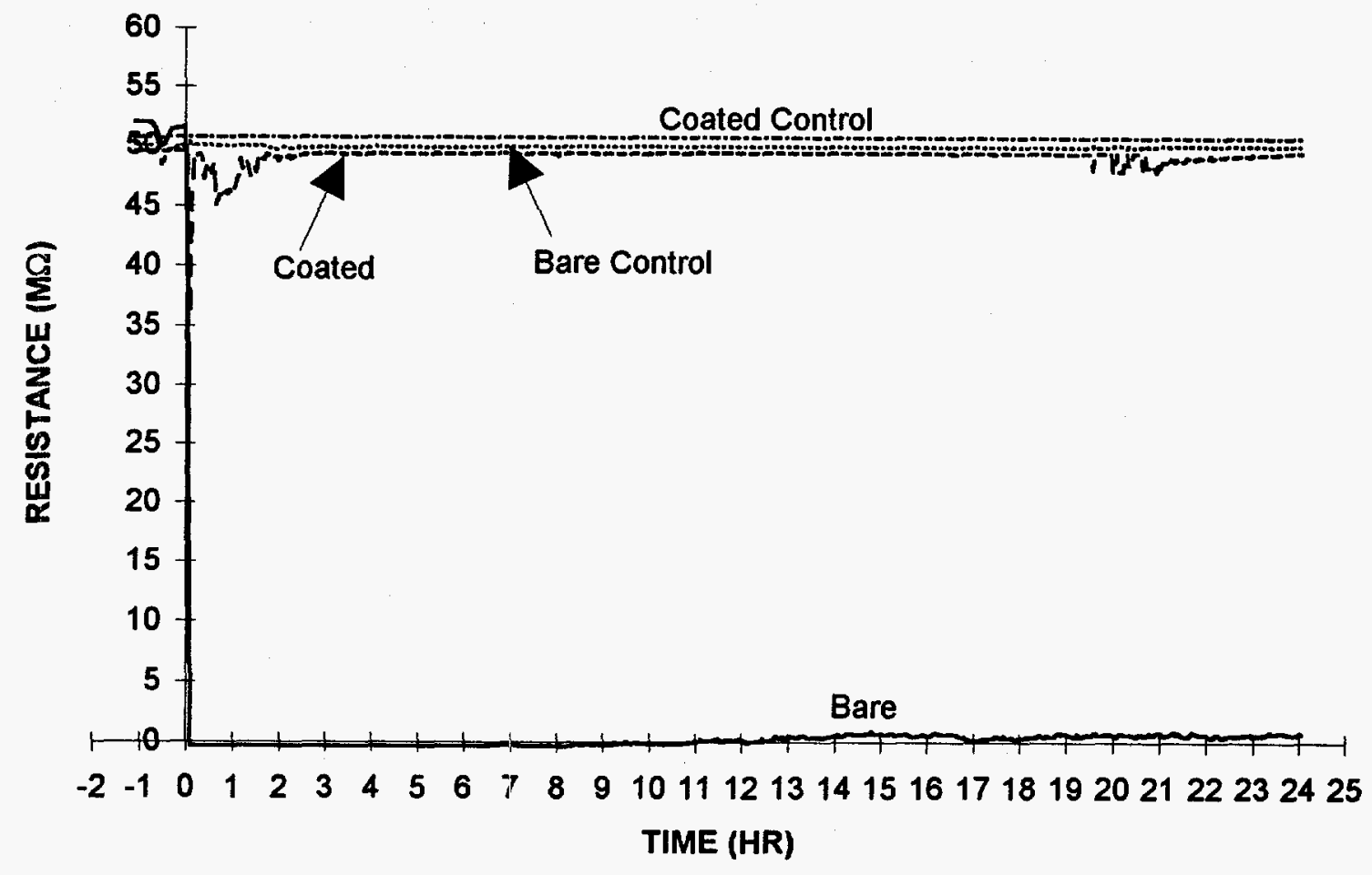

Figure 28. HVLC PTH vs. time for a high-fuel, high-flux burn. 


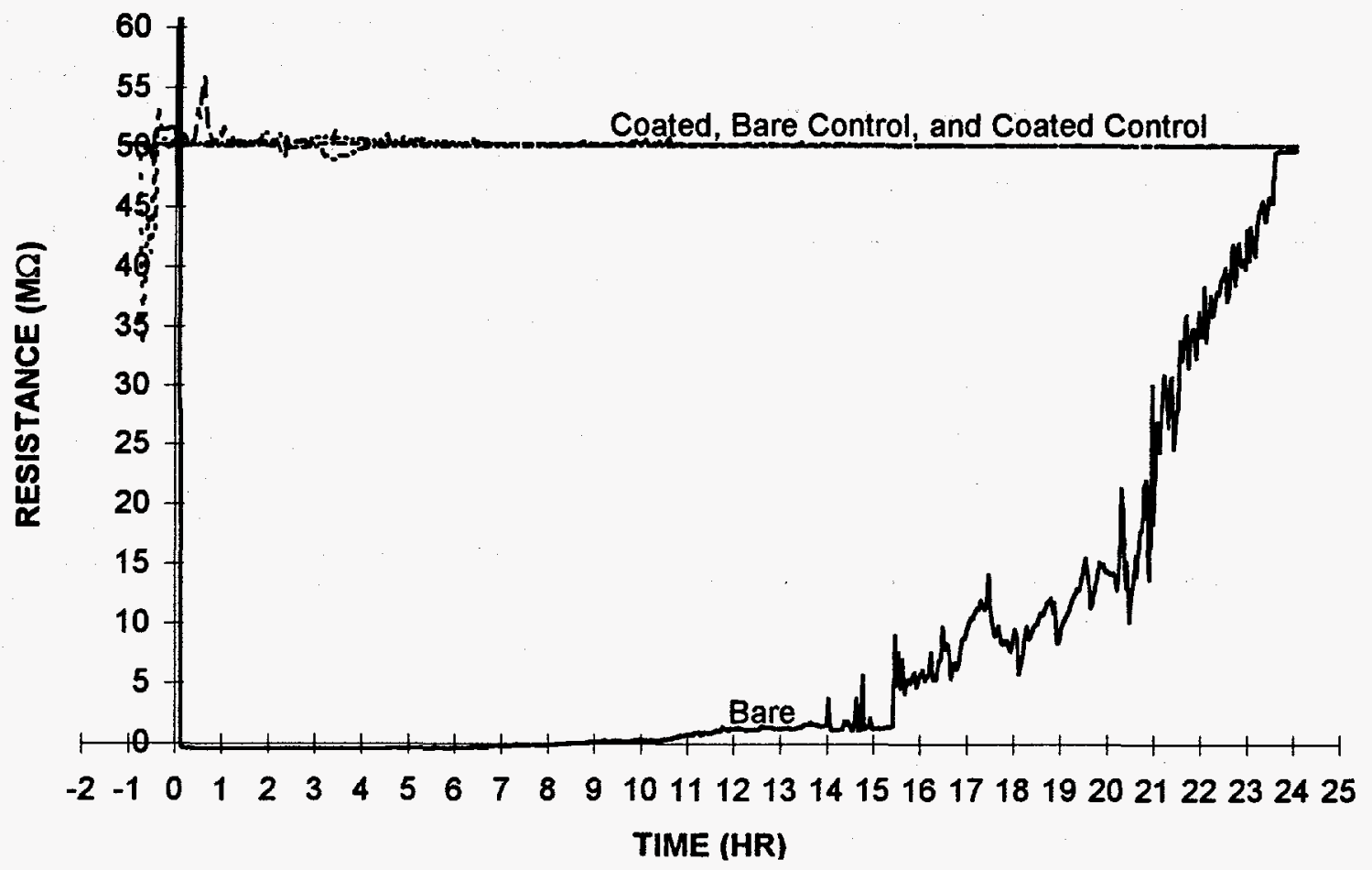

Figure 29. HVLC SMT vs. time for a high-fuel, high-flux burn.

Table 9. HVLC change in resistance values

\begin{tabular}{|c|c|c|c|c|c|c|c|c|c|}
\hline \multirow{2}{*}{$\begin{array}{l}\text { Fuel } \\
\text { level } \\
\left(\mathrm{g} / \mathrm{m}^{3}\right)\end{array}$} & \multirow{2}{*}{ 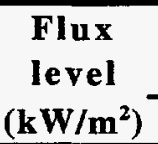 } & \multicolumn{2}{|c|}{ Bare PTH } & \multicolumn{2}{|c|}{ Bare SMT } & \multicolumn{2}{|c|}{ Coated PTH } & \multicolumn{2}{|c|}{ Coated SMT } \\
\hline & & 1st hr & $2-24 \mathrm{hr}$ & 1st hr & $2-24 \mathrm{hr}$ & 1st hr & $2-24 \mathrm{hr}$ & 1st hr & $2-24 \mathrm{hr}$ \\
\hline 3 & 25 & 0.8 & 0.6 & -21.5 & -13.3 & 0.6 & 0.6 & -2.2 & 0.3 \\
\hline 3 & 50 & -23.3 & -10.0 & -3.5 & 1.0 & 0.0 & 0.1 & 1.0 & 0.9 \\
\hline 25 & 25 & -32.7 & 1.4 & -38.9 & -27.2 & -0.9 & 0.3 & 0.7 & 0.8 \\
\hline 25 & 50 & -46.0 & -31.6 & -46.0 & -38.0 & -3.7 & 0.0 & 0.0 & 0.8 \\
\hline 50 & 25 & -46.6 & -38.5 & 686.5 & 15.7 & -1.2 & 0.0 & 0.8 & 0.9 \\
\hline 50 & 50 & -47.1 & -49.9 & -44.3 & -45.5 & 23.2 & 24.6 & 1.9 & 1.3 \\
\hline
\end{tabular}

exposure in these tests $\left(50 \mathrm{~g} / \mathrm{m}^{3}\right)$ is approximately midway between the "low" and "high" levels of smoke observed in the earlier tests $\left(3\right.$ and $100 \mathrm{~g} / \mathrm{m}^{3}$, respectively) where the "low" levels recovered and the "high" levels did not. A summary of the changes in resistance for different smoke exposures is shown in Table 9 in which changes in resistance from pretest values are listed. Each value is the average result from two tests. Most of the bare boards decreased in resistance ( $-92 \%$ change in resistance) with higher amounts of smoke except for one test for the high-fuel, low-burn case where the circuit reacted as if it were open (-686.5 M $\Omega$ ), a $1370 \%$ increase. The coated boards did not react as much as the bare boards.

Analysis of the circuit traces that connect the high voltage input and ground to the HVLC circuits showed that the greatest drops in potential per distance between conductors occurred on the surface of the printed wiring board. On these surfaces the traces are separated by $0.76 \mathrm{~mm}$ (nominal $30 \mathrm{mil}$ by design) and carry a potential difference of $300 \mathrm{Vdc}$. In comparison, the voltage drop across any of the components in the circuit is at most $60 \mathrm{Vdc}$ and the component leads are at least $2 \mathrm{~mm}$ apart. Thus most of the shorting through smoke should occur between the traces rather than between soldering surfaces of the components. Since the trace leads for both the PTH and SMT circuits are similar in length and separation, both circuits reacted similarly.

The addition of humidity to the HVLC circuit tended to cause its resistance to change slightly, sometimes by increasing and sometimes by decreasing in value by 


\section{Test Results}

Section 3

approximately $1 \mathrm{M} \Omega$. This change in resistance was only temporary and the circuit returned to the original value after 15 minutes.

\subsubsection{High Current Low Voltage}

The measurement for the HCLV circuit yielded the voltage needed to produce a 1-Adc current through the circuit. The average value was $1.460 \mathrm{~V}$ for the PTH and $1.472 \mathrm{~V}$ for the SMT circuits. The HCLV circuit was not affected by smoke or humidity as much as the HVLC circuit. The addition of smoke tended to increase the voltage, a change that corresponds to an increase in the resistance of the circuit. The PTH circuits reacted slightly to the smoke for a high-fuel, high-flux level exposure (Figure 30), but the uncoated SMT circuits tended to increase in resistance and remain higher (Figure 31). This change was also

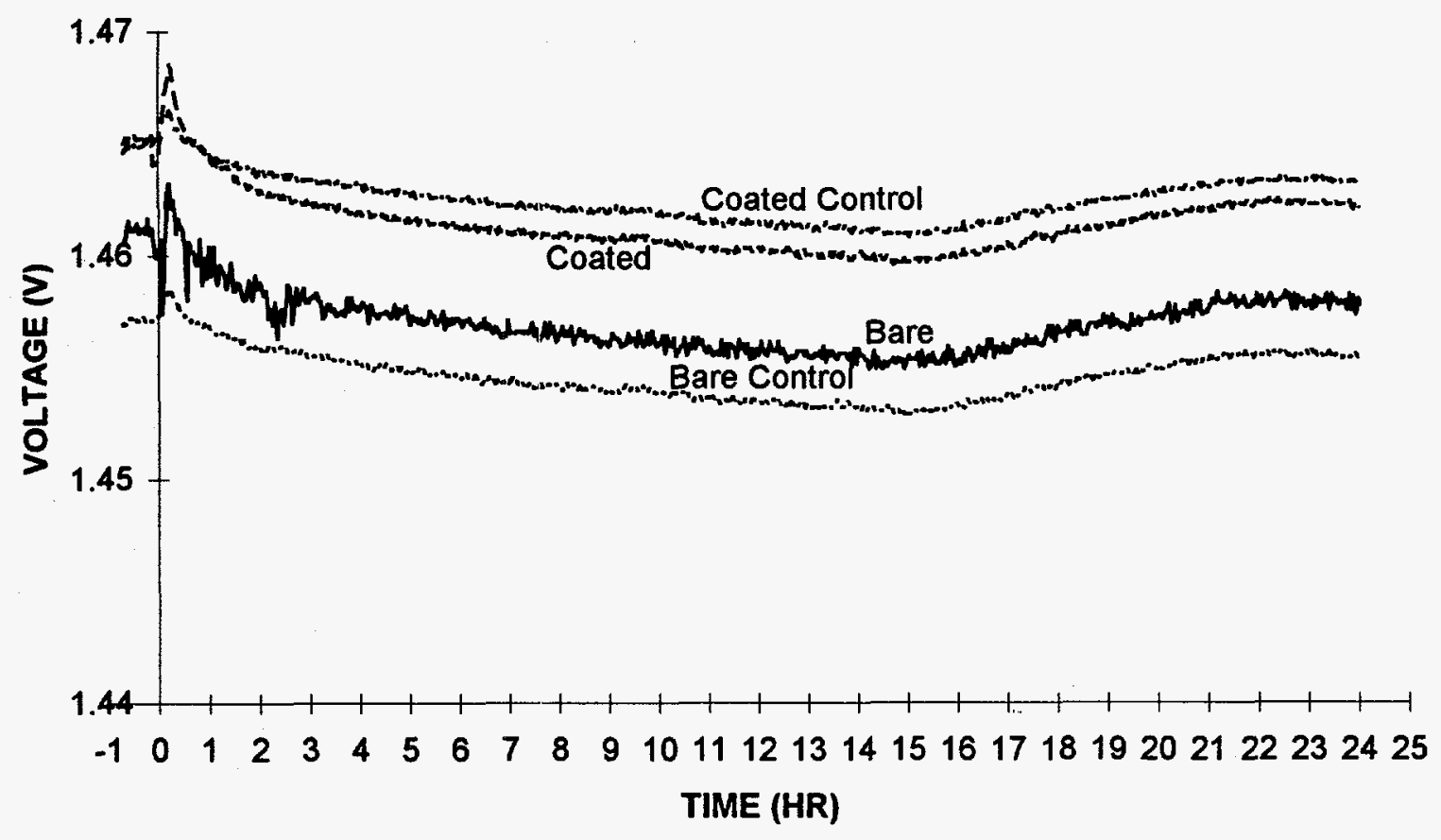

Figure 30. HCLV P'TH vs. time for a high-fuel, high-flux burn.

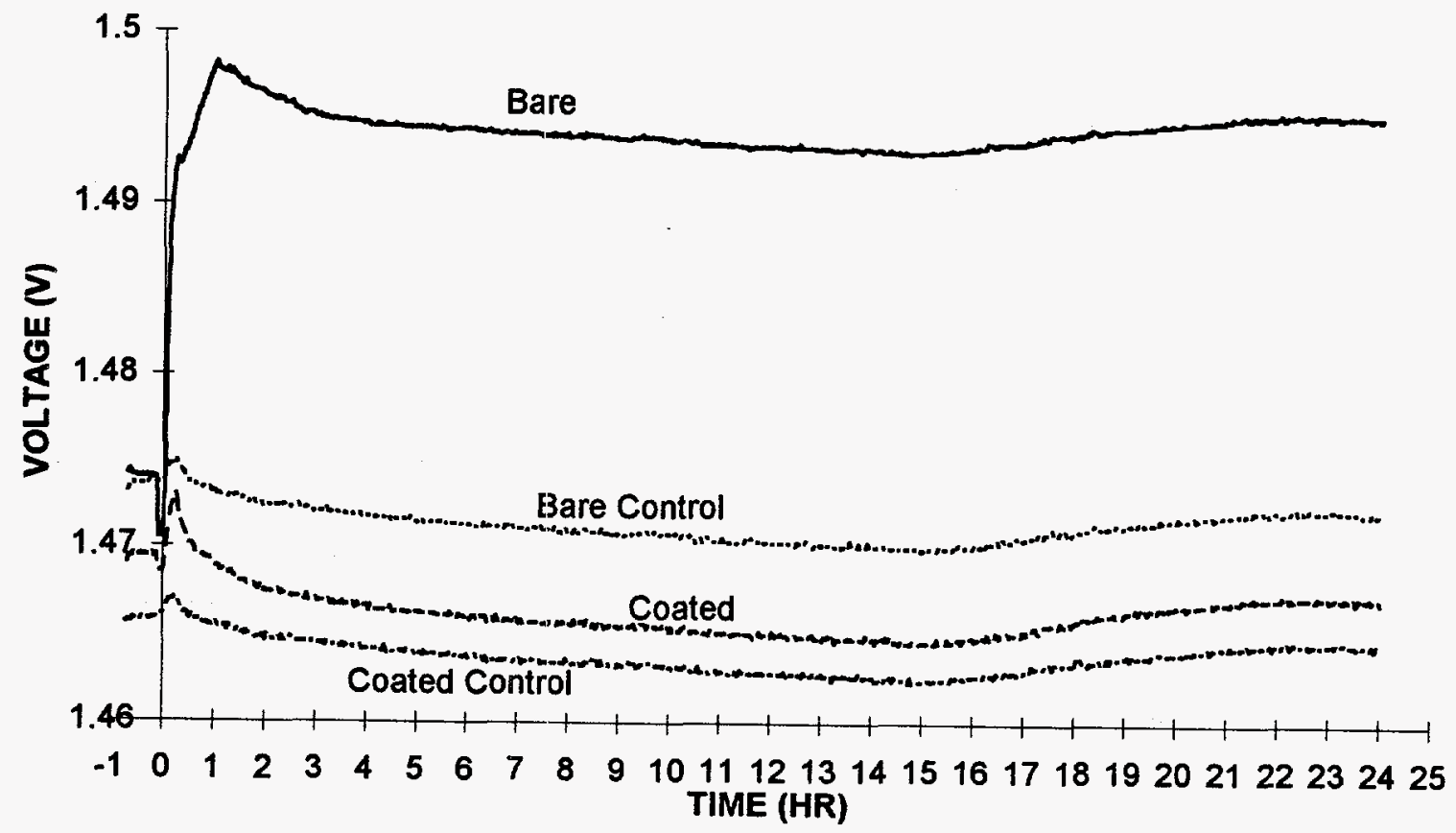

Figure 31. HCLV SMT vs. time for a high-fuel, high-flux burn. 
Table 10. HCLV results $(\Delta V$ in $\mathrm{mV})$

\begin{tabular}{|c|c|c|c|c|c|c|c|c|c|}
\hline \multirow{2}{*}{$\begin{array}{l}\text { Fuel } \\
\text { level } \\
\left(\mathrm{g} / \mathrm{m}^{3}\right) \\
\end{array}$} & \multirow{2}{*}{$\begin{array}{c}\text { FIux } \\
\text { level } \\
\left(\mathrm{kW} / \mathbf{m}^{2}\right)\end{array}$} & \multicolumn{2}{|c|}{ Bare PTH } & Bare & SMT & \multicolumn{2}{|c|}{ Coated PTH } & \multicolumn{2}{|c|}{ Coated SMT } \\
\hline & & 1st hr & $2-24 \mathrm{hr}$ & 1st hr & $2-24 \mathrm{hr}$ & 1st hr & $2-24 \mathrm{hr}$ & 1st hr & $2-24 \mathrm{hr}$ \\
\hline 3 & 25 & 0.4 & -1.5 & 0.6 & -1.6 & 0.3 & -0.6 & 0.7 & -1.5 \\
\hline 3 & 50 & 0.9 & -2.1 & 1.2 & -1.3 & 1.3 & -1.6 & 1.4 & -1.3 \\
\hline 25 & 25 & 0.1 & 0.1 & 13.1 & 16.9 & 0.1 & -0.4 & 1.2 & -0.4 \\
\hline 25 & 50 & 2.2 & -1.6 & 12.1 & 13.5 & 2.0 & -1.8 & 2.3 & -1.5 \\
\hline 50 & 25 & 0.3 & -2.1 & 18.5 & 24.2 & 0.9 & -1.4 & 1.6 & 0.0 \\
\hline 50 & 50 & -0.5 & -4.4 & 18.6 & 20.6 & 0.7 & -4.0 & 1.1 & -3.4 \\
\hline
\end{tabular}

evident in the differences between pre- and post-test manual measurements. Table 10 shows the average change in voltage based on two tests. As the data show, the bare circuits in general reacted more than the coated circuits.

This HCLV circuit had a very low initial resistance, $1.4 \Omega$. The resistance of the surrounding printed wiring board and air probably decreased when the smoke was added, but since the circuit resistance was so low, the current continued to flow through the circuit. Thus the measured resistance did not change much in most cases. However, for the SMT circuit, the smoke probably corroded the contacts or solder joints because the resistance increased (as did the voltage since the current was held constant). This failure mechanism is very different from the case of the HVLC circuit. Although there was a measurable change in the voltage, the overall effect on these circuits was small. The original measured voltages were approximately $1.45 \mathrm{~V}$; thus the maximum circuit change was $1.7 \%$.

\subsubsection{High-speed Digital}

The measurements performed on the HSD circuit included rise time, fall time, and delay between the input and output pulses. The manual pre- and post-test measurements and the automatic measurements could not be compared because the cable lengths were a significant factor for both the delay (increased time was needed for longer automatic measurement cables) and rise and fall time (high frequency loss). Nevertheless, comparisons of the HSD circuit measurements from early in the test, before the lamps were energized, and during the smoke exposure show that the HSD circuit was not significantly affected by smoke at these exposure levels. The rise times (Table 11), fall times (Table 12), and delay times (Table 13) show a fairly constant behavior regardless of flux level or amount of fuel.

The highest fuel level for these tests was $50 \mathrm{~g} / \mathrm{m}^{3}$. In previous tests such fuel levels resulted in resistances that were so low that they were at the threshold of the measurement ability $(1000 \Omega)$ for the circuit bridging tests (Tanaka, Nowlen and Anderson, 1996). This limitation was partially a result of the wide range of measurement planned for the circuit bridging tests $\left(10^{10}\right.$ to $10^{3} \Omega$ ). Since these tests were performed, however, measurements of critical resistance (see the appendix)

Table 11. HSD rise time, averages over time range (ns)

\begin{tabular}{|c|c|c|c|c|c|c|c|c|c|}
\hline \multirow{2}{*}{$\begin{array}{r}\text { Fuel } \\
\text { level } \\
\left(\mathrm{g} / \mathrm{m}^{3}\right) \\
\end{array}$} & \multirow{2}{*}{$\begin{array}{c}\text { Flux } \\
\text { level } \\
\left(\mathbf{k W} / \mathbf{m}^{2}\right)\end{array}$} & \multicolumn{2}{|c|}{ Bare PTH } & Bare & SMT & \multicolumn{2}{|c|}{ Coated PTH } & \multicolumn{2}{|c|}{ Coated SMT } \\
\hline & & 1st hr & $2-24 \mathrm{hr}$ & 1st hr & $2-24 \mathrm{hr}$ & 1st hr & 2-24 hr & 1st hr & 2-24 hr \\
\hline 0 & 50 & 2.56 & 2.54 & 2.61 & 2.62 & 2.58 & 2.56 & 2.61 & 2.62 \\
\hline 3 & 25 & 2.47 & 2.50 & 2.64 & 2.65 & 2.52 & 2.52 & 2.69 & 2.66 \\
\hline 3 & 50 & 2.52 & 2.53 & 2.67 & 2.69 & 2.49 & 2.53 & 2.77 & 2.73 \\
\hline 25 & 25 & 2.52 & 2.52 & 2.79 & 2.71 & 2.55 & 2.55 & 2.73 & 2.73 \\
\hline 25 & 50 & 2.52 & 2.50 & 2.72 & 2.69 & 2.52 & 2.52 & 2.73 & 2.70 \\
\hline 50 & 25 & 2.56 & 2.55 & 2.81 & 2.70 & 2.57 & 2.54 & 2.72 & 2.76 \\
\hline 50 & 50 & 2.62 & 2.53 & 2.85 & 2.76 & 2.54 & 2.52 & 2.77 & 2.73 \\
\hline
\end{tabular}


Table 12. HSD fall time, averages over time range (ns)

\begin{tabular}{|c|c|c|c|c|c|c|c|c|c|}
\hline \multirow{2}{*}{$\begin{array}{l}\text { Fuel } \\
\text { level } \\
\left(\mathrm{g} / \mathrm{m}^{3}\right) \\
\end{array}$} & \multirow{2}{*}{$\begin{array}{c}\text { Flux } \\
\text { level } \\
\left(\mathbf{k W} / \mathbf{m}^{2}\right)\end{array}$} & \multicolumn{2}{|c|}{ Bare PTH } & \multicolumn{2}{|c|}{ Bare SMT } & \multicolumn{2}{|c|}{ Coated PTH } & \multicolumn{2}{|c|}{ Coated SMT } \\
\hline & & 1st hr & 2-24 hr & 1st hr & $2-24 \mathrm{hr}$ & 1st hr & $2-24 \mathrm{hr}$ & 1st hr & $2-24 \mathrm{hr}$ \\
\hline 0 & 50 & 2.96 & 3.03 & 3.70 & 3.83 & 3.01 & 3.09 & 3.91 & 3.83 \\
\hline 3 & 25 & 3.01 & 3.02 & 3.67 & 3.72 & 3.12 & 3.10 & 3.75 & 3.86 \\
\hline 3 & 50 & 3.13 & 3.04 & 4.03 & 3.91 & 2.96 & 2.88 & 3.99 & 3.94 \\
\hline 25 & 25 & 3.14 & 3.07 & 3.92 & 3.95 & 3.13 & 2.98 & 4.06 & 4.06 \\
\hline 25 & 50 & 3.00 & 3.02 & 3.93 & 3.81 & 3.11 & 3.07 & 4.05 & 3.88 \\
\hline 50 & 25 & 3.02 & 2.95 & 3.55 & 3.79 & 2.96 & 2.91 & 3.99 & 3.92 \\
\hline 50 & 50 & 3.24 & 3.11 & 4.30 & 4.13 & 2.98 & 2.91 & 3.91 & 3.89 \\
\hline
\end{tabular}

Table 13. HSD delay time, averages over time range (ns)

\begin{tabular}{|c|c|c|c|c|c|c|c|c|c|}
\hline \multirow{2}{*}{$\begin{array}{r}\text { Fuel } \\
\text { level } \\
\left(\mathrm{g} / \mathrm{m}^{3}\right) \\
\end{array}$} & \multirow{2}{*}{$\begin{array}{c}\text { Flux } \\
\text { level } \\
\left(\mathrm{kW} / \mathrm{m}^{2}\right)\end{array}$} & \multicolumn{2}{|c|}{ Bare PTH } & \multicolumn{2}{|c|}{ Bare SMT } & \multicolumn{2}{|c|}{ Coated PTH } & \multicolumn{2}{|c|}{ Coated SMT } \\
\hline & & 1st $\mathrm{hr}$ & $2-24 h r$ & 1st hr & $2-24 \mathrm{hr}$ & 1st hr & 2-24 hr & 1st hr & $2-24 \mathrm{hr}$ \\
\hline 0 & 50 & 50.8 & 50.7 & 45.8 & 45.9 & 50.6 & 50.7 & 46.1 & 46.1 \\
\hline 3 & 25 & 50.5 & 50.6 & 45.9 & 46.0 & 50.7 & 50.7 & 46.1 & 46.1 \\
\hline 3 & 50 & 50.7 & 50.7 & 46.0 & 46.1 & 50.6 & 50.6 & 46.1 & 46.3 \\
\hline 25 & 25 & 50.7 & 50.7 & 46.2 & 46.2 & 50.8 & 50.8 & 46.1 & 46.2 \\
\hline 25 & 50 & 50.6 & 50.7 & 46.1 & 46.2 & 50.6 & 50.6 & 46.2 & 46.2 \\
\hline 50 & 25 & 50.9 & 50.7 & 46.3 & 46.1 & 50.7 & 50.7 & 46.3 & 46.3 \\
\hline 50 & 50 & 51.1 & 51.0 & 46.4 & 46.5 & 50.6 & 50.7 & 46.4 & 46.4 \\
\hline
\end{tabular}

have shown that this range of resistance would cause failure only in CMOS chips and not in FAST TTL chips. Since the chips used in this test were FAST TTL chips, they were not expected to fail as a result of tests with a fuel load of $50 \mathrm{~g} / \mathrm{m}^{3}$.

\subsubsection{High-frequency Low-pass Filter}

The HF LPF measurement was made to determine the throughput of a filter at various frequencies. Because of limitations of the automatic testing equipment, only one frequency ( $250 \mathrm{MHz}$ ) was used; however, data at 50 $\mathrm{MHz},-3 \mathrm{~dB}$, and $-40 \mathrm{~dB}$ were recorded during the manual measurements. This circuit was exprected to react to stray capacitance that could be caused by any debris on the circuit. No changes were measured in any of the tests. The automatic measurement frequency, $250 \mathrm{MHz}$, occurs at a high section of the throughput curve shown in Figure 19. At this frequency, changes in capacitance should not be very obvious. The capacitors in the circuit act as open elements, and it is not until the frequency is higher ( $>500 \mathrm{MHz}$ ) that the capacitors begin to conduct to ground. Tests at these frequencies would be needed to determine if stray capacitance is a problem. The pre- and post-test measurements at the higher frequencies did not change significantly; however, in many of these measurements the effect of smoke is most obvious during the exposure and almost disappears after the smoke is vented.

\subsubsection{High-frequency Transmission Line}

The transmission line measurement determines the coupling between one transmission line and another that is very close. As the transmission lines accumulate debris, the coupling between the two lines will change because the insulation resistance is reduced. For low frequencies, there should be more coupling, but at higher frequencies, the expected result is not easily modeled. The manual measurements were made with both the forward coupling and reverse coupling configurations, but the automatic measurements were made only with the forward coupling configuration. The automatic measurements were made at three different values: $50 \mathrm{MHz}, 500 \mathrm{MHz}$, and $1 \mathrm{GHz}$. Figure 32 shows the response to smoke for $50 \mathrm{MHz}$ in a high-fuel, high-flux exposure. The bare circuit (solid line) shows the most response by increasing in 


\section{Section 3}

coupling from $-52 \mathrm{~dB}$ to $-17 \mathrm{~dB}$ during the 1-hour exposure. The coupling at $50 \mathrm{MHz}$ then decreases as the smoke is vented until the final value is very close to the pretest value.

Table 14 presents the change in coupling from pretest measurements $(\mathrm{dB})$ with fuel level and flux level. The values in Table 14 are averages for two tests and over the time periods listed in the table (either the first hour or from 2 to 24 hours). The bare transmission lines generally couple more than the coated transmission lines in response to smoke. The values of the transmission lines are very close to the original pretest values by the end of the exposure for both the bare and coated cases. This behavior is similar to earlier circuit
Test Results

bridging tests in which conductance was higher during the smoke exposure, but fell as the smoke was vented. One odd value should be noted in the second row of Table 14 for the bare HF TL in the 2-24 hour period. This is a result of one transmission line, which exhibited an anomalous increase 3 hours after exposure. This behavior was not repeated in any of the other experiments.

The results for the $500-\mathrm{MHz}$ and $1-\mathrm{GHz}$ frequencies are similar to those at $50-\mathrm{MHz}$ except that the coupling changes in the opposite direction for the first hour. The averages for hours 2 to 24 are similar to the 50$\mathrm{MHz}$ case; i.e., they are close to the original values.

Table 14. HF TL at $50 \mathrm{MHz}$, averages over time range (dB)

\begin{tabular}{|c|c|c|c|c|c|}
\hline \multirow{2}{*}{$\begin{array}{c}\text { Fuel } \\
\text { level } \\
\left(\mathrm{g} / \mathrm{m}^{3}\right)\end{array}$} & \multirow{2}{*}{$\begin{array}{c}\text { Flux } \\
\text { level } \\
\left(\mathbf{k W} / \mathbf{m}^{2}\right)\end{array}$} & \multicolumn{2}{|c|}{ Bare } & \multicolumn{2}{|c|}{ Coated } \\
\hline & & $1 \mathrm{hr}$ & $2-24 \mathrm{hr}$ & $1 \mathrm{hr}$ & 2-24 hr \\
\hline 0 & 50 & -0.3 & -0.6 & -0.2 & 0.6 \\
\hline 3 & 25 & -1.8 & 7.1 & -0.5 & 0.1 \\
\hline 3 & 50 & -0.8 & -0.9 & 1.2 & 1.6 \\
\hline 25 & 25 & 4.5 & -1.3 & -0.3 & -0.2 \\
\hline 25 & 50 & 7.9 & -1.3 & 1.0 & 1.1 \\
\hline 50 & 25 & 23.2 & 0.0 & -1.1 & -0.8 \\
\hline 50 & 50 & 22.3 & -0.6 & 0.2 & 0.3 \\
\hline
\end{tabular}

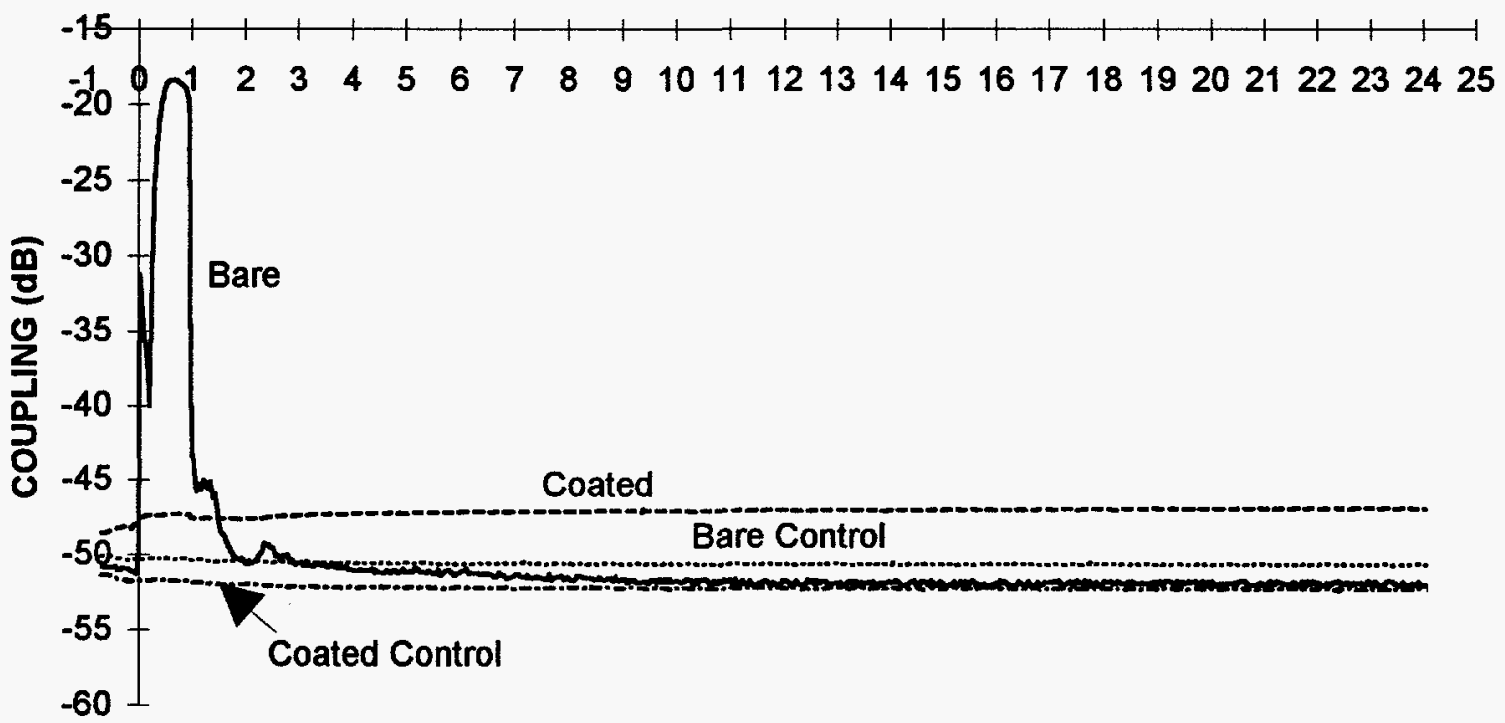

TIME (HR)

Figure 32. HF TL (50 MHz) vs. time for a high-fuel, high-flux burn. 


\subsubsection{Leakage Measurements}

The pads circuit measures leakage current from two rows of through-holes that are biased with $5 \mathrm{Vdc}$.

Leakage current was converted to resistance across the pads. The $\log _{10}$ of the resistance values is presented in Table 15. The starting resistance was 13.4 (in $\log _{10} \Omega$ units). As the functional boards are exposed to smoke, the resistance between the pads decreases. In Table 14 the averages over the first hour of the smoke exposure and over the period between 2 and 24 hours after the start of the exposure can be compared. The resistance falls the most for high-fuel, low-burn, bare pads. The coating significantly reduced the change. As with many of these circuits in which the shunt resistance is affected by smoke, the resistance is lowest during the smoke exposure and increases as the smoke is vented.
The leakage measurements from the IPC-B-24 boards determined the surface insulation resistance of a 20square (a dimensionless measurement of surface insulation resistance) area. The same type of circuit was used to determine leakage currents as was used in the pad measurements. The results are shown in Table 16 in which the values listed are averages of the differences between the boards that were in the smoke exposure chamber and the control boards. This comparison was made because there was no pretest measurement. In general, the higher the heat flux, the more loss in resistance during the smoke exposure. After the smoke was vented, the resistance recovered somewhat.

Table 15. Pads measurements, averages over time range $\left(\log _{10} \Omega\right)$

\begin{tabular}{|c|c|c|c|c|c|}
\hline \multirow{2}{*}{$\begin{array}{r}\text { Fuel } \\
\text { level } \\
\left(\mathrm{g} / \mathrm{m}^{3}\right)\end{array}$} & \multirow{2}{*}{$\begin{array}{c}\text { FIux } \\
\text { level } \\
\left(\mathrm{kW} / \mathrm{m}^{2}\right)\end{array}$} & \multicolumn{2}{|c|}{ Bare } & \multicolumn{2}{|c|}{ Coated } \\
\hline & & 1st: hr & $2-24 \mathrm{hr}$ & 1st hr & $2-24 \mathrm{hr}$ \\
\hline 0 & 50 & 13.4 & 13.4 & 12.7 & 13.4 \\
\hline 3 & 25 & 13.4 & 13.4 & 12.9 & 13.4 \\
\hline 3 & 50 & 11.9 & 12.1 & 13.4 & 13.4 \\
\hline 25 & 25 & 7.3 & 12.3 & 12.8 & 13.3 \\
\hline 25 & 50 & 7.1 & 9.1 & 13.4 & 13.4 \\
\hline 50 & 25 & 6.9 & 7.0 & 13.4 & 13.4 \\
\hline 50 & 50 & 6.7 & 8.1 & 13.1 & 13.4 \\
\hline
\end{tabular}

Table 16. Summary of the surface insulation resistance $\left(\log _{10} \Omega_{\text {exposed }}-\log _{10} \Omega_{\text {control }}\right)$

\begin{tabular}{cc|cccc}
\hline $\begin{array}{c}\text { Fuel level } \\
\left(\mathbf{g} / \mathbf{m}^{\mathbf{3}}\right)\end{array}$ & $\begin{array}{c}\text { Flux level } \\
\left(\mathbf{k W} / \mathbf{m}^{\mathbf{2}}\right)\end{array}$ & \multicolumn{2}{|c}{$\mathbf{3 0}$ V Bias } & \multicolumn{2}{c}{$\mathbf{5}$ V Bias } \\
\cline { 3 - 6 } & $\mathbf{1 s t} \mathbf{~ h r}$ & $\mathbf{2 - 2 4} \mathbf{~ h r}$ & $\mathbf{1 s t} \mathbf{~ h r}$ & $\mathbf{2 - 2 4} \mathbf{~ h r}$ \\
\hline 0 & 50 & 1.2 & 1.5 & 0.6 & 1.4 \\
3 & 25 & 0.1 & 0.7 & 0.7 & 0.8 \\
3 & 50 & -1.9 & -1.5 & 0.3 & 0.2 \\
25 & 25 & -0.2 & 1.3 & -0.6 & 1.1 \\
25 & 50 & -3.1 & -2.4 & -1.5 & 0.1 \\
50 & 25 & -1.1 & 0.6 & -2.6 & -0.3 \\
50 & 50 & -2.8 & -2.4 & -1.9 & -1.6 \\
\hline
\end{tabular}




\section{CONCLUSIONS}

These smoke exposures provided data on the effect of smoke on simplified functional circuits. The results showed (1) the predominant effects of smoke, (2) how circuits are affected by smoke, (3) which types of circuits are most vulnerable, and (4) under what conditions circuits are most affected. The advantage of exposing simplified circuits is that the effect on each circuit is easier to determine. However, the results of exposing more complicated circuits would probably be similar to those found here.

Smoke may cause three different, immediate effects on electrical circuits: (1) it may lower resistance by acting like a shunt; (2) it may increase resistance by attacking solder joints or adding debris to connectors; and (3) it may increase stray capacitance. All of the circuits in these tests could be used to determine one of these three effects. The HVLC circuit, leakage measurements, HF TL, and HSD determined effects of an added shunt. The HCLV circuit indicated the effect of increased resistance. The HF LPF determined the effect of stray capacitance.

The predominant effect was lowered resistance (increased conductance) and the most vulnerable circuits were those that had high input impedance. Clean printed wiring boards have resistances higher than $10^{12}$ $\Omega$ between traces. When smoke lowers electrical resistance in the vicinity of a circuit, a high impedance circuit will be bridged by the relatively low impedance of the smoke. Thus the circuits that were most affected were those that reacted to added shunt resistance, such as the HVLC. For the HVLC circuit, virtually all of the current was transmitted through the smoke and soot deposits instead of through the circuit when the fuel level was higher than $25 \mathrm{~g} / \mathrm{m}^{3}$. However, smoke did not affect the HSD circuit; the shunt resistance was not low enough to affect the FAST TTL logic chips in the HSD circuits. FAST TTL chips have a high tolerance to smoke because they have low impedance and high output current. If the HSD circuit contained a CMOS chip instead, it might have been damaged just as the memory chips in the earlier component tests were because CMOS chips have lower output current drive.
The resistance of the HCLV SMT circuit measurably increased when it was exposed to fuel levels of $25 \mathrm{~g} / \mathrm{m}^{3}$ or greater, but not in any of the PTH circuits or coated circuits, which remained stable. The lowered resistance in the vicinity of the circuit was not low enough to cause circuit bridging; however, this implies that the smoke increased the resistance in the solder joints of this low-impedance circuit. These effects were not decreased by venting the smoke; however, they made relatively small changes in circuit performance, less than $2 \%$ in the worst cases. Smoke did not cause any obvious change in the HF LPF circuit, indicating that there was little change in stray capacitance.

The increased conductance induced by smoke was highest during the smoke exposure and was reduced by venting. Therefore, smoke and not just surface deposition causes increased conductivity by orders of magnitude. Results from tests earlier in this program showed that fuel levels greater than $100 \mathrm{~g} / \mathrm{m}^{3}$ caused increased conductivity that remained after the smoke was vented. This implies that for higher smoke densities, the increased surface deposition will cause lingering effects. The polyurethane coating helped considerably to prevent smoke from increasing conductance or damaging solder joints.

This test series is the fourth in this program to determine the impact of smoke on digital I\&C equipment. The tests included exposures of microprocessor-based A/D boards, an experimental digital safety channel (computers linked by a network), and component packages to determine leakage currents. The first two tests in this series indicated that communications could be interrupted intermittantly by smoke. The exposures of component packages indicated how components may be affected by smoke, and the tests reported here show the effect of smoke on simple circuits. The next test will determine the effect of different conformal coatings on the same functional circuit board. A future report will summarize the results of the coating tests and overall insights from this program. It will also evaluate the effectiveness of current fire protection regulations intended to shield electronics from smoke and current recommended practices in smoke damage recovery. 


\section{REFERENCES}

Bustard, Larry D., and P. Holzman. 1994. "LowVoltage Environmentally-Qualified Cable License Renewal Industry Report; Revision 1," TR-103841, Electric Power Research Institute, Palo Alto, CA .

Caudill, Loren M., J. Thomas Chapin, R. B. Commizzoli, Pravin Gandhi, G. A. Peins, and J. Doug Sinclair. 1995. "Current State of Fire Corrosivity Testing: Preliminary Electrical Leak Current Measurements," in Proc. International Wire \& Cable Symposium, pp. 432-437, Army Communications Electronics Command, Fort Monmouth, NJ.

Iman, Ronald L., Robert V. Burress, Dennis J. Anderson, Dennis J. Huffman, Jeffry F. Koon, Barbara M. Waller, Mahendra S. Gandhi, Thomas A. Carroll, Mark J. Shireman, Carol M. Krska, Gary A. Becka, Robin L. Sellers, David P. Carlton, Roger D. Nickell, Mark I. Siewers, Gary S. Falconbury, and Terry L. Munson. 1995a. "Evaluation of LLowResidue Soldering for Military and Commercial Applications: A Report from the Low-Residue Soldering Task Force," SAND 95-1060, Sandia National Laboratories, Albuquerque, NM.

Iman, Ronald L., Robert V. Burress, Dennis J. Anderson, Dennis J. Huffman, Jeffry F. Koon, Barbara M. Waller, Mahendra S. Gandhi, Thomas A. Carroll, Mark J. Shireman, Carol M. Krska, Gary A. Becka, Robin L. Sellers, David P. Carlton, Roger D. Nickell, Mark I. Siewers, Gary S. Falconbury, and Terry $\mathbb{L}$. Munson. 1995b. "Appendix to the Report from the Low-Residue Soldering Task Force: Phase II Results," SAND 95-1060, Sandia National Laboratories, Albuquerque, NM.
Jacobus, Mark J. 1984. "A Review of Regulatory Requirements Governing Control Room Habitability Systems," NUREG/CR-3786, SAND84-0978, Sandia National Laboratories, Albuquerque, NM.

Korsah, Kofi, R. L. Clark, and Richard T. Wood. 1994. "Functional Issues and Environmental Qualification of Digital Protection Systems of Advanced Light-Water Nuclear Reactors," NUREG/CR-5904, ORNL/TM-12164, Oak Ridge National Laboratory, Oak Ridge, TN.

Korsah, Kofi, Tina J. Tanaka, T. L. Wilson, Jr., and Richard T. Wood. 1996. "Environmental Testing of an Experimental Digital Safety Channel," NUREG/CR-6406, ORNL/TM-13122, Oak Ridge National Laboratory, Oak Ridge, TN.

Pauls, Doug. 1992. "IPC Cleaning and Cleanliness Test Program Phase 3 Water Soluble Fluxes Part 1," Paper presented at the IPC 1992 Fall Meeting, October 12-15, 1992, Minneapolis, MN, Institute for Interconnecting and Packaging Electronics Circuits (IPC), Lincolnwood, IL, IPC TP-1043.

Reagor, Barbara. 1992. "Smoke Corrosivity: Generation, Impact, Detection, and Protection," Fire Sciences, v. 10, pp. 169-179.

Tanaka, Tina J., Steven P. Nowlen and Dennis J. Anderson. 1996. "Circuit Bridging of Components by Smoke, NUREG/CR-6476, SAND96-2633, Sandia National Laboratories, Albuquerque, NM. 
Appendix

\title{
APPENDIX
}

\section{DETERMINATION OF CRITICAL SHUNT RESISTANCE FOR CIRCUIT BRIDGING FAILURES IN LOGIC CIRCUITS}

\author{
Tina J. Tanaka, Stephen J. Martin, and Kelly M. Hays \\ Sandia National Laboratories
}

\section{Summary}

Smoke creates leakage paths between component leads and can therefore cause logic errors in digital systems. For example, if the high output from a lead is shorted to a low output nearby, a low signal may be transmitted instead of a high. The loss of resistance due to smoke was simulated with a variable shunt resistor to determine the tolerance to resistance loss for different logic chips. The tests were performed on quad 2-input AND and OR gates from three logic families (Table A-1): transistor-to-transistor logic (TTL), complementary metal oxide-semiconductor (CMOS), and emitter-coupled logic (ECL). The components that tolerated the lowest resistances had the highest output drive current. Components with a high tolerance to resistance loss are more tolerant of smoke. The components with high tolerance included advanced Schottky, TTL (FAST), and advanced CMOS (FACT). Standard CMOS components were the least tolerant to a decrease in resistance, especially at low power supply voltages.

The circuit bridging tests that were performed in 1995$96^{1}$ only measured down to resistances of $1000 \Omega$; this level of resistance would cause metal gate CMOS failure, but other components would not be likely to fail. The circuit bridging tests can be viewed as providing conservative estimates of smoke levels that would cause errors in logic circuits.

\section{Evaluation Criteria and Results}

\section{Evaluation Criteria}

Motorola AND and OR gates were tested to determine the level of shunt resistance needed to cause erroneous results in circuits $1 \mathrm{a}$ and $1 \mathrm{~b}, 2$, and 3 (Figures A-1 and A-2). The simple circuits shown in Figures A-1 and A-2 were assembled using a single chip. The inputs to gates $A$ and $B$ were connected to a power supply while the input to gate $C$ was connected to the output of $A$ and $B$. The shunt resistance was always placed between high and low voltages. The voltage from the output at gate $\mathrm{C}$ was measured to determine if an error was caused when the shunt resistance was lowered to a minimum of $10 \Omega$. The results are presented in Table A-1. A more detailed discussion of the results follows. For the OR gates, the expected result was a high state, and for the AND gate tests, a low state; failure resistances were recorded when the output of the OR circuit was low or the AND gate was high. Both OR and AND gates were tested because sometimes the addition of a shunt resistance can either pull the "low" output to "high" or the "high" output to "low," depending on the component. Circuits 2 and 3 were included in the tests because a shunt to the power supply should be more severe than a shunt to the output of a gate because of the limited output of a gate.

All of the components tested were selected from the Motorola Semiconductor Master Selection Guide. ${ }^{2}$ Other families of integrated circuits are also in production, but this selection is representative of a range in power consumption, speed, and technology. In general, the fastest logic circuits have the highest

\footnotetext{
${ }^{2}$ Motorola Semiconductor, Master Selection Guide, Rev 7 ,

Motorola Literature Distribution, Phoenix Arizona (1994).
}

\footnotetext{
1 Tina J. Tanaka, Dennis J. Anderson, and Steven P. Nowlen, Circuit Bridging of Components by Smoke, NUREG/CR-6476, SAND96-2633, Sandia National Laboratories, Albuquerque, NM (1996).
} 
Appendix

tolerance to smoke because gates have higher drive currents and can more easily supply enough current to drive the voltage of the next gate to the correct level.

TTL and CMOS chips operate in saturation; the output of gate $\mathrm{C}$ changes abruptly when the critical resistance is reached. For these chips, the value of resistance at which the output of gate $C$ changed state was recorded as the failure resistance. ECL chips operate in a nonsaturation region; the output from gate $C$ changes linearly with input voltage. Since the input voltage varies with shunt resistance, the output of gate $C$ varies slowly rather than changing abruptly with changes in the resistance. A range of resistance was included in the results for the ECL chips that corresponds to the voltage limits of the high and low states (minimum high-level voltage and maximum low-level voltage).

These tests provide only an approximate estimate of what will cause an error in a logic gate because only one pair of leads is shorted at a time and all gate outputs are connected to only one input gate (no fanout). These estimates are conservative because in a smoke exposure more than one lead is expected to be shorted at once, causing current to flow through more than one faulty path. The other condition- allowing each output to be tied to only one input-is not conservative, but since the output currents are generally 20 to 10,000 times larger than the input currents, depending on the technology, this assumption may not affect the results as strongly.
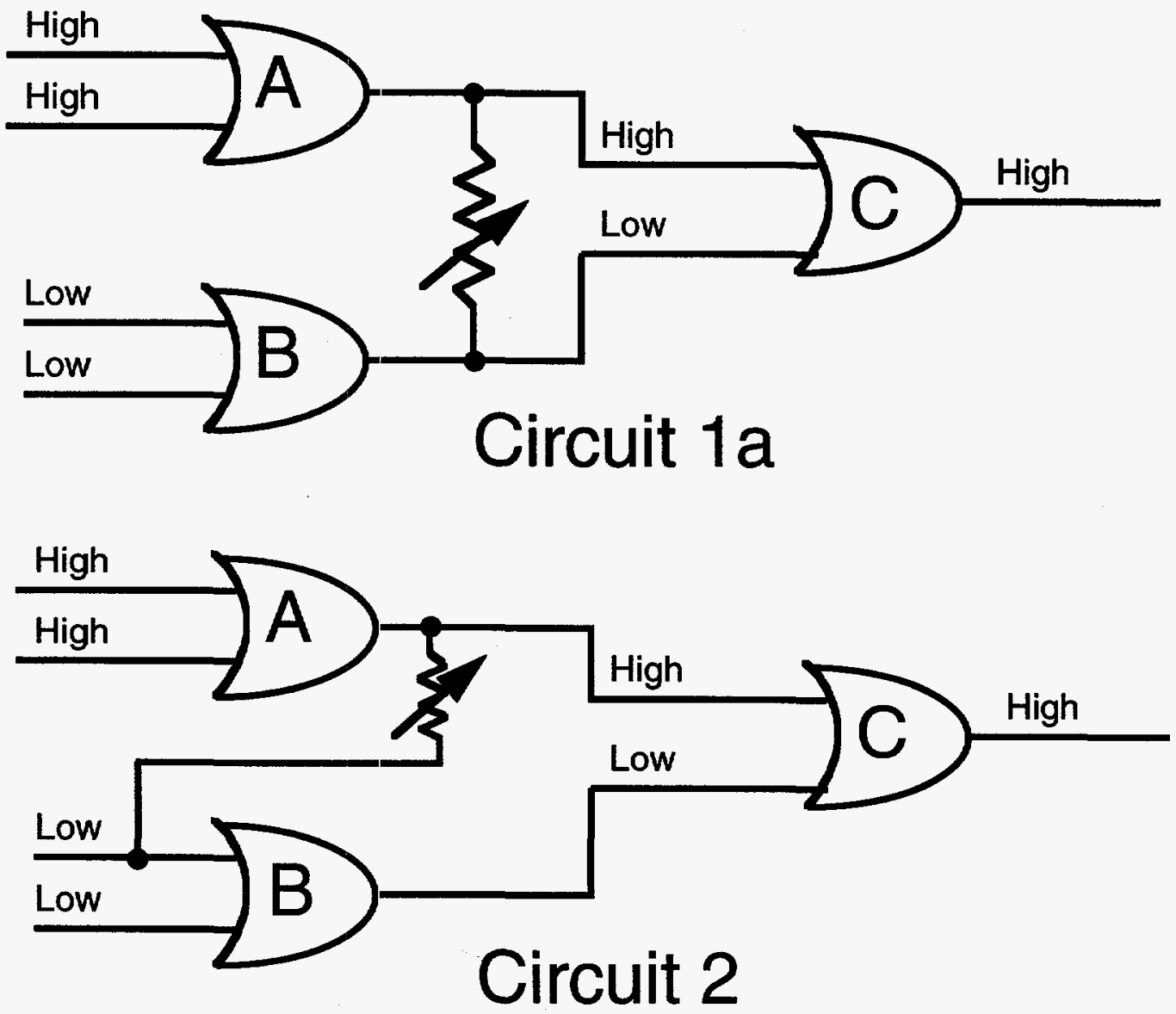

Figure A-1. OR gate wiring diagrams 

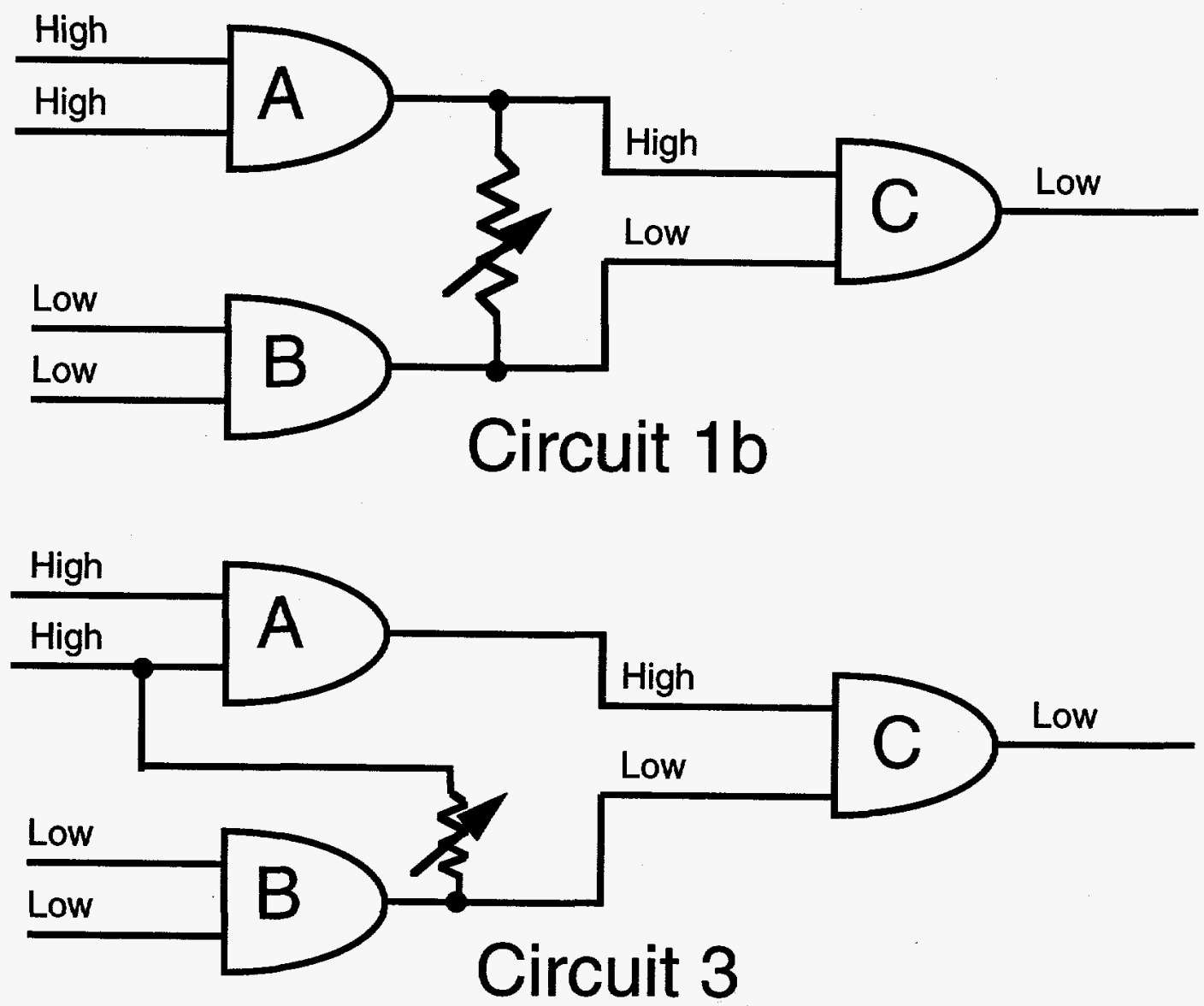

Figure A-2. AND gate wiring diagrams 
Table A-1. Components tested and results

\begin{tabular}{|c|c|c|c|c|c|c|c|c|c|c|}
\hline \multirow[b]{2}{*}{ Logic } & \multirow[b]{2}{*}{ Family } & Motorola & te Device No. & \multirow{2}{*}{$\begin{array}{c}\text { Supply } \\
\text { Voltage } \\
\left(V_{s}\right)\end{array}$} & \multirow{2}{*}{$\begin{array}{l}\mathbf{t}_{\mathrm{plh}}{ }^{*} \\
\text { (ns) }\end{array}$} & \multirow{2}{*}{$\begin{array}{c}\text { Output Drive } \\
\begin{array}{c}(\mathbf{m A}) \\
(\mathrm{hi} / \mathrm{lo})\end{array}\end{array}$} & \multicolumn{2}{|r|}{ Critical } & \multicolumn{2}{|c|}{ Resistance $(\Omega)$} \\
\hline & & AND Chip & OR Chip & & & & Circuit & 1a Circuit & 1b Circuit 2 & 2 Circuit 3 \\
\hline \multicolumn{11}{|c|}{ TTL } \\
\hline LS & & SN74LS08N & SN74LS32N & +5 & 9 & $-0.4 / 8$ & $\mathbf{N} / \mathrm{F}^{\dagger}$ & $\mathrm{N} / \mathrm{F}$ & 29 & 100 \\
\hline FAST & & MC74F08N & MC74F32N & +5 & 3 & $-1.0 / 20$ & $\mathrm{~N} / \mathrm{F}$ & 24 & 45 & 31 \\
\hline \multicolumn{11}{|l|}{ CMOS } \\
\hline \multirow[t]{3}{*}{ MG } & & MC14081BCP & $\mathrm{MC} 14071 \mathrm{BCP}$ & +5 & 160 & \pm 0.88 & 690 & $N / F$ & 837 & 1220 \\
\hline & & & & +10 & 65 & \pm 2.25 & 230 & $\mathrm{~N} / \mathrm{F}$ & 391 & 605 \\
\hline & & & & +15 & 50 & \pm 8.8 & 170 & $\mathrm{~N} / \mathrm{F}$ & 288 & 490 \\
\hline \multirow[t]{3}{*}{$\mathrm{HC}$} & & MC74HC08AN & MC74HC32AN & +2 & 75 & \pm 0.02 & $\mathrm{~N} / \mathrm{F}$ & 50 & 130 & 120 \\
\hline & & & & +4.5 & 15 & \pm 4.0 & $\mathrm{~N} / \mathrm{F}$ & 25 & 68 & 57 \\
\hline & & & & +6 & 13 & \pm 5.2 & $\mathrm{~N} / \mathrm{F}$ & 19 & 56 & 49 \\
\hline \multirow[t]{3}{*}{ FACT } & & MC74AC08N & MC74AC32N & +3 & 5 & \pm 12 & $\mathrm{~N} / \mathrm{F}$ & 10 & 30 & 15 \\
\hline & & & & +4.5 & 4 & \pm 24 & $\mathrm{~N} / \mathrm{F}$ & 10 & 20 & 30 \\
\hline & & & & +5.5 & 3 & \pm 24 & $\mathrm{~N} / \mathrm{F}$ & $\mathrm{N} / \mathrm{F}$ & 17 & 25 \\
\hline \multicolumn{11}{|l|}{ ECL } \\
\hline $100 \mathrm{~K}$ & & MC10104P & MC10103P & -5.2 & 0.75 & $50-\Omega$ load $^{\ddagger}$ & N/F & $15-33$ & $47-56$ & $77-105$ \\
\hline $10 \mathrm{H}$ & & $\mathrm{MC10H} 104 \mathrm{P}$ & $\mathrm{MC} 10 \mathrm{H} 103 \mathrm{P}$ & -5.2 & 1 & $50-\Omega$ load & $\mathrm{N} / \mathrm{F}$ & $18-33$ & $93-66$ & $79-107$ \\
\hline
\end{tabular}

" Gate propagation delay time.

N/F means no failure

ECL gates give output drive in terms of impedance instead of $\mathrm{mA}$. 


\section{Analysis and Discussion}

\section{General Conclusions}

In Table A-1, a comparison of the results for circuits $1 \mathrm{a}$ and $1 \mathrm{~b}$ shows that only one of these circuits fails for each logic family. This is expected because these circuits are designed to either raise the low-level output to a high level, or the high level to a low level by partially shorting the output leads together. For each logic family, one case or the other will occur: the output source of the high level will overcome the sink power of the low level, or vice versa. If the low logic level is raised to a high level, then the AND circuit output will change from low to high, but the OR gate will not change. If the high level is pulled down, then the OR gate will change from high to low, but the AND gate will not change. Only one of these outcomes should occur in each logic family.

The failure resistances for circuits 2 and 3 are higher than for circuits $1 \mathrm{a}$ and $1 \mathrm{~b}$. This can be expected because in circuits 2 and 3 the input signals to gate $C$ are shunted to the power supply instead of one of the gate outputs. The power supply has more current available to overcome either the sink or source current of a gate and therefore these shunts can cause failures at higher resistance values than shunts between gate outputs.

The failure resistance was highly correlated with the output current drive. This is especially evident for the standard CMOS, where the drive current changes with supply voltage. Gates with higher current drives can better supply the current necessary to maintain a voltage level despite a shunt. For the CMOS family, higher supply voltages correspond to higher drive current and to lower failure resistance. CMOS gates with higher supply voltage will be more impervious to smoke.
Failure resistances for circuits 2 and 3 are not necessarily equivalent. For example, the LS AND gate fails in circuit 3 at $100 \Omega$ and the LS OR gate in circuit 2 fails at $29 \Omega$. The magnitudes of sink and source currents for LS gates are not equivalent and failure shunt resistances for circuits 2 and 3 are dependent on these currents.

\section{Component Families}

Components are categorized into logic families and further into technologies. Logic families are defined by the voltage levels required to define high (1) and low (0) states. Table A-2 lists the minimum voltage level for a high state and maximum voltage level for a low state for the different components tested; they were obtained from data sheets for each chip. Since CMOS chips can have a range of supply voltages, the minimum voltage level for a high state and maximum level for a low state are dependent on the supply voltage. These values are typical for most of these chips when they are operating around $25^{\circ} \mathrm{C}$. Values are a function of operating temperatures.

The TTL family is very commonly used; it is inexpensive and has high output drive current. The two technologies tested offer different advantages; the LS version uses less power, but the FAST is faster. The TTL chips are all operated between 0 and $+5 \mathrm{~V}$ and have output levels of near 0 and +4.5 to $+5 \mathrm{~V}$.

The advantages of CMOS chips are lower supply voltage, less power consumption, and smaller size (for densely packed logic chips). The standard CMOS can operate with supply voltages ranging from +3 to +18 V. Since standard CMOS gates were introduced, newer CMOS technologies with enhanced speed have been

Table A-2. Minimum high level and maximum low levels for logic families

\begin{tabular}{l|ccc}
\hline \multicolumn{1}{c|}{ Family } & $\begin{array}{c}\text { Supply voltage } \\
\left(\mathbf{V}_{\mathrm{s}}\right)\end{array}$ & $\begin{array}{c}\text { Minimum high level } \\
(\mathbf{V})\end{array}$ & $\begin{array}{c}\text { Maximum low level } \\
(\mathrm{V})\end{array}$ \\
\hline TTL (LS and FAST) & +5.0 & 2.0 & 0.08 \\
CMOS (HC) & +2.0 & 1.5 & 0.05 \\
CMOS (standard) & +5.0 & 3.5 & 1.5 \\
CMOS (standard) & +10.0 & 7.0 & 3.0 \\
CMOS (standard) & +15.0 & 11.0 & 4.0 \\
ECL (10K and 100H) & -5.2 & -0.96 & -1.65 \\
\hline
\end{tabular}




\section{Appendix}

introduced. These newer technologies do not operate over the same range of supply voltage; the $\mathrm{HC}$ and FACT operate between +2 and $+6 \mathrm{~V}$. Although they are faster, these newer technologies consume more power.

The ECL family is the fastest of all those tested, but these gates cost more, are more complicated to use, require the use of two supply voltages, and consume more power. To measure the output voltage, a $50-\Omega$ resistor must be placed between the $-2.0-\mathrm{V}$ supply and the output of the gate, with the voltage measured at the gate side of the resistor. Since the high and low states are separated by less than $1 \mathrm{~V}$, and the power consumption is high ( 25 to $50 \mathrm{~mW} /$ gate compared to
$0.04 \mathrm{~mW} /$ gate for the standard CMOS at $1 \mathrm{MHz}$ ), such gates should be much faster than gates of other families.

Digital circuit designers have many choices of chip technology and usually base their decisions on requirements of speed, power consumption, and size. For nuclear power plants, one consideration may be smoke tolerance. The experiment described here was a simple test to determine tolerance to shunt resistance. These results could also be obtained by modeling the operation of logic chips (i.e., SPICE ${ }^{3}$ ). Based on these tests and the results of smoke exposure tests, it is clear that the chip technology used can make a great difference in tolerance to smoke.

\footnotetext{
${ }^{3}$ Giuseppe Massobrio and Paolo Antognetti, eds., Semiconductor Device Modeling with SPICE, 2nd ed., 479 p., McGraw-Hill, New York (1993).
} 